UNIVERSITE DU QUEBEC

\author{
MEMOIRE \\ PRESENTE A \\ L'UNiversite DU QUEBEC EN ABITIBI-TEMISCAMINGUE \\ COMME EXIGENCE PARTIELLE \\ DE LA MAITRISE EN GESTION DES PETITES ET MOYENNES ORGANISATIONS
}

PAR

FRANCINE BESSETTE

B.A.A.

DIAGNOSTIC D'INTERVENTION

A LA CORPORATION DES METIERS D'ART DE L'ABITIBI-TEMISCAMINGUE

MARS 1988 


\section{Bibliothèque}

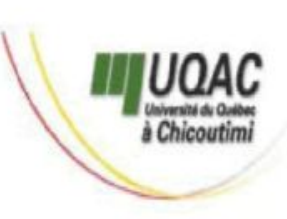

\section{Mise en garde/Advice}

Afin de rendre accessible au plus Motivated by a desire to make the grand nombre le résultat des results of its graduate students' travaux de recherche menés par ses research accessible to all, and in étudiants gradués et dans l'esprit des accordance with the rules règles qui régissent le dépôt et la governing the acceptation and diffusion des mémoires et thèses diffusion of dissertations and produits dans cette Institution, theses in this Institution, the I'Université du Québec à Université du Québec à Chicoutimi (UQAC) est fière de Chicoutimi (UQAC) is proud to rendre accessible une version make a complete version of this complète et gratuite de cette œuvre. work available at no cost to the reader.

L'auteur conserve néanmoins la The author retains ownership of the propriété du droit d'auteur qui copyright of this dissertation or protège ce mémoire ou cette thèse. thesis. Neither the dissertation or Ni le mémoire ou la thèse ni des thesis, nor substantial extracts from extraits substantiels de ceux-ci ne it, may be printed or otherwise peuvent être imprimés ou autrement reproduced without the author's reproduits sans son autorisation. permission. 
Ce mémoire a été réalisé à

l'Université du Québec en Abitibi-Témiscamingue

Dans le cadre du programme de la Maîtrise

en gestion des petites et moyennes organisations

Extensionné de l'Université du Québec à Chicoutimi 


\section{La Corporation des métiers d'art de l'Abitibi-Témiscamingue \\ (CMAAT)}

\section{Résumé}

Implantée depuis 1979 , la CMAAT se veut un regroupement d'artisans. A l'automne 1985, l'organisme se trouve en situation financière difficile. Devant la situation, le ministère des Affaires Culturelles propose de défrayer les frais d'une étude. Les membres acceptent la proposition du MAC.

Mandat de l'étude:

Emettre des suggestions dans le but de rendre la Corporation des métiers d'art de l'Abitibi-Témiscamingue efficiente au niveau des services qu'elle of fre aux artisans qui la composent, tout en tenant compte de ses ressources financières et humaines, de ses grandes orientations gestionnaires et de son environnement socioéconomique.

Le système général de la CMAAT se compose de six soussystèmes interdépendants: $\quad 5.5$ Planification

S.S Promotion

S.S Concertation

S.S Information

S.S Développement

S.S Contróle

Le système de la CMAAT est, en autre, en relation constante avec son environnement.

Principaux problèmes soulevés dans l'étude:

- La CMAAT n'a pas suivi l'évolution de son environnement

- Pas de mission claire

- Pas d'objectifs

- Buts vagues

- Participation des membres quasi inexistante

- Groupe très hétérogène 
Comme principale problématique, nous avons retenu l'absence d'une stratégie organisationnelle. En effet, la cMAAT ne réussissait pas à planifier son action et rien ne nous indiquait ce qu'elle envisageait faire dans l'avenir. Il fallait que le CMAAT soit capable de retenir des buts et des objectifs fondamentaux à long terme et d'adopter des modes d'action et d'allocation des ressources nécessaires pour atteindre ces buts. En fait, la CMAAT devait pouvoir élaborer une stratégie organisationnelle efficace. Mais pour élaborer une stratégie organisationnelle, il fallait d'abord reconnaitre la CMAAT comme une organisation. Après une revue de littérature nous concluions qu'elle ne répondait pas aux critères. Entre autre, nous n'avions pas l'impression que les membres croyaient que le groupe était indispensable pour répondre à leurs besoins.

Nous avons donc proposé comme modèle conceptuel un système de détermination d'une organisation. Après quoi, nous pensions que la CMAAT serait capable d'élaborer une stratégie organisationnelle.

Modèle conceptuel proposé:

\author{
Cerner une cible commune \\ Choisir la mission \\ Définir les buts \\ Définir les objectifs \\ Elaborer le programme d'actions
}

Modèle proposé:

Dès la première étape de ce modèle, les membres de la CMAAT se sont butés à une difficulté, cerner une cible consistait à identifier un objectif commun et croire que seul le groupe va leur permettre d'atteindre cet objectif. Effectivement, plusieurs faits nous démontraient que les artisans poursuivaient un même objectif, soit la vente de leurs oeuvres d'art. Par contre, les artisans se différenciaient nettement les uns des autres, soit par leur famille de métiers, leur motivation à produire ou à vendre, leur besoin de formation, etc. 
En fait, les artisans sont des individualistes éprouvant des problèmes personnels qu'eux seuls peuvent régler individuellement.

C'es pourquoi nous avons recommandé la dissolution de la CMAAT. Nous croyons que l'enveloppe budgétaire destinée aux métiers d'art apportera de meilleurs résultats si elle sert à des projets individuels spécifiques. Il faut comprendre que nous ne concluons pas que les artisans n'ont pas besoin de l'aide financière du MAC. Mais nous croyons que regrouper les artisans en corporation n'est pas la meilleure façon de leur venir en aide. Nous suggérons que le MAC octroie l'aide financière à des projets tels le développement d'une nouvelle technique, la formation des études de marché, etc. 


\section{REMERCIEMENTS}

Je tiens à remercier toutes les personnes qui ont collaboré, de près ou de loin, à l'élaboration de ce mémoire, et, en particulier:

Le Conseil d'administration et les membres de la Corporation des métiers d'art de l'Abitibi-Témiscamingue (CMAAT), pour leur attention et leur disponibilité;

Le personnel du bureau rëgional du ministère des Affaires culturelles, pour le suivi du dossier;

Mon directeur, M. Jean-Pierre Bégin, pour ses nombreux conseils et ses encouragements constants;

Mme Michēle Grenier, pour son professionnalisme et sa disponibilité;

Mes parents, pour leur soutien moral;

Mon ami, pour sa compréhension, sa patience et son aide prēcieuse dans la recherche en bibliothèque. 
TABLE DES MATIERES

page

REMERCIEMENTS............................... ii

LISTE DES TABLEAUX............................. vi

LISTE DES FIGURES ............................. ix

LISTE DES ABREVIATIONS .......................... $\quad$.

LISTE DES ANNEXES............................ xi

LEGENDE DES FIGURES.......................... xi

1. PRESENTATION DE L'ORGANISATION................... 2

1.1 Historique............................. 2

1.2 Problēmatique des regroupements régionaux.......... 4

1.3 Dëfinition d'artisan....................... 5

1.4 Description des membres..................... 5

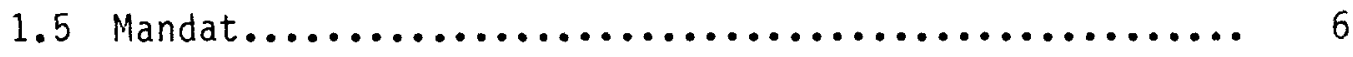

1.6 Principales étapes de 1 'étude................... 7

1.6.1 1'élaboration de la problématique........... 7

1.6.1.1 étude de l'environnement........... 7

1.6.1.2 étude des structures............. 7

1.6.1.3 ètude des processus............. 7

1.6.1.4 analyse des ressources............ 7

1.6 .1 .5 le climat...................... 8

1.6.2 ancrage et conceptualisation............. 8

1.6 .3 recommandations....................... 8

2. ENVIRONNEMENT............................... 10

2.1 Préambule.............................. 10 
2.2 Identification et description des composantes environnementales de la Corporation des métiers....... d'art de l'Abitibi-Témiscamingue (CMAAT)............ 13

2.2.1 ses clients........................... 13

2.2.2 environnement poritique................. 15 2.2.2.1 le Ministère des Affaires culturelles. 15

2.2.3 environnement géographique................ 16 2.2.4 environnement relié à la diffusion et à la promotion............................ 18

2.2.4.1 Te marchē des mëtiers d'art......... 18

2.2.4.2 les autres corporations............ 20

2.2.4.3 autres regroupements régionaux d'artisans...................... 21

2.2.4.4 les comités des expositions artistiques........................ 22

2.2.4.5 le tourisme..................... 23

2.2.4.6 Sociēté de mise en marché des métiers d'art (SOMART)............. 24

2.2.5 organismes de consultation................ 26

2.2.5.1 Conseil des métiers d'art........... 26

2.2.5.2 Conseil de la Culture de l'AbitibiTémiscamingue.................... 26

2.2.5.3 Comité consultatif permanent des mëtiers d'art................... 26

2.2.5.4 Conseil canadien de l'artisanat...... 27 
2.2.6 organismes de formation................ 27

2.2.6.1 Institut des métiers d'art......... 27

2.2.6.2 Commission de formation profes-

sionnelle.................... 28

3. DESCRIPTION DES STRUCTURES........................ 30

3.1 Préambule................................ 30

3.2 Buts de la Corporation....................... 32

3.3 Organigramme $\ldots \ldots \ldots \ldots \ldots \ldots \ldots \ldots \ldots \ldots \ldots \ldots \ldots \ldots, 34$

3.4 Composition du Conseil d'administration............ 36

3.5 Description de la tâche de la directrice générale.... 37

3.6 Description des membres..................... 38

3.6.1 $\operatorname{artisan}($ e) professionnel(le)............. 38

3.6.2 $\operatorname{artisan}(\mathrm{e})$ aspirant(e)................ 39

3.7 La CMAAT: organisation sans but lucratif (OSBL)..... 39

4. DESCRIPTION DES PROCESSUS $\ldots \ldots \ldots \ldots \ldots \ldots \ldots \ldots \ldots \ldots \ldots, 45$

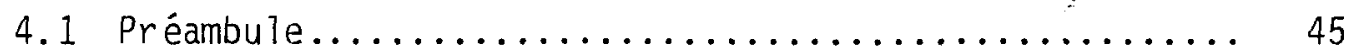

4.2 Le système général........................ 46

4.3 Le sous-système "planification"............... 49

4.4 Le sous-système "promotion".................. 60

4.5 Le sous-système "concertation"................. 63

4.6 Le sous-système "information"................. 67

4. 7 Le sous-système "développement"................ 70

4.8 Le sous-système "contrôle"................... 76

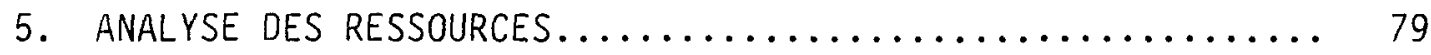

5.1 Caractéristiques des artisans................. 79 
page

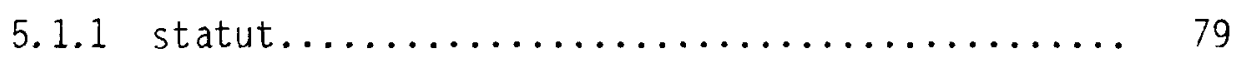

5.1 .2 philosophie de travail................. 79

5.1.3 l'artisan et la gestion.................. 80

5.2 La production............................. 81

5.3 La mise en marché et la commercialisation.......... 83

5.4 La création.............................. 84

5.5 Rentabilité sociale....................... 85

5.6 Ressources financières..................... 86

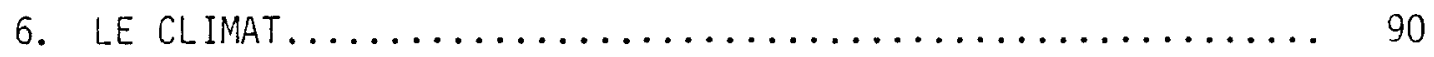

7. CANDIDATS AU POSTE PROBLEME...................... 97

7.1 Liens avec son environnement................. 97

7.2 Activités de planification................... 100

7.3 Activités de promotion..................... 103

7.4 Activités de concertation................... 103

7.5 Activités d'information..................... 105

7.6 Activités de développement................... 105

7.7 Activités de contrôte..................... 106

7.8 Climat organisatione $1 \ldots \ldots \ldots \ldots \ldots \ldots \ldots \ldots \ldots .108$

8. GOULOT D'ETRANGLEMENT........................... 113

8.1 Choix de la problématique à traiter............. 113

8.2 Justification du choix..................... 114

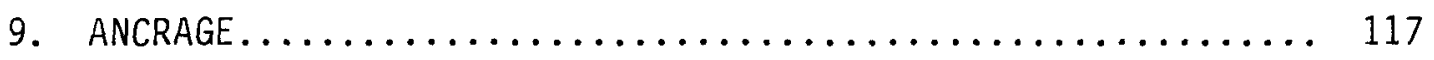

9.1 Choix du système pertinent.................. 117

9.2 Définition du système pertinent............... 120

9.3 Validation de la définition................... 120 


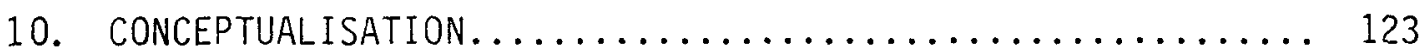

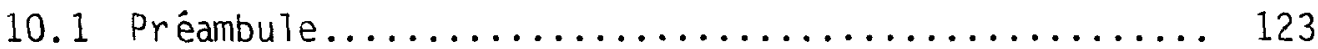

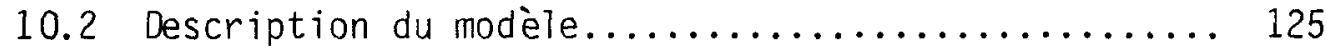

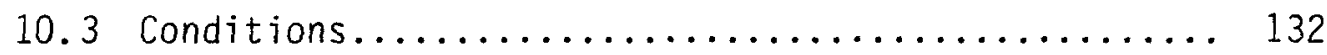

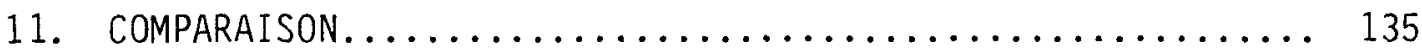

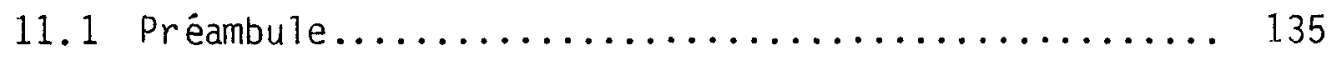

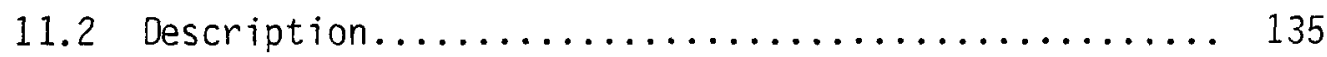

12. RECOMMANDATIONS.......................... 141

13. REFLEXION SUR LA METHODOLOGIE................. 147

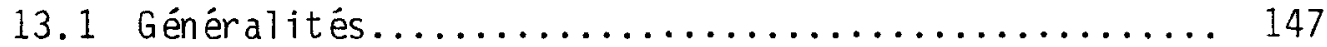

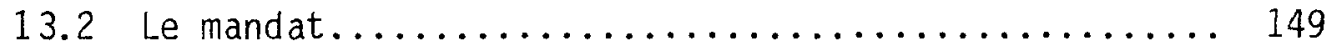

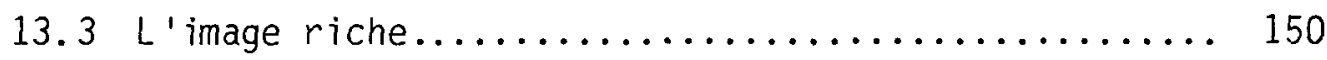

13.4 Ancrage et conceptualisation............... 153

13.5 Comparaison et recommandations.............. 154

13.6 Validation d'une recherche-action.............. 154

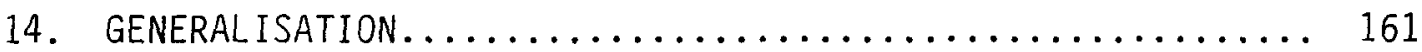

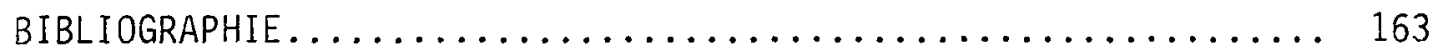

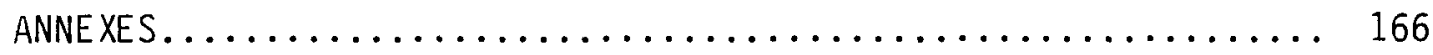


TABLEAU 1 Nombre d'artisans vs secteur géographique......... 188

TABLEAU 2 Nombre d'artisans vs discipline............... 189

TABLEAU 3 Objectif primaire de la vente de produits........ 190

TABLEAU 4 Chiffre de ventes de produits............... 191

TABLEAU 5 objectif primaire vs ventes............... 192

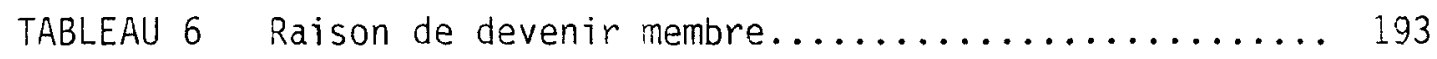

TABLEAU 7 Participation aux différentes activités de 1 a Corporation en pourcentage............... 194 
FIGURE 1 Environnement de 1 a CMAAT.................... 12

FIGURE 2 Le système général..................... 48

FIGURE 3 Le sous-système "planification".............. 49

FIGURE 4 Le sous-système "promotion"............... 60

FIGURE 5 Le sous-système "concertation"............... 63

FIGURE 6 Le sous-système "information"............... 67

FIGURE 7 Le sous-système "développement" $\ldots \ldots \ldots \ldots \ldots \ldots \ldots$

FIGURE 8 Le sous-système "contrôle"................ 76

FIGURE 9 Modèle conceptuel..................... 124

FIGURE 10 Méthodologie systémique de diagnostic organisation-

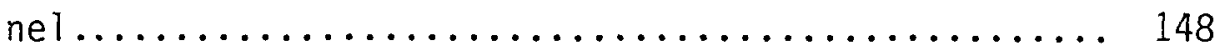


CFP Commission de formation professionnelle

CMAAT Corporation des métiers d'art de l'Abitibi-Témiscamingue

CMAQ Corporation des métiers d'art du Centre du Québec

IMA Institut des mëtiers d'art

MAC Ministère des Affaires culturelles

MAQAM Métiers d'art du Québec à Montréa?

OSBL Organisme sans but lucratif

SOMART Société de mise en marché des métiers d'art limitée 
ANNEXE 1 Mandat............................... 166

ANNEXE 2 Sondage................................. 172

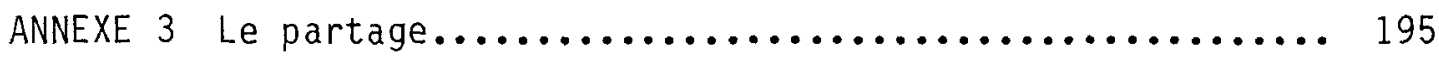

ANNEXE 4 Critères d'admissibilité de l'aide financière du

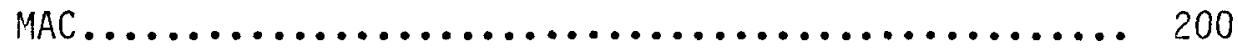

ANNEXE 5 Réflexion sur les grandes orientations de 1 a

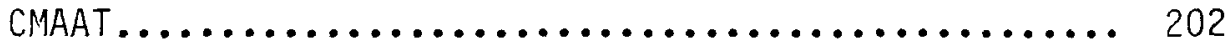




\section{LEGENDE DES FIGURES}

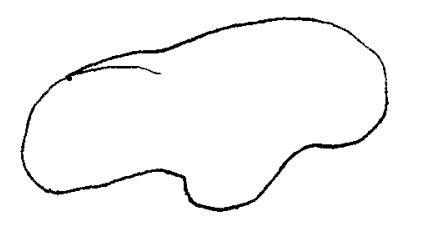

Elément environnemental

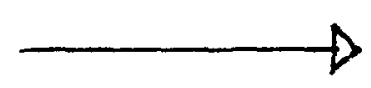

Flux d'information

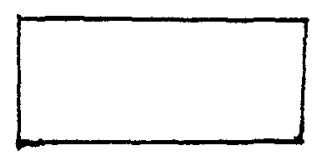

Activité

$\begin{array}{ll}1 & 1 \\ 1 & 1 \\ 1 & 1 \\ 1 & 1\end{array}$

Délimitation d'un sous-système

* *

Zone problématique 
CHAPITRE 1 
CHAPITRE I

PRESENTATION DE L 'ORGANISATION

\subsection{HISTORIQUE}

En 1976, une étude sur le secteur des métiers d'art fut menée par un comité interministériel composé de membres des ministères de l'Industrie et du Commerce et des Affaires culturelles. Cette étude rapporte, qu'en règle générale, les faits démontrent un déséquilibre réel entre la dimension culturelle et la dimension économique dans l'industrie des métiers d'art.1 De par ses interventions passées, le ministère des Affaires culturelles a toujours considéré le développement culturel comme facteur de développement économique, et non 1 'inverse. 2

En 1977, dans la foulée québécoise de la concertation et de 1'auto-détermination, le ministère des Affaires culturelles incitait les artisans des régions du Québec à se regrouper autour d'un organisme. L'idée fut retenue en Abitibi-Témiscamingue donnant ainsi naissance à la Corporation des métiers d'art de l'Abitibi-Témiscamingue.

Les faits qui suivent jalonnent l'histoire récente du secteur des métiers d'art en Abitibi-Témiscamingue.

- Le 28 mars 1977,26 personnes rencontraient, à Rouyn, M. Jean-Claude Cyr, du Service de l'artisanat du MAC, et M. François Desjardins, du ministère de l'Industrie et du Commerce.

1. Procès-verbaux, rapports d'activités, correspondance, notes, etc. (documents non paginés à consulter aux archives du MAC).

2. Idem. 
- Le 4 juin 1977, lors d'une réunion de concertation, les participants ont décidé de diviser la région en 6 sous-régions: Amos, La Sarre, Val-d'Or, Rouyn-Noranda - Témiscamingue et Senneterre-Quévilion.

- Le 23 janvier 1978, I'Association Coopérative des Artisans d'Amos acceptait de prêter sa raison sociale et d'agir pour et au nom de l'Association coopérative des artisans de l'Abitibi-Témiscamingue auprès du ministère des Affaires culturelles, afin de demander et d'administrer une subvention pour l'exercice financier 19771978.

- Le 19 juin 1978, la Corporation des métiers d'art de l'Abitibi-Témiscamingue (CMAAT) fut incorporée sous l'autorité de la troisième partie de la Loi des compagnies.

- En novembre 1980, suivant la volonté des artisans de se donner un point de vente, elle amendait la charte pour permettre l'ouverture d'une boutique. Ainsi, tous les membres pouvaient laisser leurs oeurres sous concession, moyennant une charge de $35 \%$ du prix de vente au détail. La CMAAT ne voulait pas poursuivre un but lucratif avec l'ouverture d'une boutique. Par contre, les membres voulaient que celle-ci puisse s'autofinancer. Au cours des années, il s'est avéré que la Boutique permit de diminuer le déficit de la Corporation. Mais, en 1984, les ventes ont commencé à diminuer. Après avoir examiné le rapport financier de la Boutique, 20 septembre 1985, les membres, réunis en assemblée spéciale, décidèrent de la fermer. 
Voilà donc les principaux événements ayant marqués le secteur des métiers d'art dans la région ces dernières années. Durant la même période, des regroupements régionaux d'artisans étaient mis sur pied à travers tout le Québec.

\subsection{PROBLEMATIQUE DES REGROUPEMENTS REGIONAUX D'ARTISANS}

Implantées pour la plupart entre 1976 et 1978 sous l'instigation du ministère des Affaires culturelles, les corporations régionales étaient présentes dans chacune des 13 régions ou sousrégions administratives du Québec en 1979.3

Parmi ces corporations, cinq ont cessé leurs activités au cours des dernières années, et trois autres se sont regroupées pour former, avec la Corporation du Salon des métiers d'art du Québec, à Montréal, la plus importante corporation d'artisans professionnels du Qu ébec. 4

Il ne reste donc, à ce jour, que cinq corporations régionales d'artisans, soit celles des régions du Saguenay-Lac St-Jean, de Québec, de 1'Estrie, de Montréal et de 1'Abitibi-Témiscamingue. 5

De telles structures de regroupements ont pu se maintenir en partie grâce à une aide gouvernementale issue d'une politique nationale de régionalisation du développement des métiers d'art. Toutefois, ce mouvement est aujourd'hui compromis par un retrait pro-

3. Idem.

4. Idem.

5. Idem. 
gressif de l'aide gouvernementale accordēe jadis dans ce secteur. Aussi, il va sans dire que l'autonomie financière des regroupements n'a pu se concrêtiser comme on le prévoyait à l'origine. 6

Là oũ les corporations ont disparu, le ministère des Affaires culturelies a instauré un programme formation/production, destiné à aider individuellement les artisans. Poursuivant le même objectif, on retrouve en outre des comités de mëtiers d'art, au sein des conseils de la culture.

Le 19 novembre 1984, lors de la journée nationale d'orientation des métiers d'art, l'ensemble des partenaires et des intervenants dans ce domaine parvenait, lors d'une concertation aujourd'hui historique, à s'entendre concernant la mise sur pied de programmes, d'instruments et de moyens de dēveloppement respectueux de ce que sont les métiers d'art, et en tenant aussi compte d'une certaine cohérence nationale.

\subsection{DEFINITION D'ARTISAN}

Un artisan est un individu qui conçoit (crēation) et fabrique, de façon artisanale (production), unique, ou en petite série, des produits traditionnels ou des produits nouveaux.

\subsection{DESCRIPTION DES MEMBRES}

En novembre 1985, soit au début de la présente étude, la directrice générale de la CMAAT comptait 47 membres dans son organisme.

6.Idem. 
Répartition selon la discipline:

1. Textiles, cuir et peaux : 11

2. Silicates et métaux $: 14$

3. Bois, pierre et produits nouveaux : 7

4. Graphisme et techniques bidimendionnelles: 15

Répartition selon le secteur géographique:

- Secteur d'Amos : 9

- Secteur de La Sarre : 14

- Secteur de Rouyn-Noranda : 16

- Secteur de Val-d'Or : 6

- Secteur de Ville-Marie : 2

\subsection{MANDAT}

Au cours de l'assemblēe gēnērale spéciale du 20 septembre 1985, le Conseil d'administration de la Corporation des métiers d'art accepte que le ministère des Affaires culturelles finance une étude ayant pour mandat $d^{\prime}$ :

Emettre des suggestions dans le but de rendre la Corporation des métiers d'art efficiente au niveau des services qu'elle offre aux artisans qui la composent, tout en tenant compte de ses ressources financières et humaines, de ses grandes orientations gestionnaires et de son environnement socio-économique.? 
1.6 PRINCIPALES ETAPES DE L'ETUDE

1.6.1 L'élaboration de l'image riche

1.6.1.1 Etude de l'environnement

- Ses clients

- Environnement politique

- Environnement géographique

- Environnement relié à la diffusion et à la promotion

- Organismes de consultation

- Organismes de formation

1.6.1.2 Etude des structures

- Ses buts

- Organigramme

- Composition du Conseil d'administration

- Description de tâches

- Description des membres

- Caractéristiques d'une OSBL

\subsubsection{Etude des processus}

1.6.1.4 Analyse des ressources

- Caractéristiques des artisans

- La production

- La mise en marché et la commercialisation

- La création

- La rentabilité sociale 
1.6.1.5 Le climat

1.6.1.6 Candidats au poste problème

1.6.2 Ancrage et conceptualisation

1.6.3 Recommandations 
CHAPITRE 2 
CHAPITRE 2

ENVIRONNEMENT

\title{
2.1 PREAMBULE
}

Tout système est en continuelle interaction avec l'environnement dans lequel il est inclus; il en puise les ressources qu'il transforme et lui retourne. Considérant l'organisation comme un système ouvert, elle dépend donc de l'environnement pour s'approvisionner en énergie et ressources. 1 L'environnement est composé de variables incontrôlables qui affectent l'organisation sans la contrôler directement. Une description de T'environnement peut comprendre des informations sur des sujets aussi divers que l'environnement économico-technologique, l'environnement socio-humain-politique et l'environnement physique.

\begin{abstract}
"L'organisation vit dans un environnement dynamique qui se compose d'autres systèmes, les uns plus vastes et les autres plus petits que l'organisation; ils lui imposent de diverses manières des exigences et des contraintes dont il faut tenir compte pour comprendre comment elle fonctionne dans sa totalité".?
\end{abstract}

Lorsqu'on analyse une organisation, il s'avère primordial d'étudier l'environnement, car il influence tous les choix auxquels elle doit procéder tels sa mission, ses buts, ses objectifs, sa

1. GAGNON, Dominique, Le développement organisationnel dans une perspective d'excellence, Montréal, Tes éditions Agence d'Arc Inc., 1986, p. 15.

2.CRENER, M. et MONTEIL, B., Principes de management, Sillery, Les Presses de 1 'Université du Québec, 1981, p. 465. 
structure, etc. Il représente en fait l'élément clé de sa stratégie. Mintzberg explique clairement ce lien entre une stratégie et son environnement.

\begin{abstract}
On peut concevoir la stratégie comme une force médiatrice entre l'organisation et son environnement. Formuler la stratégie consiste alors à interpréter l'environnement, et à développer dans les flux de décisions organisationnelles des formes cohérentes (les stratégies) pour faire face à $T$ 'environnement. Ainsi, en gérant les conditions de frontière de l'organisation, les cadres du sommet stratégique développent leur compréhension de l'environnement et en remplissant leur rôle de supervision directe, ils cherchent à adapter la stratégie aux forces et aux besoins de l'organisation, maintenant un rythme de changement qui réponde à l'évolution de l'environnement et de la stratêgie sans être insupportable à l'organisation. ${ }^{3}$
\end{abstract}

Depuis sa naissance, l'environnement de la CMAAT s'est beaucoup modifié. Les goûts des consommateurs ont changé, certains organismes sont disparus, d'autres ont été créés, les mandats ont été modifiés pour certains, etc. Dans ce contexte, il est donc impérieux d'étudier les liens que la CMAAT entretient avec son environnement, et surtout de vérifier si elle a su s'adapter aux changements survenus dans celui-ci.

3.MINTZBERG, Henry, Structure et dynamique des organisations, Montréal, les éditions Agence d'Arc Inc., 1984, p. 42 


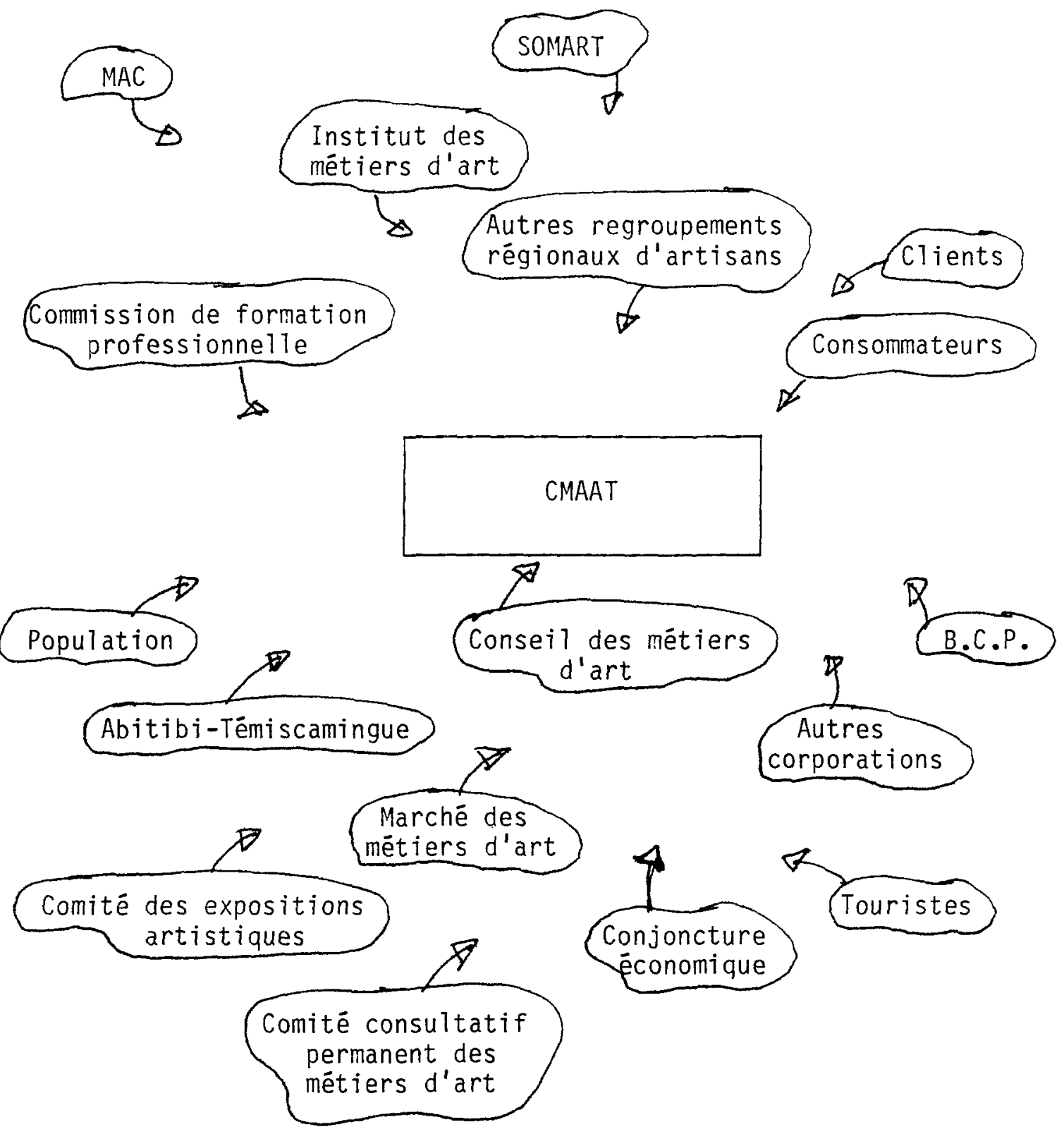

FIGURE 1: Environnement

NOTE: La CMAAT vit dans un environnement composé d'autres organismes et d'individus qui influencent son fonctionnement. 


\subsection{IDENTIFICATION ET DESCRIPTION DES COMPOSANTES ENVIRONNEMENTALES}

\section{DE LA CMAAT}

\subsubsection{Ses clients}

Si nous définissons un client comme celui qui requiert des services moyennant une rétribution, les membres deviennent les clients de la CMAAT. Ils paient une cotisation pour recevoir les services qu'elle offre.

Par ailleurs, les artisans professionnels de la rëgion ne sont pas obligés d'en être membres pour pratiquer leur métier. En tout temps, ils peuvent se retirer de cette organisation.

Aussi, le marchē potentiel de la CMAAT comprend l'ensemble des artisans professionnels de la région qui répondent à ses critères de sēlection. En Abitibi-Témiscamingue, cependant, on compte des artisans qui ne font partie d'aucun regroupement, tantôt parce qu'ils veulent se dëbrouiller seuls, tantôt parce qu'ils produisent peu.

Un sondage, effectué en novembre 1985 (annexe 2) auprès des membres de la CMAAT, révèle que $77,8 \%$ sont satisfaits des services offerts par celle-ci. Par contre, lors de ce même sondage, les membres avouent avoir adhéré à la CMAAT pour vendre leurs produits par l'intermédiaire de la Boutique. Bien qu'au moment du sondage la boutique était fermée, i1 semble que cette raison demeure toujours importante. De plus, nous pouvons lire sur le questionnaire plusieurs commentaires concernant cette fermeture. Les artisans semblent dęçus 
de cette dëcision. Rappelons que cette décision fut prise par les artisans eux-mêmes, lors de l'assemblée génērale spéciale tenue le 20 septembre 1985. Ils en ont décidé ainsi parce que les ventes diminuaient et que le Conseil d'administration ne voulait pas se rendre responsable du déficit.

Dans un même ordre d'idées, citons ici les résultats d'une recherche effectuẻe dans le cadre du programme "Outil de gestion",4 qui démontre que les modes de distribution que préfērent les artisans sont, par ordre d'importance:

- Tes expositions;

- la boutique des métiers d'art;

- les autres boutiques privēes de la région et d'ailleurs;

- la vente à domicile;

- les distributeurs.

La deuxième place qu'occupe dans cette hiérarchie la boutique des métiers d'art attire notre attention. Compte tenu que les ventes diminuent aussi dans les différentes expositions, on croît peut-être que la solution serait de multiplier les lieux de diffusion. Mais, comme les ventes diminuent à tous les niveaux, il ne s'agit pas là d'une solution, à notre avis. Car la baisse des ventes est peut-être davantage imputable aux produits eux-mêmes, qui ne correspondent plus aux goûts des consommateurs.

4.COTE, Brigitte, La Corporation des métiers d'art de l'AbitibiTémiscamingue, Rouyn-Noranda, Université du Québec en Abitibi-Témiscamingue, septembre 1985, p. 16. 


\subsubsection{Environnement politique}

2.2.2.1 Le Ministère des Affaires Culturelles (MAC)

La structure politique la plus importante, pour la Corporation des métiers d'art de l'Abitibi-Témiscamingue, est sans contredit le ministère des Affaires culturelles. En 1977, c'est même lui qui a incité les artisans des régions du Québec à se regrouper autour d'un organisme et qui acceptait, du même coup, de supporter financièrement cet organisme. Nous pouvons dire que la CMAAT émane du MAC pour répondre à un besoin spécifique. Comme elle en dépend entièrement pour survivre, elle doit répondre aux attentes de celui-ci. A plusieurs reprises au cours de l'étude, nous constaterons que cette dépendance financière influence les décisions et les orientations de la CMAAT.

Le MAC a défini les modes de calcul des subventions et les critères d'admissibilité des plans quinquennal et triennal de cette organisation (annexe 4). Depuis 1978, la seule responsabilité du Bureau régional était d'administrer rëgionalement les subventions et de faire la promotion des programmes d'aide. Depuis 1985, le MAC procède à la régionalisation de l'enveloppe destinée aux arts visuels et aux métiers d'art. Pour l'annēe 1985-1986, l'Abitibi-Tëmiscamingue a reçu $40500 \$ ; 31000$ \$ furent versēs à la CMAAT et $9500 \$$ à l'Atelier des mille-feuilles. Plusieurs organismes oeurrant dans le secteur des arts visuels et des métiers d'art respectent maintenant les critères d'admissibilité du programme d'aide financière. L'enveloppe globale demeurant à $40500 \$$, le bureau régional peut décider s'il 
subventionne les organismes les plus dynamiques dans leur milieu ou s'il partage les miettes entre tous les organismes admissibles.

A la suite à l'assemblẻe générale annuelle de mai 1986, où peu de membres se sont présentés pour décider de l'avenir de leur corporation, le Bureau régional du MAC a remis en question le versement de la subvention habituelle à la CMAAT. Les représentants des Affaires culturelles en région veulent une preuve concrète à l'effet que des artisans supportent cette structure. Compte tenu de la situation, ils désirent simplement exercer un meilleur contrôle sur les subventions octroyées. Ils se demandent également si la CMAAT ne devrait pas affecter le montant qu'elle reçoit d'habitude à la promotion des salons des métiers d'art et conclure des ententes de service avec le Conseil de la culture, plutôt que d'assumer des frais de fonctionnement.

Le MAC pourrait aussi augmenter sensiblement I'enveloppe disponible dans le cadre du programme "Soutien à la création", qui répond à des projets individuels de perfectionnement (d'une technique, d'expérimentation d'une nouvelle technique ou encore de création d'une collection). En 1986, un montant de $98000 \$$ était versé dans ce programme pour les arts visuels, les métiers d'art, la littérature et les arts d'interprétation. Cinq artisans ont pu profiter de cette aide financière individuelle, pour un montant totalisant $22000 \$$.

\subsubsection{Environnement géographique}

L'Abitibi-Témiscamingue est une région composêe de deux ensembles territoriaux, unis tant par leur histoire que par leur situa- 
tion géographique. Il s'agit aussi d'une région de vaste dimension - 45000 milles carrés - et on y dénombre environ 160000 habitants. Troisième région la plus faiblement peuplēe du Québec après ia CôteNord et le Nouveau-Quëbec, l'Abitibi-Témiscamingue se caractérise ainsi par la dispersion de sa population sur un vaste territoire. Et cela $n$ 'est pas sans effet sur l'offre des services, qui devient beaucoup plus complexe qu'ailleurs.

Toujours selon le sondage que nous avons effectué en novembre 1985 (annexe 2), deux pôles se dessinent au sein de la CMAAT. En effet, on retrouve un peu $p$ lus de $70 \%$ des membres de celle-ci dans les secteurs de Rouyn-Noranda et de La Sarre. Nous croyons que, compte tenu que la Boutique ètait située à Rouyn et que ce service semblait important pour les membres de la CMAAT, les artisans de la région de Rouyn-Noranda étaient davantage intéressés que les autres à payer une cotisation à cet organisme.

Mais comment expliquer que la CMAAT attire plus de membres à La Sarre que dans les régions de Val-d'Or et d'Amos? Est-ce qu'on compte plus d'artisans à La Sarre ou est-ce que l'effort marketing ne fut pas déployé avec 1 a même vigueur dans chacun des secteurs de l'Abitibi-Témiscamingue?

Il s'avère important, ici, de bien comprendre que les caractëristiques gēographiques de la rëgion (vaste territoire et faible population) influencent $l^{\prime}$ 'efficacité des services que la CMAAT veut 
offrir. Elle ne peut être organisée et/ou comparée à MAQAM (Métiers d'art du Québec à Montréal), qui possède beaucoup plus de membres concentrés sur un même territoire, ce qui facilite les ëchanges. En terme de prorata de la population, cependant, la CMAAT se compare à MAQAM: le pourcentage "membres/population totale" est sensiblement le même. Par contre, il n'en demeure pas moins que la CMAAT compte moins de membres que MAQAM. Conséquemment, l'offre de certains services devient plus difficile à rēaliser, et 1 'effet de synergie est d'autant moins visible.

\subsubsection{Environnement relié à la diffusion et à la promotion}

\subsubsection{Le marché des métiers d'art}

En novembre 1983, la firme conseil Mallette, Major et Martin notait que les métiers d'art, au Québec, représentaient un marchē de 70 millions d'habitants et que les artisans québécois ne détenaient que $40 \%$ de ce marché. Quant au marché global du cadeau, il était èvalué à plus de 125 millions. Plusieurs études démontrent également que plus de $50 \%$ des produits de mëtiers d'art vendus au Québec sont importēs.

En très peu de temps, le consommateur a inversé son intérêt de 1 a façon suivante: avant 1981, i1 achetait québécois d'abord et si c'était de qualité tant mieux; maintenant, il achète un produit de qualité et si c'est québécois, tant mieux! 5

5.Procès-verbaux, rapports d'activitēs, correspondance, notes, etc. (documents non paginés à consulter aux archives du MAC). 
Contrairement à la situation qui prévalait il y a quinze ans, le créateur québécois doit, sur le territoire même du Québec, concurrencer de plus en plus les concepteurs ou les créateurs étrangers qui, à chaque jour, deviennent davantage présents grâce au développement des médias d'information et des réseaux de distribution.

La crise économique a aussi fait sentir son influence sur la demande; les oeuvres d'art sont des produits de luxe. Ainsi le rapport d'activités de 1981-1982 de la CMAAT soulignait que les pièces utilitaires avaient tendance à mieux répondre à la demande que les pièces décoratives.

En mars 1984, les artisans de l'Abitibi-Témiscamingue ont tenu une journēe de rēflexion sur la situation des métiers d'art. Plusieurs participants ont soulignè à ce moment-là qu'ils pourraient vivre des métiers d'art s'ils réussissaient à vendre une partie de leur production à l'extérieur de la région. Mais, avant de consacrer des énergies à la recherche de lieux de diffusion à l'extērieur de la région, les artisans de 1'Abitibi-Témiscamingue devraient à notre avis vérifier le marché. Par exemple, il semble que les artisans montrēalais, ainsi que les producteurs étrangers, répondent de façon fort convenable à la demande de produits d'artisanat à Montréa 1 .

En outre, l'étude réalisẻe dans le cadre du programme "Outi1 de gestion"6 démontre que les boutiquiers du nord-est de l'0ntario seraient intéressēs à offrir à leur clientèle les oeuvres des ar-

6. COTE, Brigitte, La Corporation des métiers d'art de l'AbitibiTémiscamingue, Rouyn-Noranda, UQAT, septembre 1985, p. 18. 
tisans de la région de l'Abitibi-Témiscamingue. Mais aucune action ne fut engagée à la suite de cette étude. Ce nouvel outil de commercialisation demanderait que les artisans acceptent de produire les oeurres demandées en quantité suffisante et respectent les délais des boutiquiers ontariens. Toujours selon cette étude, les artisans de I'Abitibi-Témiscamingue ont acquis auprès des boutiquiers la réputation de manquer de professionnalisme. Par exemple, ils ne respecteraient pas les dēlais de livraison et les conditions d'exclusivité promis au départ.

\subsubsection{Les autres corporations}

Mise à part la CMAAT, il existe quatre autres corporations régionales:

- Les Métiers d'art des Cantons de I'Est;

- La Corporation des métiers d'art du Saguenay-Lac St-Jean;

- La Corporation des mëtiers d'art du Centre du Québec (CAQ);

- Les Métiers d'art du Québec à Montréal (MAQAM).

Les autres corporations régionales deviennent en quelque sorte concurrentes de la CMAAT; elles viennent elles aussi piger dans le portefeuille que le MAC réserve aux métiers d'art, et, par l'élément selon des critères d'èvaluation d'efficience et d'efficacité que celui-ci a dēterminé en comparant ces corporations. De plus, les membres de ces dernières visent le même marché potentiel de consommateurs d'oeuvres d'art. Ils deviennent donc des concurrents directs des membres de la CMAAT. S'ils reçoivent des meilleurs services de 
leur corporation, il peut alors devenir difficile de les concurrencer. Ainsi, l'efficacité des services offerts par une corporation influencerait indirectement les ventes de ses membres.

Le MAQAM et le CAQ de par leur représentation et le leadership qu'elles assurent dans certains dossiers (Comité national de sélection, l'ëtiquette de certification et la Quinzaine nationale des métiers d'art), deviennent les centres nerveux des métiers d'art au Québec. Ils veulent que plusieurs des services offerts actuellement par chacune des corporations régionales soient regroupés nationalement (annexe 3).

En juin 1986, dans le cadre du programme "Service de développement de métier", MAQAM voulait que la CMAAT lui fournisse 20000 \$. Mais le bureau régional du MAC a refusé de verser cette somme. Le service offert s'avērait intēressant (1igne "watt" pour informations sur base individuelle) mais hélas trop dispendieux.

En général, au sein de la CMAAT, on se mëfie de toutes les nouvelles orientations prises au niveau national. Les artisans des régions éloignées craignent de ne plus pouvoir manifester leurs besoins.

\subsubsection{Autres regroupements régionaux d'artisans}

Certains artisans, soit par goût ou parce que leurs demandes d'adhésion comme membres de la CMAAT leur furent refusées, s'associent à d'autres regroupements d'artisans. Ils peuvent aussi bien 
sûr, être membres de la CMAAT et s'associer quand même à d'autres regroupements comme:

- Le Club Artiste Enr. (Amos);

- La Guilde d'art et d'artisanat de Rouyn-Noranda (RouynNoranda);

- Les Artisans Créateurs Associēs (Senneterre);

- Le Cercle Laborieux d'Artistes Cassés (CLAC) (Val d'Or).

En outre, les Cercles des fermières demeurent des organismes de regroupement très présents dans les milieux rural et urbain. Des expositions annuelles et des stages de formation permettent aux membres de ces organismes de se rencontrer et d'échanger sur leurs besoins respectifs.

Cette situation amène les consommateurs à confondre ces regroupements avec la CMAAT. Ils ne semblent pas réaliser que celle-ci est un regroupement d'artisans professionnels. Car il faut comprendre que 1'achat d'une oeuvre d'art est avant tout subjectif; pour le consommateur, la provenance de l'oeuvre n'est pas un critère de choix; c'est plutōt l'évaluation qu'il en fait qui l'amènera à sélectionner telle ou telle oeuvre.

\subsubsection{Les comités des expositions artistiques}

Les comités des expositions artistiques ont pour but de promouvoir le développement des arts dans leurs villes respectives. Au mois de décembre de chaque année, chaque comité s'occupe d'organi- 
ser un saion des mëtiers d'art. En janvier 1986, ces comités et la CMAAT décidèrent d'entretenir des relations plus étroites. Les comitẻs parlent même de rendre obligatoire l'adhésion à la CMAAT pour les organismes ou les individus qui désirent participer aux différents salons. Ils souhaitent ainsi favoriser la concertation régionale. Aussi, la CMAAT pourrait revendiquer à ce moment-là sa part de l'enveloppe budgétaire "Quinzaine des métiers d'art", qui supporte sur le plan promotionnel les salons des mētiers d'art.

Nous pouvons remarquer également que les liens qu'a entretenus la CMAAT avec les comités des expositions artistiques le furent souvent sur une base personnelle; nous n'assistions pas à une relation entre organismes. En effet, si le personnel en place au sein des deux organismes s'entendait, ceux-ci collaboraient plus facilement.

\subsubsection{Le tourisme}

Selon le directeur général de l'office du Tourisme et des Congrès de Rouyn-Noranda, d'août 1984 à août 1985, le taux d'occupation des chambres dans les hôtels et motels, en Abitibi-Témiscamingue, a augmenté de 13,3\%.

De même, le nombre de visiteurs au kiosque touristique de Rouyn-Noranda pour cette même période a augmenté de $11 \%$. Par contre, il faut admettre que 14 municipalitēs des environs de Rouyn-Noranda fêtaient leur cinquantenaire, créant ainsi un certain achalandage. 
Mais il est important aussi de souligner que plusieurs congrès se sont tenus à Rouyn-Noranda en 1985, attirant environ 2700 congressistes. L'Office du Tourisme et des Congrès du Rouyn-Noranda rēgional attendait, en 1986, plus de 5000 congressistes. Et aucun plan d'action ne fut èlaboré par la CMAAT pour rejoindre ces clients potentiels.

Même si le nombre de touristes augmentait, la boutique des métiers d'art n'a pas profité de cette augmentation; au contraire, les ventes diminuaient. Deux hypothèses peuvent être avancēes pour expliquer ce fait: 1) les produits ne répondaient pas aux goûts des consommateurs et/ou 2) la boutique, de par son emplacement et son aménagement, n'attirait pas les touristes.

\subsubsection{Sociēté de mise en marché des métiers d'art} (SOMART)

En 1984, les artisans apprenaient la naissance de la Sociétē de mise en marchē des métiers d'art limitēe (SOMART). Cette société s'est donné comme objectif de commercialiser les produits des métiers d'art au Québec et à l'étranger. La SOMART vise ainsi à distribuer, partout au Québec, les produits des mëtiers d'art, en exploitant simultanément le marché institutionnel et le marché de gros, axé sur le commerce des boutiques et 1'exportation. Elle espère, ce faisant, augmenter de 2,5 millions par année la part des produits québécois au cours des cinq prochaines années. Quant aux produits des mētiers d'art, la SOMART entend les sélectionner selon des critères purement commerciaux. 
La création de la SOMART pose des problèmes aux artisans régionaux, parce qu'elle s'adresse à des artisans dont la production est considérable. Dans la région, certains craignent que les produits qu'elle vendra feront concurrence aux produits rēgionaux, chez les boutiquiers privés. De plus, les artisans pensent que le mode de fixation des prix de la SOMART aura une influence sur les prix de tous les produits des métiers d'art. Ils croient que cette sociēté pourrait générer une hausse artificielle des prix des produits, dont la vente deviendrait alors de plus en plus difficile. Ils craignent aussi que certains artisans, à moyen et à long terme, se sentant attirés par les grands centres, quittent leur région d'origine, ce qui entrainerait une baisse du dynamisme de la vie culturelle dans les régions pēriphériques.

Devant ces inquiētudes, le Conseil d'administration de la CMAAT faisait deux propositions, lors de la journée d!orientation de 1 'automne 1984:

- reconnaître 1'existence et le développement, dans les régions, de structures intermédiaires de diffusion;

- assurer une complémentarité entre les services offerts par ces structures régionales de diffusion et SOMART, permettant ainsi à tous les artisans d'avoir accès à des outils de commercialisation répondant à leurs besoins. 


\subsubsection{Organismes de consultation}

\subsubsection{Le Conseil des métiers d'art}

Le Conseil des métiers d'art regroupe, au niveau national, les cinq corporations régionales, les deux écoles de formation des métiers d'art et des représentants des régions où les corporations n'existent plus. Mis sur pied récemment, il en est encore à la phase de structuration.

\subsubsection{Le Conseil de la culture de l'Abitibi-Témisca-}

mingue

Le Conseil de la culture de l'Abitibi-Témiscamingue a un rôle consultatif. Il définit les besoins de la rēgion en matière culturelle et s'occupe de la promotion des activités.

Depuis mai 1986, le Conseil de la culture s'est beaucoup impliqué dans la gestion de la CMAAT, compte tenu qu'il assurait la tutelle de l'organisme avec le bureau régional du MAC. C'est au cours de cette tutelle que le processus de restructuration a vraiment èté enclenché. Le bureau régional du MAC, le Conseil régional de la culture et le Conseil d'administration de la CMAAT ont révisé les zones problématiques dēlimitēes dans cette étude.

\subsubsection{Le Comité consultatif permanent des métiers}

$\underline{\text { d'art }}$

Le Comité consultatif permanent des métiers d'art s'assure le suivi des décisions prises lors de la Journée nationale des métiers d'art (19 novembre 1984). 


\subsubsection{Le Conseil canadien de I'artisanat}

Le Conseil canadien de 7 'artisanat a pour projet principal la mise sur pied d'un réseau d'information informatique interactif en métiers d'art.

\subsubsection{Organismes de formation}

\subsubsection{L'Institut des mëtiers d'art}

L'Institut des métiers d'art (IMA) est un centre d'excellence qui n'a qu'un seul but: le développement et le rayonnement des métiers d'art. Il forme les nouveaux artisans et réalise, et organise en tenant compte des demandes et des besoins exprimés par les artisans professionnels, des activités de perfectionnement sur mesure. Il fournit également une aide technique aux entreprises artisanales, encourage la recherche appliquëe et diffuse de l'information spécialisée. Situé à Montrēal, l'Institut exerce ses activitēs sur un vaste territoire, délimité par les régions des Cantons de l'Est, de l'Outaouais et de l'Abitibi-Témiscamingue. Un organisme similaire, implanté à Québec, rejoint les autres régions (Le Centre de formation et de consolidation en métiers d'art).

En région, peu d'artisans se montrent intēressés par ces centres; en règle générale, ils ne sont pas prêts à quitter leur ville pour aller se perfectionner. S'agit-il seulement d'une question de distance? Nous croyons que non. Car, si la production des artisans de la région n'est que le résultat d'un hobby, pourquoi ces derniers iraient-ils se perfectionner à l'extérieur? 


\subsubsection{Commission de formation professionnelle}

La formation et le perfectionnement sont maintenant assurés par la Commission de formation professionnelle (CFP). Celle-ci s'associe au ministère des Affaires culturelles et, en collaboration avec les représentants des artisans, ils planifient et opérationalisent des mécanismes d'identification des besoins de formation, d'apprentissage et de perfectionnement.

En mars 1986, un cours de design fut offert aux artisans de 1a région. La participation à ce cours fut relativement bonne. Par contre, le Conseil d'administration de la CMAAT envisage une baisse de participation lorsque les cours seront plus spécialisēs. De là à craindre que, un jour, la faible participation à un cours ne permette pas de l'offrir, il n'y a qu'un pas.

A 1 'automne 1986, le bureau régional du MAC a fait parvenir un questionnaire élaboré par MAQAM aux artisans de la région pour connaitre leurs besoins en formation. Il aurait par 1 a suite transmis les informations recueillies à la CFP de la région, dans le but que celle-ci organise des cours destinés aux artisans; ou encore il aurait assuré autrement la dispensation de la formation. Il voulait ainsi pouvoir informer la CFP de la région ou sinon rendre accessible la formation par une autre alternative. Mais le MAC n'a reçu que 15 réponses sur 75 envois. Ce résultat nous amène à nous interroger sur l'intérêt des artisans pour la formation. 
CHAPITRE 3 


\section{CHAPITRE 3}

OESCRIPTION DES STRUCTURES

\subsection{PREAMULEE}

Une organisation tend à devenir plus complexe que les éléments qui la composent. Ainsi, comme l'explique Etzioni, cette situation rend plus difficile le contrôle et plus confuse l'identification des participants à la mission.

The artificial quality of organizations, their high concern with performance, their tendency to be far more complex than natural units, all make informal control inadequate and reliance on identification with the job impossible. Most organizations most of the time cannot rely on most of their participants to internalyse their obligations, to carry out their assignments voluntary without additional incentives. 1

Comme le souligne Etzioni face à cette réalité, il faut trouver des moyens pour motiver les participants. Il faut que 1'organisation se donne la structure qui lui convient le mieux pour atteindre ses objectifs. La structure d'une organisation réside dans les moyens qu'elle prend pour parvenir à ses fins.

Dans ce chapitre, nous allons discuter du design organisationnel de la CMAAT. Nous entendons par design organisationnel l'ensemble des décisions que doit prendre une organisation pour assurer la cohérence entre les éléments qui la composent. Galbraith nous explique bien ce concept.

1.ETZIONI, A., Modern Organizations, New-Jersey, Prentice-Ha11, 1963, p. 59. 
The concept of organization design results from a combination of our definition of organization and the concept of strategic choice. Organization design is conceived to be a decision process to bring about a coherence between the goals or purpose for wich the organization exists, the paterns of division of labor and interunit coordination and the people who will do the work. The notion of strategic choice suggests that there are choice of goals and purposes choices of different organizing modes, choices of processes for integrating individuals into the organization and finally a choice as to whether goals, organizations, individuals, or some combination of them should be changed in order to adapt to changes in the environment. Organization design is concerned with maintaining the coherence of these interwined choices over time.?

Af in de mieux comprendre cette notion, nous reproduisons une figure du même auteur. Nous constatons que l'organisation doit premièrement procéder à des choix stratégiques. Ensuite, elle doit organiser le travail, c'est-à-dire décomposer les tâches et assurer une coordination entre les différents postes. Enfin, elle doit sélectionner et former les individus et concevoir un système de récompense.

2. GALBRAITH, Jay R., Organization Design, USA, Abdison Wesley Publishing Company, 1977, p. 5. 
Concept du design organisationne ${ }^{3}$

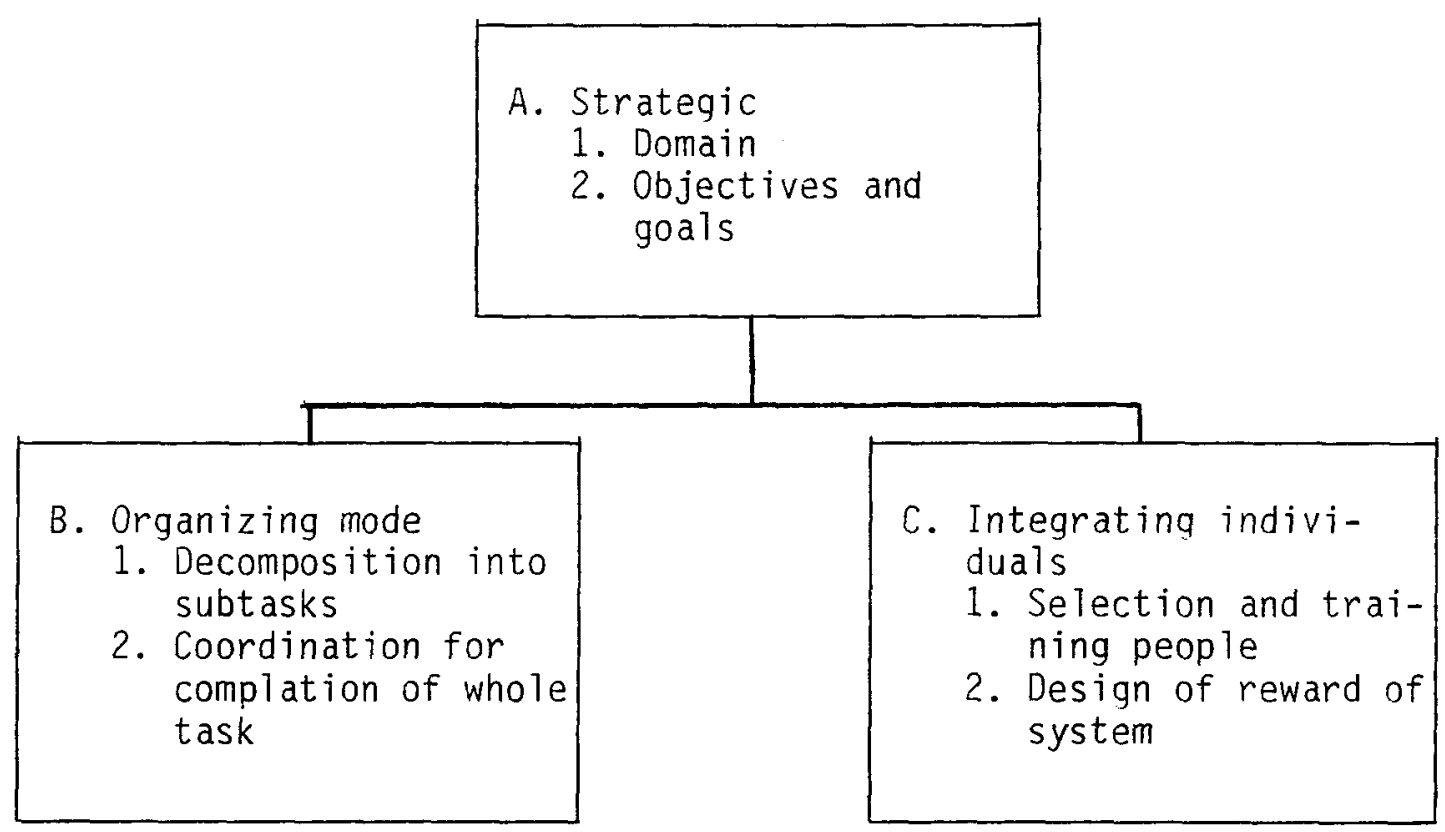

\subsection{BUTS DE LA CORPORATION}

Les buts de la Corporation sont de:

a) Regrouper les artisans et les personnes intéressées au développement de l'artisanat de la région de l'Abitibi-Témiscamingue.

b) Promouvoir et favoriser les intérêts artistiques, économiques et sociaux de ses membres.

c) Dans le but de promouvoir la création artistique et artisanale québécoise, l'association pourra:

- apporter, à tout créateur et à toute association de créateurs artistiques et artisanaux, 1'aide que 1'association jugera nécessaire, sous quelque forme que ce soit; 
- participer à toute manifestation culturelle telle que concours, expositions, colloques et autres activités du même genre.

d) Réunir et mettre à la disposition des membres la documentation nécessaire sur les métiers d'art et l'artisanat.

e) Imprimer, éditer, distribuer toute publication pour les gens de l'Association et ainsi promouvoir l'intérêt de ses membres.

f) Acquérir par achat, location ou autrement, posséder et exploiter des biens, meubles et immeubles nécessaires.

g) Offrir à ses membres des services de gestion dans les domaines:

- Marketing: afin d'assurer une distribution de la production artisanaie.

- Gestion: afin d'assurer une gestion adéquate des entreprises artisanales.

(Les lettres patentes de la Corporation ne lui permettent pas de se livrer, sur le territoire du Québec, à des activités qui se situent dans le champ d'exercice exclusif à une profession, en vertu d'une loi.)

h) Favoriser l'épanouissement de ses membres par l'êtablissement de programmes sociaux, éducatifs et culturels. 
i) Conseiller, aider les artisans ou groupes d'artisans dans l'établissement de projets ou de programmes en relation avec les différents ministères et/ou agences gouvernementales.

j) Promouvoir le perfectionnement de ses membres, sous réserve de la Loi de l'enseignement privé et des règlements adoptés sous son autorité.

k) Instaurer des kiosques, des boutiques, organiser des expositions afin d'aider à la mise en marché des oeuvres artistiques ou artisanales et à l'approvisionnement en matières premières.

\subsection{ORGANIGRAMME (mai 1986)}

La CMAAT est un organisme sans but lucratif regroupant des artisans de l'Abitibi-Témiscamingue. Tous ses membres forment 1'assemblée générale. Une fois par année celle-ci élit un conseil d'administration qui se réunira régulièrement afin d'orienter les destinées de la CMAAT. Chaque zone géographique et chaque famille de métiers d'art doivent être représentées sur ce conseil. Ensuite, parmi les membres choisis, le conseil d'administration élit un exécutif.

Afin de mieux comprendre les rapports mutuels entre les différents niveaux d'autorité, nous traçons l'organigramme de la CMAAT 


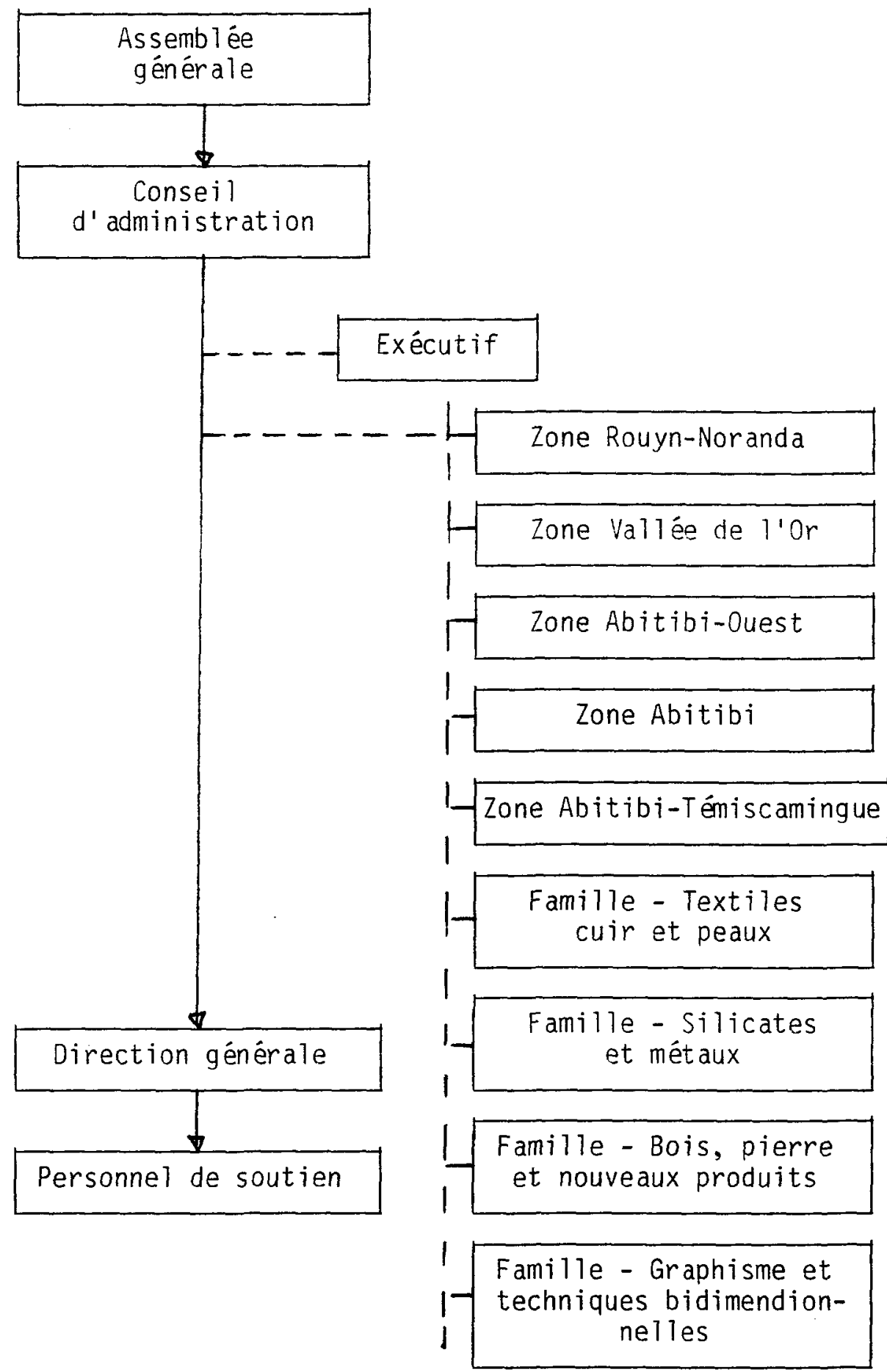




\subsection{COMPOSITION DU CONSEIL D'ADMINISTRATION}

Jusqu'en mai 1986, le Conseil d'Administration se composait de 9 membres actifs, élus par l'assemblée générale représentant des zones géographiques et des disciplines. Chacune des cinq zones se nommait un représentant et chacun des quatre groupes de métiers d'art (regroupements d'individus qui ont en commun les matériaux et les techniques afférentes, ainsi que le désir de vivre de leur métier) ènumérés ci-après s'élisait un représentant.

1. Textiles, cuir et peaux: tissage, tapisserie, macramé, tricot, crochet, broderie, couture, courtepointe, fléché, dentelle, reliure, cordonnerie, maroquinerie, cuir ciselé, etc.

2. Silicates et métaux (argile, verre et métaux): poterie, céramique, forge, ferronnerie, joaillerie, orfèverie, cuivre, poterie d'étain, émaillerie, vitrail, etc.

3. Bois, pierre et produits nouveaux: ébénisterie, sculpture, ciselure, etc.

4. Graphisme et techniques bidimendionnelles: lithographie, gravure, sérigraphie, batik, impressions et dessins sur tissu, dessins, aquarelles, huiles, etc.

Lors de l'assemblée générale annuelle de mai 1986, Madeleine Rivard Inc., une firme de consultation, suggère de revoir la com- 
position du Conseil d'Administration. Cette firme estime qu'un Conseil d'Administration composề de moins de représentants tiendrait davantage compte des activités et des ressources de la corporation. A la suite de cette remarque, et parce que, de toute façon, peu de membres se montraient intéressés à siéger sur le Conseil d'Administration, l'assemblée générale décide d'amender l'article 20 des règlements généraux: le Conseil d'Administration se compose donc depuis ce temps de cinq membres actifs, élus par l'assemblée générale.

Conséquemment, on amende également l'article 27 des règlements généraux: le Conseil d'Administration doit, dès la première réunion suivant l'assemblée générale annuelle, élire, parmi les membres choisis, un exécutif de trois membres, dont un(e) président(e), un(e) vice-président(e) et un(e) secrétaire-trésorier(ière).

\subsection{DESCRIPTION DE TACHE DE LA DIRECTRICE GENERALE}

Sous la direction du Conseil d'administration:

- gérer le personnel;

- $\quad$ superviser une boutique communautaire;

- gérer et planifier le budget de fonctionnement;

- préparer des demandes de subvention pour l'organisme;

- maintenir des relations avec les intervenants du milieu;

- promouvoir et développer le secteur des métiers d'art dans la région.

Depuis février 1986, ce poste est temporairement vacant. Lorsque la boutique existait, sa gestion occupait une grande partie 
du travail de la directrice générale. La description de tâche n'ayant pas été révisée depuis la fermeture de la boutique, le mandat de la directrice générale n'était clair ni pour la personne occupant ce poste ni pour le Conseil d'Administration qui devait superviser son travail.

\section{6 DESCRIPTION DES MEMBRES}

Lors de 1 a rencontre de réflexion tenue 1 es 23 et 24 juillet 1986, les personnes présentes ont révisé les critères d'admissibilité. Ils ont convenu qu'il s'avèrait nécessaire que la corporation s'adresse exclusivement aux artisans professionnels ou à ceux qui cherchent à le devenir.

\subsubsection{Artisan(e) professionnel(1e)}

Un(e) artisan(e) professionnel(le) est une personne qui:

- fait un travail de création en métiers d'art;

- produit ou fait produire par d'autres à partir d'un prototype conçu par elle;

- a une expérience de production d'au moins deux ans;

- a reçu une formation (académique ou audodidacte) dans son corps de métier (critieres nationaux);

- a un inventaire et/ou peut rencontrer les exigences de la demande dans des délais jugés raisonnables par elle et l'acheteur potentiel. 


\subsubsection{Artisan(e) aspirant(e)}

Une personne qui ne rencontre pas tous les critères cidessus, mais qui produit des oeuvres de métiers d'art répondant aux critères nationaux d'excellence.

\subsection{LA CMAAT: ORGANISATION SANS BUT LUCRATIF (OSBL)}

Nous venons d'étudier les structures de la CMAAT. Pour compléter cette partie, nous croyons opportun de faire ressortir les caractéristiques d'une organisation sans but lucratif (OSBL) et d'établir un parallèle entre ce type d'organisation et la CMAAT.

En général, dans une OSBL, une partie importante des ressources ne provient pas de l'échange sur un marché des biens et services produits par cet organisme. Et, comme son nom 1'indique, elle ne vise pas un profit quelconque. Selon la classification de Rhenman4, les objectifs de ce type d'organisation sont multiples, et plutôt orientés sur la fourniture de biens et de services que sur la réalisation d'un profit. Il ajoute qu'en général, le pouvoir, dans ces organisations, appartient à des coalitions d'individus, c'est-àdire à des individus qui poursuivent un but commun. Selon la classification de Mintzberg ${ }^{5}$, les stratégies des OSBL ont un caractère adaptatif, si bien que, dans un environnement souvent complexe et

4. DEMESTERE, R. et VIENS, G., "Le contrôle de gestion des organisations sans but lucratif" dans Revue française de gestion, numéro 6 , septembre-octobre 1976, p. 17-18.

5. Idem. 
changeant, la coalition au pouvoir prendra progressivement, et à la suite de marchandages, des décisions à court terme.

Au sein de la CMAAT, il est difficile d'identifier l'instance détenant réellement le pouvoir; est-ce l'assemblée générale ou le Conseil d'Administration? Bien sûr, d'après l'organigramme, comme l'assemblée générale élit les membres du Conseil d'Administration, elle peut en principe leur confier des mandats spécifiques, juger de leur efficacité et prendre les mesures qui s'imposent s'ils n'atteignent pas les objectifs fixés. Toujours selon l'organigramme, si des permanents sont engagés, ceux-ci relèvent du Conseil d'Administration. Cette structure d'autorité, dont rend compte l'organigramme en délimitant verticalement des champs de pouvoir, représente le pouvoir formel. Mais, dans toute organisation, il existe aussi ce qu'on appelle le pouvoir informel, c'est-à-dire celui qui ne prend pas sa source dans la structure officielle. Souvent, nous entendons dire que celuj qui possède l'information détient le pouvoir. Etant donné en ce moment l'absence de permanents, les membres du Conseil d'administration deviennent les plus informés.

En dépit de cela, ces derniers ne savent pas tellement ce qu'ils doivent faire ni quelle orientation suivre. Cette situation peut s'expliquer par le fait que les membres voient les choses différemment et qu'aucun d'eux dirige vraiment le groupe; on ne reconnait pas de leader. Personne ne possède vraiment plus d'informations que les autres, car chacun est responsable d'un seul dossier. Un leader 
devrait apparaître cependant, si un dossier s'avérait plus important qu'un autre.

Par ailleurs, Crozier et Friedberg identifient quatre sources de pouvoir:

\begin{abstract}
(...) celles découlant de la maîtrise d'une compétence particulière et de la spécialisation fonctionnelle; celles qui sont liées aux relations entre une organisation et son ou mieux, ses environnements; celles qui naissent de la maitrise de la communication et des informations; enfin, celles qui découlent de l'existence de règles organisationnelles générales. 6
\end{abstract}

Nous ne pouvons, au sein de la CMAAT, identifier un membre tirant profit de 1'une de ces sources de pouvoir. Crozier et Friedberg $^{7}$ abordent aussi le pouvoir en terme de caractère relationnel. D'après eux, le pouvoir implique toujours la possibilité que certains individus ou groupes agissent sur d'autres individus ou groupes. Telle notion peut expliquer beaucoup de choses. Sur quoi et sur qui peuvent agir les membres du Conseil d'Administration? Toujours selon Crozier et Friedberg, le pouvoir ne se conçoit que dans la perspective d'un but qui motive l'engagement de ressources. Quels sont les buts des membres du Conseil d'Administration?

6.CROZIER, M. et FRIEDBERG, E., L'acteur et le système, Viennes, Edition du Seui1, 1977, p. 71.

7. Idem. 
Etant donné que le MAC finance à $100 \%$ la CMAAT, la survie de celle-ci en dépend entièrement. Ce ministère dêtient donc réellement le pouvoir, car, si ses attentes ne sont pas respectées, $i 1$ peut toujours cesser de subventionner l'organisme. Et, à moins que cet organisme ne trouve une autre source de revenus, il devra fermer ses portes.

Le bureau régional affirmait avant 1985 ne pas s'être mêlé de la gestion de l'organisation, puisqu'il ne voulait pas se voir accusé d'ingérence. Mais, étant donné la situation de la boutique en septembre 1985, il a à ce moment-là confié à des experts l'analyse de la situation financière de la CMAAT. C'est à la suite de ce rapport que l'assemblée générale décidait de fermer la boutique communautaire. Rappelons-nous aussi qu'au même moment, il proposait de financer la présente étude. Par la suite, le bureau a surveillé de plus près les activités de la CMAAT. Finalement, compte tenu des positions prises par les membres lors de l'assemblée générale annuelle du mois de mai 1986, 1e MAC a décidé d'assumer la tutelle de Ia CMAAT, avec 1 'aide du Conseil régional de la culture de l'Abitibi-Témiscamingue.

Selon nous, ces faits montrent à quel point le MAC se trouve en position de force au sein de cette organisation.

Nous constatons ici que la notion de pouvoir informel est étroitement liée au financement, et que c'est en lui, en fait, que réside le véritable pouvoir. Bien qu'une OSBL ne cherche pas à tirer profit de ses activités, l'aspect financier n'en demeure pas moins 
important, car il est intimement lié à sa survie. Greffe Xavier a étudié cette notion d'équilibre financier comme condition de survie:

La prédominance du service rendu sur les aspects financiers ne signifie pas que ceux-ci soient des préoccupations inexistantes dans une OSBL. L'équilibre financier représente pour certain une condition de survie, donc un préalable à l'accomplissement de l'idéal à long terme. 8

8. XAVIER, Greffe, "La gestion du non marchand" dans Revue française de gestion, sept.-oct. 1979 , p. 59. 
CHAPITRE 4 
CHAPITRE 4

DESCRIPTION DES PROCESSUS

\subsection{PREAMBULE}

Au deuxième chapitre, nous avons vu que la CMAAT est un système ouvert, en interaction constante avec un environnement. El le importe des matières premières, personnes, énergies et informations, qu'elle convertit en produits et services qu'elle exporte dans l'environnement. 1

L'organisation se compose aussi de nombreux sous-systèmes interdépendants qui impliquent de multiples interactions.2 Cette interdépendance fait en sorte que les changements survenant dans l'un d'eux peuvent produire des répercussions sensibles sur les autres.

Comme il s'avérait important d'étudier l'environnement de la CMAAT, il devient ici nécessaire de décrire les comportements individuels des sous-systèmes. Cette étape s'appelle la description des processus.

Le processus comprend l'ensemble des activités de gestion et de transformation de l'organisation, le tout interrelié par des

1.CRENER, M. et MONTEIL, B., Principes de management, Sillery, Les Presses de 1'Université du Québec, 1981, p. 465.

2. Idem. 
flux d'information, de monnaie, de personnel et de matière. ${ }^{3}$ L'un ou l'autre de ces flux pourrait être privilégié, selon le mandat et le type de problématique abordé.

I1 s'agit donc ici de décrire avec le plus d'exactitude possible les opérations réelles qui sont effectuées à la CMAAT et de les agencer sur un diagramme en respectant leur séquence logique et en les interreliant par des flux d'information, sans référence à la personne responsable ou à tout autre élément structurel. Afin de s'assurer que les éléments du diagramme constituent bien des activités, l'utilisation de verbes pour décrire les éléments du processus sera de mise ici.

Enfin, puisque la méthodologie de diagnostic-intervention de Checkland adopte la perspective des flux et qu' on y considere les organisations comme des systèmes d'activités, ce chapitre sur la description des processus devient crucial et doit occuper une place importante dans l'ensemble de la problématique.

\subsection{LE SYSTEME GENERAL}

Selon l'approche systémique, une organisation est un ensemble de sous-systèmes interreliés.

3. PREVOST, PaUT, Le diagnostic-intervention: une approche systémique au diagnostic organisationnel et à la recherche-action, Chicoutimi, UQAC, 1983, 92 pages. 
A la CMAAT, le système général se compose de 6 soussystèmes:

- le sous-système Planification;

- le sous-système Promotion;

- le sous-système Concertation;

- le sous-système Information;

- Te sous-système Développement;

- le sous-systiène Contrôle.

Le sous-système Planification s'avère le noyau puisqu'il entretient des liens étroits avec tous les autres sous-systèmes. De plus, c'est à partir de celui-ci qu'on élabore les activités des autres sous-systèmes.

Les sous-systèmes "concertation", "information" et "développement" deviennent dans notre étude le bloc "transformation". Ils représentent les services offerts par la CMAAT.

Les sous-systèmes "Promotion" et "Contrôle" apparaissent comme des sous-systèmes connexes. Et le sous-système "promotion" est tourné vers l'environnement externe à la CMAAT, tandis que le soussystème "Contrôle" entretient plutôt des liens internes. 


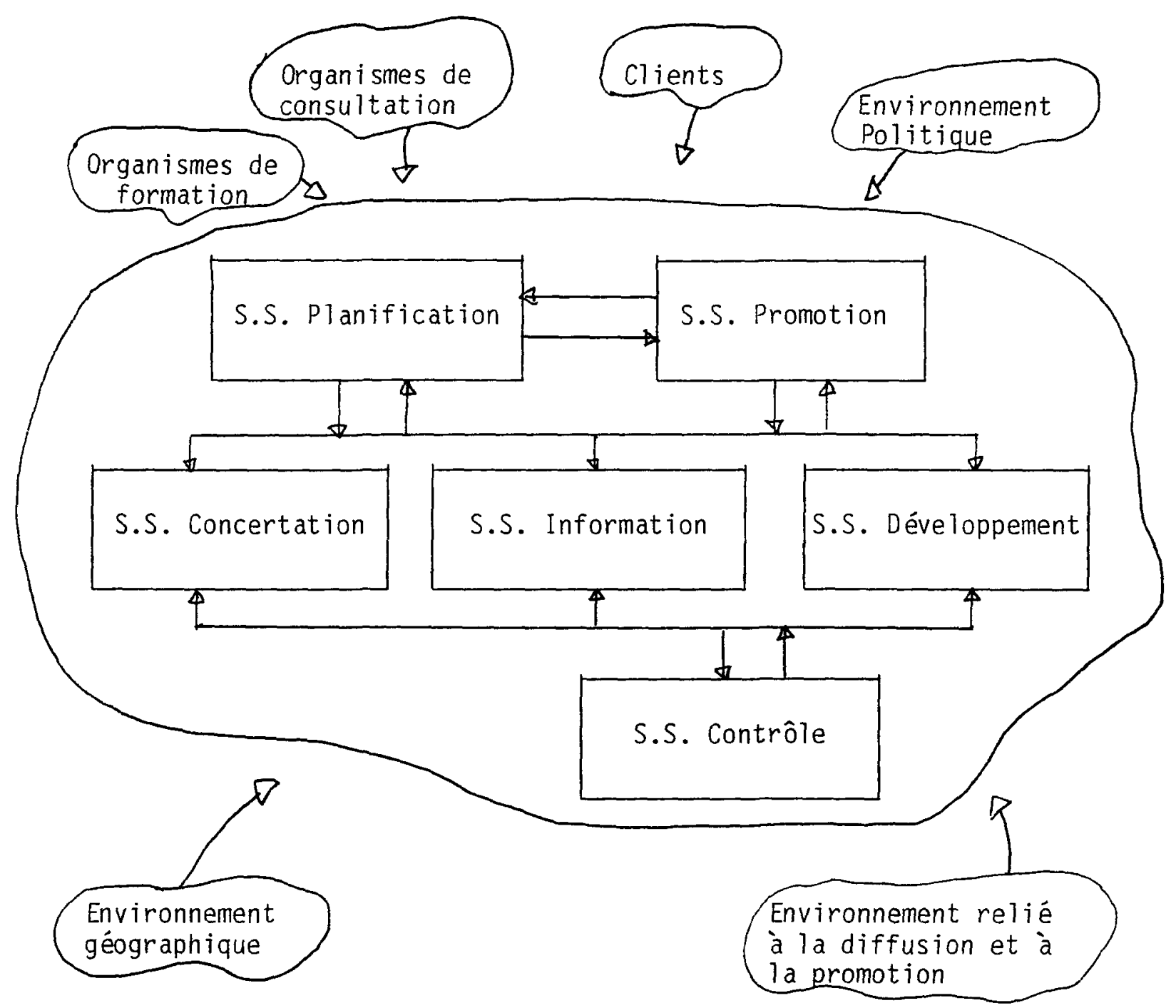

FIGURE 2: Le système général

NOTE: Nous pouvons identifier 6 sous-systèmes au sein du système général de la CMAAT. Ils sont interdépendants; les actions de 1 'un peuvent avoir des répercussions sur un autre. Le système de la CMAAT est, en outre, en relation constante avec son environnement. 


\subsection{SOUS-SYSTEME "PLANIFICATION"}

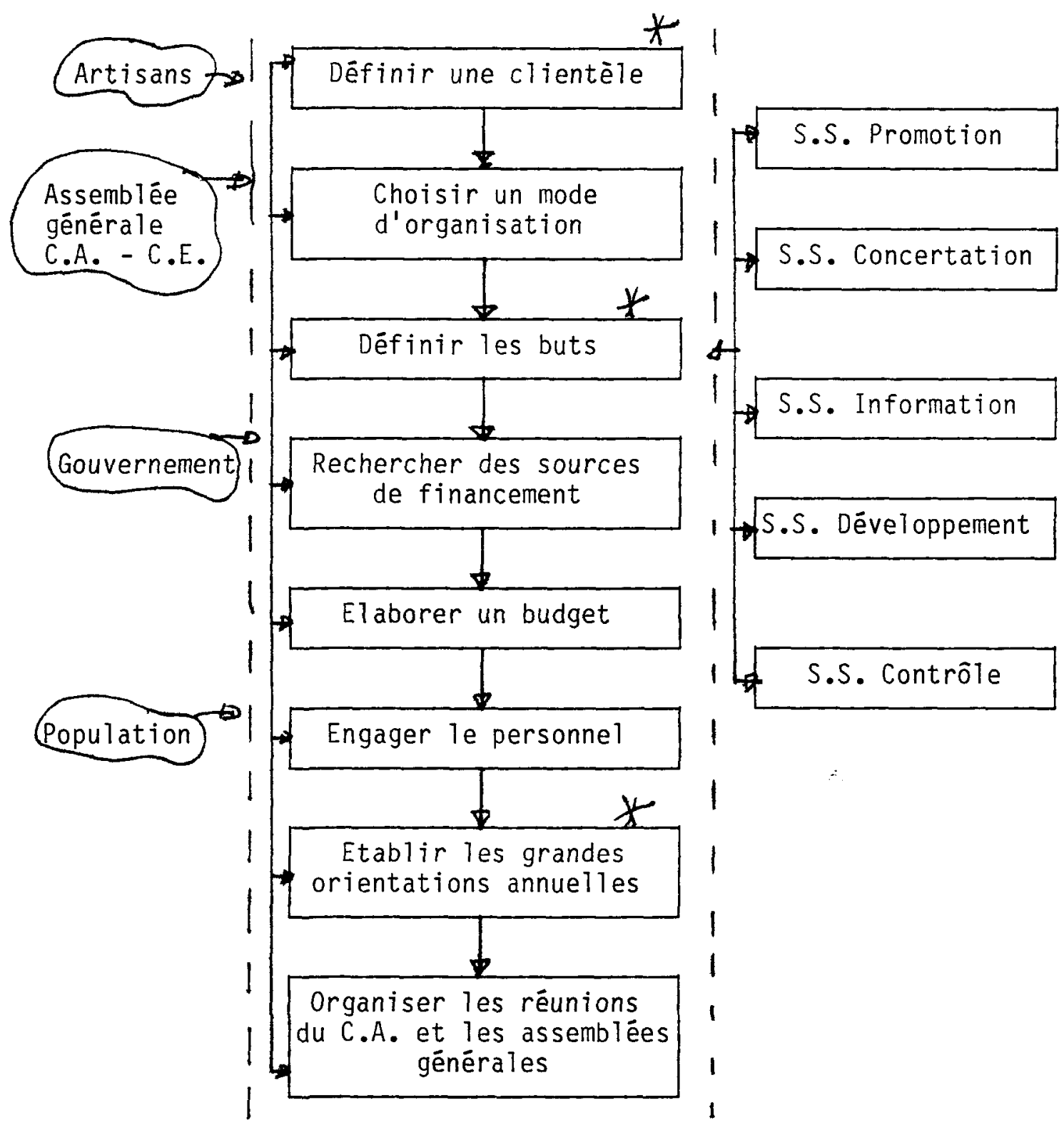

FIGURE 3: Sous-système "planjfication"

NOTE: Le sous-système "planification" est composē de 8 activités. Pour réaliser ces activités, il reçoit des informations de son environnement. Aussi entretient-i des relations avec les cinq autres sous-systèmes, qui sont également interreliés entre eux. 


\section{a) Définir la clientèle}

Depuis sa naissance, 1 a CMAAT se veut un regroupement d'artisans professionnels qui répondent aux critères de sélection qu'elle a établis. Pourtant, toujours le 25 janvier 1986, lors d'une assemblée générale spéciale, les membres présents ont discuté afin d'identifier les membres potentiels de la Corporation. Le problème provenait du sens que l'on donnait au terme professionnel. Selon le Conseil des métiers d'art, un artisan professionnel répond à certaines normes de qualité et d'éthique et cherche à vivre de son art.

Mais, comme le métier d'artisan ne rapporte souvent pas suffisamment, les artisans se voient le plus souvent contraints d'exercer un autre métier pour survivre. Cela n'enlève rien à leur professionnalisme au niveau de la qualité des produits, mais, par contre, les objectifs qu'ils poursuivent s'en trouvent affectés.

Nous pouvons observer présentement trois catégories de membres au sein de la CMAAT:

1) ceux qui veulent vivre de leur métier et qui y arrivent sans le recours de la CMAAT;

2) ceux qui veulent vivre de leur métier et qui s'attendent à ce que la CMAAT leur fournisse les outils nécessaires pour augmenter leurs ventes;

3) ceux qui pratiquent leur métier comme passe-temps ou en vue d'un épanouissement personnel. 
D'après le sondage effectué en novembre 1985 (annexe 2), $25,7 \%$ des répondants disent pratiquer leur discipline à titre de premier revenu personnel, $25,7 \%$ à titre de second revenu personnel, $25,7 \%$ à titre de passe-temps et $22,9 \%$ à d'autres fins. Ainsi, selon ce sondage, 48, $6 \%$ des membres ne chercheraient pas à vivre de leur métier. Le même sondage démontre également que les revenus demeurent relativement bas, sans égard au but des artisans; 23 artisans sur 28 ont un revenu inférieur à $10000 \$ /$ année.

Aussi est-il difficile de cerner les artisans intéressés à se perfectionner et à profiter des services offerts à ce niveau par la CMAAT et la SOMART. Un artisan qui pratique son métier à titre de second revenu peut vouloir se perfectionner af in que ce métier devienne son premier revenu. Par contre, un artisan peut pratiquer son métier à titre de premier revenu et ne pas chercher à augmenter ses profits, si le revenu familial permet de combler les besoins de la famille.

Quoiqu'il en soit, la CMAAT éprouve certains problèmes à répondre aux besoins de ses membres, besoins beaucoup trop spécifiques à chaque individu. Cette hétérogénéité rend la tâche du Conseil d'Administration fort difficile. En effet, le Conseil d'Administration a peine à orienter la CMAAT, principalement pour cette raison.

b) Choisir le mode d'organisation

La naissance du phénomène des corporations au Québec était tributaire d'une volonté politique. Le gouvernement devait s'assurer 
que chacun se fasse entendre. C'est pourquoi il imposa des critères au niveau de la représentativité. Le Conseil d'administration remet souvent en question ce mode d'organisation, mais, par contre, il est conscient que, pour bénêficier de l'aide financière gouvernementale, i1 doit s'y soumettre.

Pour plusieurs régions où les corporations furent dissoutes, celles-ci sont maintenant regroupées en comités de métiers d'art au sein des conseils de la culture. Même si cette structure peut s'avérer intéressante à maints égards, les comités se plaignent du manque de fonds et disent viser les mêmes buts qu'autrefois. Par contre, ils sont ravis de l'inexistence d'une assemblée générale à laquelle il fallait rendre des comptes.

\section{c) Définir les buts}

Les buts de la Corporation, tels que dëcrits officiellement, $n^{\prime}$ ont pas changé depuis sa fondation. A l'assemblée générale spéciale, tenue le 25 janvier 1986, les membres ont discuté des principaux services que devraient offrir la CMAAT sans en réviser les buts. De même, lors de l'assemblée génêrale annuelle, ils ont traité des activités à réaliser en laissant pour compte encore une fois les buts. C'est pourtant primordial qu'une organisation se donne une 1 igne directrice, comme le signale Charles Perrow: Organizations are established to do something; they perform work directed toward some end. We must examine the end or goal if we are to analyse organizational behavior. 4

4.PERROW, Charles, "Organizational Goals" dans Encyclopedia of Social Sciences, 11, N.Y., MacMi11an, p. 305-316. 


\section{d) Rechercher des sources de financement}

Depuis la naissance de la CMAAT, la subvention que lui accorde le MAC constitue sa principale source de financement. Il y a aussi la cotisation payée par les membres, plutôt difficile à fixer; i1 semble fastidieux pour la CMAAT d'évaluer le coût du service offert, et pour l'artisan d'évaluer ce que lui rapporte la CMAAT. Le Conseil d'administration est souvent aux prises avec le dilemme suivant: doit-il accueillir plusieurs membres en fixant une cotisation peu élevée? ou encore fixer une cotisation élevée et voir le nombre de ses membres diminuer? Lors de l'assemblée générale du mois de mai 1986, les membres ont décidé de fixer le prix de la cotisation individuelle à $10 \$$, ce qui représente une baisse de $50 \$$ par rapport aux taux en vigueur jusqu'à ce moment-ià. Précisons ici qu'en octobre 1985, date où la CMAAT décidait de fermer sa boutique communautaire, on y comptait alors 60 membres. En octobre 1986, lors de la réunion spéciale pour la survie de la CMAAT, 24 membres avaient payé leur cotisation.

Par le passé, celle-cj a tenté d'organiser des activités de financement. Selon les responsables de ces activités, le succès qu'elles ont remporté n'en valait pas la peine.

e) Elaborer le budget

Elaborer le budget représente une tâche très routinière, effectuée rapidement. En effet, le Conseil d'Administration, après avoir fixé le montant de la subvention qu'il prévoit recevoir, dresse 
le budget de l'organisme. Les mêmes postes budgétaires s'y retrouvent généralement d'une année à l'autre. Il appert que la pertinence des postes ne serait pas révisée.

\section{f) Engager le personnel}

Selon les critères établis par le MAC, la CMAAT peut engager du personnel permanent. Majs, souvent, la description de tâche n'était pas révisée malgré des changements importants au sein de la Corporation. Et les mandats du personnel n'étaient pas clairs.

De plus, comme le budget fut toujours quelque peu restreint, le personnel engagé était plus ou moins formé et expérimenté. Les employés quittaient la CMAAT aussitôt qu'ils pouvaient obtenir de meilleures conditions de travail dans une autre organisation. Il y avait donc une perte de temps considérable résultant de l'entraînement du personnel, toujours à recommencer.

\section{g) Etablir les grandes orientations annuelles}

A chaque année, le Conseil d'administration établit l'êchéancier annuel de l'organisme et le respecte dans la mesure du possible. Durant la période 1985-1986, l'échéancier fut quelque peu bouleversé par la fermeture de la boutique et la mise à pied de la directrice générale. La CMAAT se trouve, depuis octobre 1985, dans une phase de restructuration. Plusieurs réunions ont été tenues pour revoir les orientations de la CMAAT. Mais ce n'est qu'au cours de la mise en tutelle que ces orientations furent réellement remises en 
question; le MAC ne voulait pas octroyer les sommes demandées sans que les membres élaborent un plan d'action précis.

h) Organiser les réunions du Conseil d'administration et les assemblées générales

Malgré qu'officiellement chaque membre du Conseil d'administration devait représenter un secteur géographique ou un corps de métier, nous ne pouvions identifier qui représentait quoi lorsque nous assistions aux réunions. Les membres du Conseil d'Administration ne possédaient pas de mandat clair venant de l'assemblée génér a1e. Il était ainsi difficile de juger de leur efficacité à la fin de leur mandat.

Les attentes n'étaient pas claires d'un côté comme de l'autre. Pour les membres du Conseil d'Administration, il s'avérait difficile d'être motivés et de choisir une orientation précise. Compte tenu que peu d'entre eux s'impliquaient, certains s'épuisaient donc à la tâche. Quant aux membres de la CMAAT, ceux-ci justifiaient leur manque d'implication en reprochant au Conseil d'Administration de ne rien leur proposer.

Entre le 19 avril 1982 et le 20 septembre 1985, il s'est tenu 30 réunions du Conseil d'administration. Nous calculons une moyenne de sept réunions par année. Sept personnes, en moyenne, incluant la directrice générale, se sont présentées à ces réunions. Les sujets abordés étaient: 
1. La production

- Aide à la production;

- Rationalisation de la production;

- Approvisionnement en matières premières;

- Projets culturels;

- Création vs production.

2. La formation

- Organisation d'ateliers culturels;

- Stages de perfectionnement;

- Attribution de bourses;

- Accès des régions éloignées.

3. La promotion

- Emissions sur la vie d'artistes et d'artisans;

- Organisation de kiosques;

- Marque de commerce;

- Colloque sur la vie d'artisans;

- Attribution de prix (Prix Paul-Emile Borduas);

- Activités spéciales de promotion (vente-trottoir, semaine de 1 'artisan).

4. Le développement

- Possibilité d'une intégration officielle des artistes en arts plastiques au sein de la CMAAT;

- Reproduction d'oeuvres d'art de l'Abitibi-Témiscamingue; 
- Collaboration avec différents organismes;

- La distribution (solutions régionales pour l'accès à des outils de commercialisation répondant aux besoins des artisans).

5. La concertation

- Préparation au sommet culturel régional;

- Table de concertation des programmes rationalisés des arts de l'environnement;

- Position régionale (1984) à propos de "L'avenir des métiers d'art au Québec";

- Liens avec différents organismes.

6. Gestion interne

- Adoption des prévisions financières;

- Adoption du bilan;

- Adoption de la demande de subvention;

- Acceptation de nouveaux membres;

- Engagement, conditions salariales et vacances des employés.

De janvier à mai 1986, le Conseil d'Administration s'est réuni plus souvent étant donné que la Corporation éprouvait de sérieuses difficultés. Lors de ces réunions, longues et chargées, les membres discutaient beaucoup plus de gestion interne et de course aux subventions que des grandes orientations de la CMAAT. La présente étude faisait partie de l'ordre du jour de ces rencontres parce que le chercheur était présent. Les membres souhaitaient que celui-ci puisse leur apporter une aide pour obtenir une subvention. A maintes 
reprises, le chercheur a dû préciser son véritable rôle. Nous discuterons plus en profondeur de cette intervention, au cours d'un autre chapitre.

En règle générale, il est difficile de réunir les membres de l'assemblée générale puisqu'jls sont dispersés sur un grand territoire. Mais, les assemblées de secteurs que la CMAAT a tenté d'organiser ne remportaient guère plus de succès. Que signifie ce manque d'intérêt? Nous pouvons émettre deux grandes hypothèses: 1) Les artisans n'ont pas de problèmes. Cela semble toutefois difficile à croire puisque d'autres données prouvent le contraire. 2) La CMAAT ne répond pas aux attentes des artisans; les membres évaluent que le déplacement n'en vaut pas la peine.

\section{i) Remarque}

L'ordre dans lequel est présenté le sous-système "planification" ne semble pas toujours suivi. En effet, certaines activités y déroge. Ainsi, l'activité "rechercher des sources de financement" devient souvent la base de la planification. Et si le MAC accepte de subventionner la CMAAT, celle-ci peut survivre. Comme les membres ne veulent pas perdre cette subvention, ils définissent les buts et le besoin en personnel en fonction de la subvention qui devrait être accordée. Autrement dit, ils négocient une subvention avec le MAC avant de définir les buts à poursuivre et la clientèle à servir. De même, ils revendiquent de l'argent pour payer le personnel, sans se demander ce qu'ils attendent de celui-ci. 
La course aux subventions représente donc la principale activité de la CMAAT. Ce phénomène se retrouve dans plusieurs organisations; c'est ce que l'on appelle le "gouvernement bonbon". Mais, le problème, ce n'est pas tellement le fait que cette organisation soit à la recherche d'une subvention; c'est plutôt parce qu'elle éprouve des difficultés à planifier l'utilisation des argents qu'elle reçoit, et que nous ne puissions observer "d'extrants". 


\subsection{SOUS-SYSTEME "PROMOTION"}

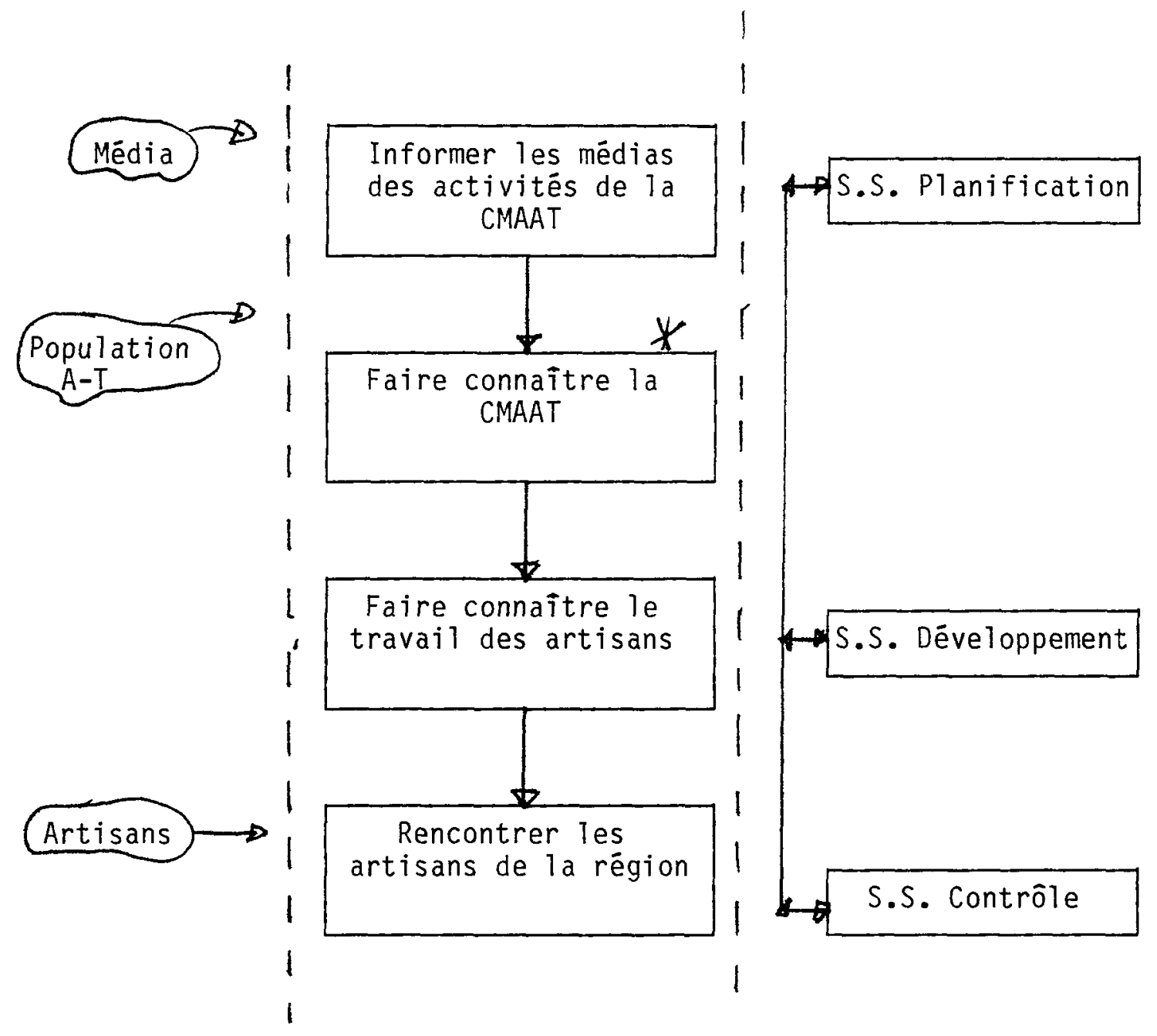

FIGURE 4: Sous-système "promotion"

NOTE: Le sous-système "promotion" est composé de quatre activités. Pour réaliser ces activités, le sous-système communique avec les médias, la population de l'Abitibi-Témiscamingue et les artisans. Il entretient des relations avec trois autres sous-systèmes interreliés. 
a) Informer les médias des activités de la CMAAT

La CMAAT annonce la tenue de ses assemblées générales et, à quelques reprises, elle a fait connaitre ses grandes orientations. Il arrive aussi que les médias communiquent avec cette corporation pour connaitre son opinion sur certains faits du domaine culturel. Depuis un an, elle n'a entretenu que peu de contacts avec les médias. Le Conseil d'Administration ne voulait pas publier les difficultés de la CMAAT.

b) Faire connaitre la CMAAT

En général, les gens connaissent peu les activités de la CMAAT. Les consommateurs connaissent, par contre, les lieux de diffusion (les salons et la boutique communautaire). L'organisme s'est par ailleurs donné une étiquette d'identification. Les membres peuvent l'afficher lorsqu' ils exposent leurs oeuvres. Nous remarquons, par contre, que peu de consommateurs connaissent vraiment ce que signifie cette étiquette; elle ne semble pas influencer leurs choix.

c) Faire connaître le travail des artisans

Pour permettre aux consommateurs de connaître les artisans et leurs techniques de travail, certains membres ont travaillé dans la boutique même. Il semble que les clients appréciaient cette initiative; le manque d'espace a cependant provoqué l'abandon de cette pratique. 
d) Rencontrer les artisans de la région

Dans la mesure du possible, la directrice générale se rendait à toutes les manifestations auxquelles participaient les artisans de la région. Elle en profitait souvent pour recruter des nouveaux membres et/ou tenter d'identifier les besoins des gens. 


\subsection{SOUS-SYSTEME "CONCERTATION"}

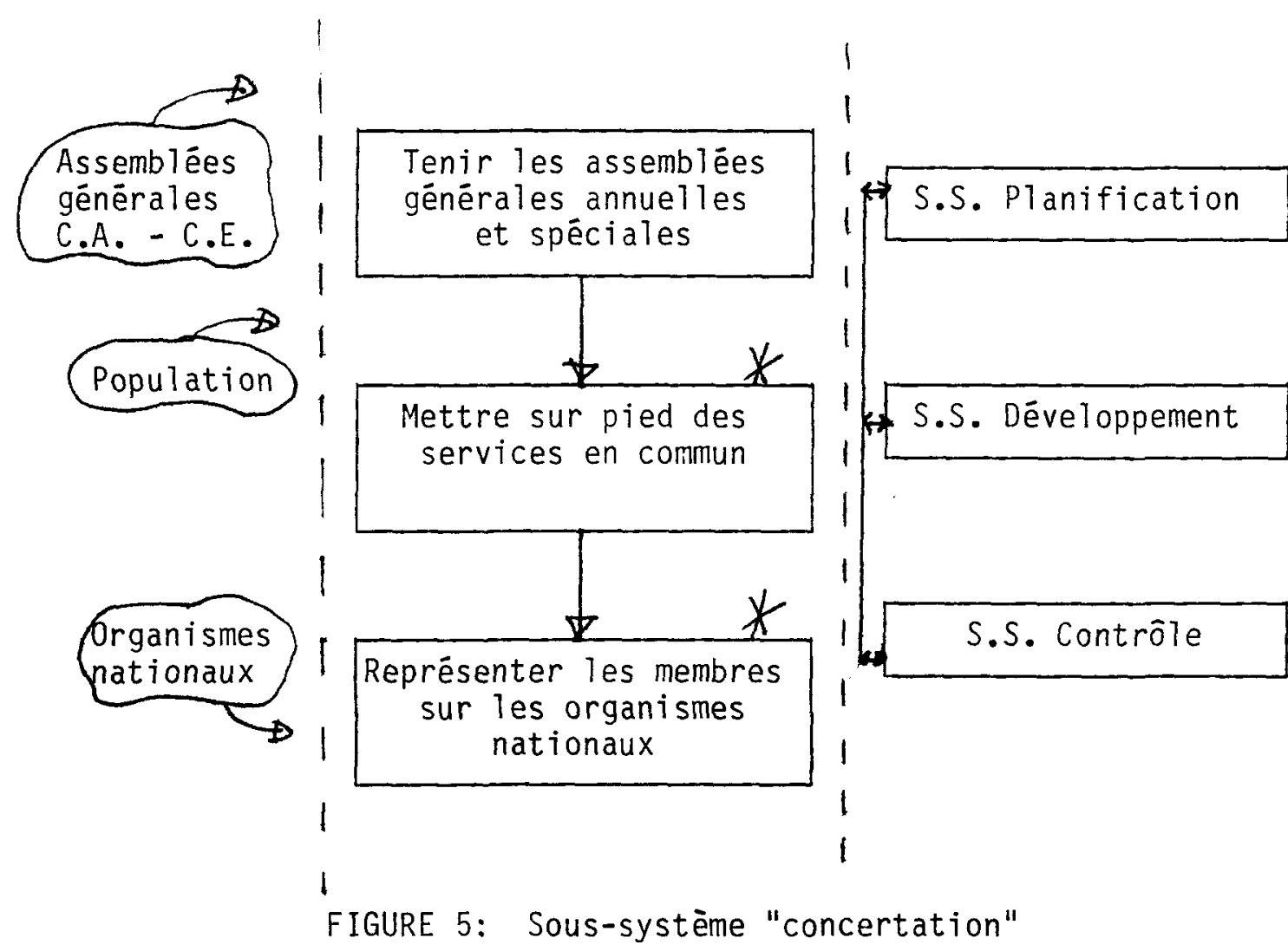

NOTE: Le sous-système "concertation" est composé de trois activités. Pour rẻaliser ces activités, le sous-système reçoit des informations de l'assemblée générale, du Conseil d'administration, du Conseil exécutif, de la population et des organismes nationaux. Il entretient des relations avec trois autres sous-systèmes interreliēs. 
a) Tenir les assembiées générales spéciales et annuelles

Les assemblées générales spéciales et annuelles permettent aux artisans d'échanger et de faire valoir leur point de vue; rappelons-nous que l'assemblée générale est l'instance suprême de décision. Par contre, l'assiduité à ces réunions est plus ou moins bonne.

L'assemblée générale annuelle est une occasion d'échanges pour les artisans, mais il semble que l'ordre du jour soit truffé de procédures administratives (adoption des procès-verbaux, adoption du rapport financier, élections, etc.) qui ne laissent pas place aux discussions sur les grandes orientations de la CMAAT.

C'est au cours de l'assemblée générale annuelle qu'on procède à l'élection du Conseil d'administration. Comme certains secteurs géographiques ne comportent pas beaucoup de membres, $i 1$ devient alors très difficile de recruter des représentants de ces secteurs.

Mais, de toute façon, les membres sont peu intéressés, en général, à siéger sur le Conseil d'administration. Le sondage (annexe 2) effectué en nombre 1985 démontre clairement ce désintéressement; $77,3 \%$ ont alors répondu qu'ils n'étaient pas intéressés à poser leur candidature, et les 7 personnes ayant répondu affirmativement à la question siégeaient déjà sur le Conseil d'Administration.

Donc, généralement, ce sont toujours les mêmes personnes qui se retrouvent sur le Conseil d'Administration. Celui-ci peut ainsi devenir un groupe fermé, peu porté à changer ses habitudes. 
b) Mettre sur pied des services en commun

Du temps de la boutique, un service d'approvisionnement en matières premières existait pour les membres. Le Conseil des métiers d'art travaille présentement sur un projet d'assurance-salaire.

En génêral, il apparaît difficile de mettre en commun des services, car les besoins diffèrent d'un membre à l'autre.

Lors du sondage effectué en novembre 1985 (annexe 2), 26, $8 \%$ des artisans ont répondu que, pour augmenter leurs ventes, il leur faudrait plus de temps pour produire; $17,9 \%$ ont répondu qu'ils voudraient disposer d'une meilleure connaissance du marché ou connaître les goûts des consommateurs, et $12,5 \%$ voudraient se familiariser avec les techniques de ventes.

c) Représenter les membres sur les organismes nationaux

Etant donné que les réunions se tiennent toujours à Montréal ou à Québec, 11 n'est guère facile de trouver un représentant prêt à sacrifier plus d'une journée de production pour y assister. Ce n'est donc pas toujours la même personne qui assiste à ces réunions. Et souvent, le représentant ne possède pas tous les éléments pour défendre les intérêts des membres. D'ailleurs, étant donné l'hétérogénéité de la clientèle, ces intérêts, fort diversifiés, ne peuvent être défendus aisément. De plus, les membres ne semblent pas tellement au courant des nouvelles orientations privilégiées au niveau national. 
Aussi sont-ils méfiants face à toute suggestion provenant des corporations majeures. Ils ont peur que ce désir d'une politique nationale leur fasse perdre des acquis.

Il faudrait savoir vraiment pourquoi les représentants de la CMAAT ne se sentent pas à T'aise lors de ces réunions au niveau national. Est-ce vraiment parce que les grosses corporations possèdent plus de représentants ou parce qu'elles sont mieux organisées, mieux informées, et qu'elles se sont préalablement concertêes sur les sujets abordés? 


\subsection{SOUS-SYSTEME "INFORMATION"}

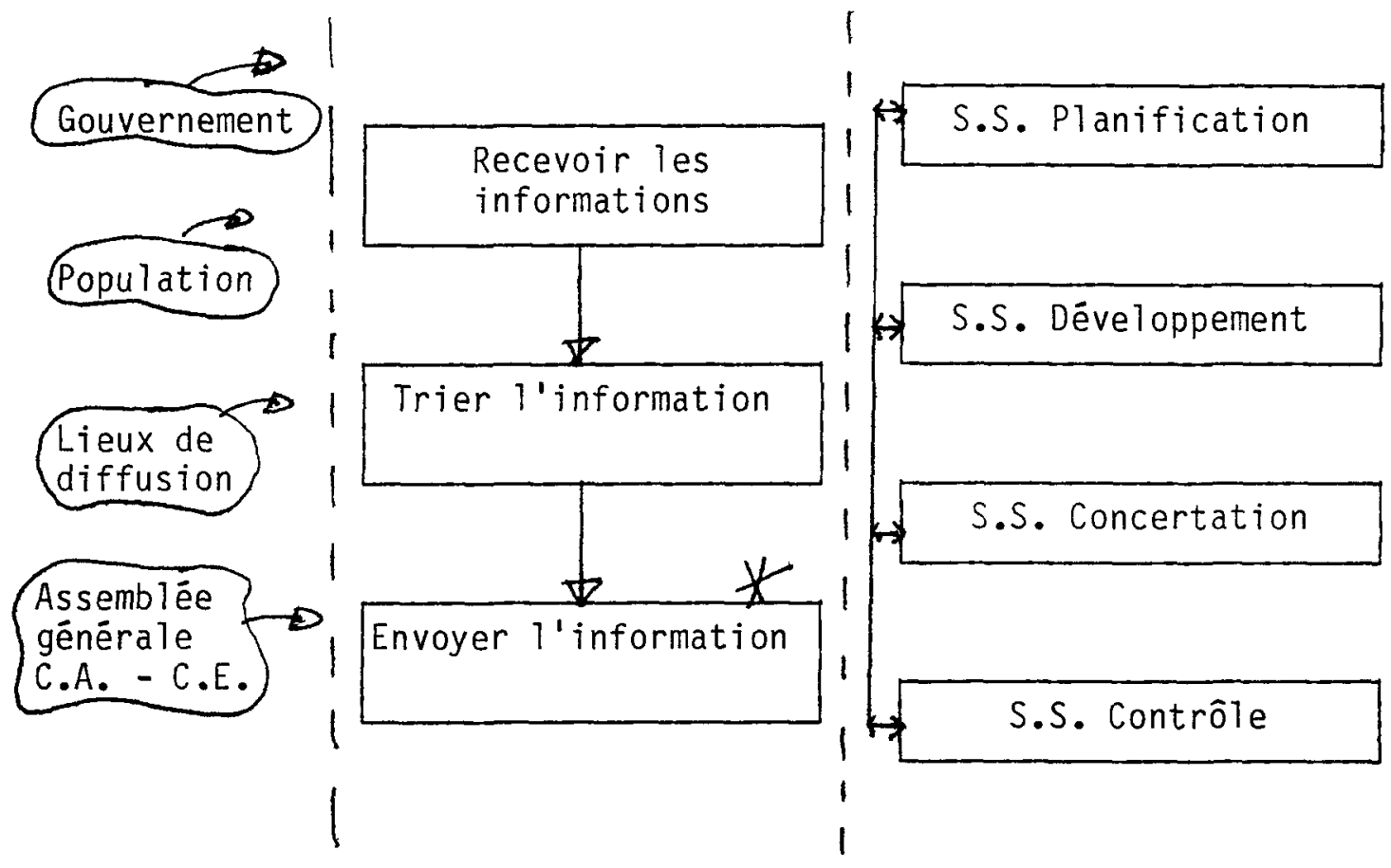

FIGURE 6: Sous-système "information"

NOTE: Le sous-sytème "information" est composé de trojs activités. Pour réaliser ces activités, le sous-système communique avec son environnement. Il est en relation avec quatre autres sous-systèmes interreliés. 


\section{a) Recevoir les informations}

En tant que regroupement d'artisans professionnels, la CMAAT reçoit beaucoup d'informations de l'environnement. Tous ceux qui veulent communiquer avec les artisans passent généralement par elle.

A la suite de la journée nationale des métiers d'art, plusieurs organismes ont vu le jour. Une grande majorité de membres semblent quelque peu mêlés; ils ne savent plus qui fait quoi.

b) Trier l'information

La CMAAT trie l'information pour la faire parvenir à tous les membres ou aux membres concernés seulement, ou encore au Conseil d'administration.

c) Envoyer l'information

Un bulletin de liaison appelé La Jasette existe, mais sa dernière publication remonte en janvier 1985. A la fin de chaque mois, les membres recevaient un feuillet d'information qui portait le nom de p'tite vite. La CMAAT pouvait aussi, sur demande, effectuer des recherches spécifiques d'informations.

La Jasette donnait des informations sur les métiers d'art, véhiculait des invitations personnelles à participer à certaines activités (expositions, salons, concours, colloques, conférences, stages, etc.), faisait connaître les diverses réglementations existant dans le domaine, les actualités, les bourses pourant être obtenues par les artisans et les événements internationaux. 
Depuis la mise à pied de la directrice générale, les membres ont reçu très peu d'informations sur les activités de la CMAAT.

Nous remarquons, par contre, un dédoublement de l'information sur les métiers d'art en général. Souvent les membres reçoivent la même information d'autres instances (le Conseil de la culture et le ministère des Affaires culturelles). 


\subsection{SOUS-SYSTEME "DEVELOPPEMENT"}

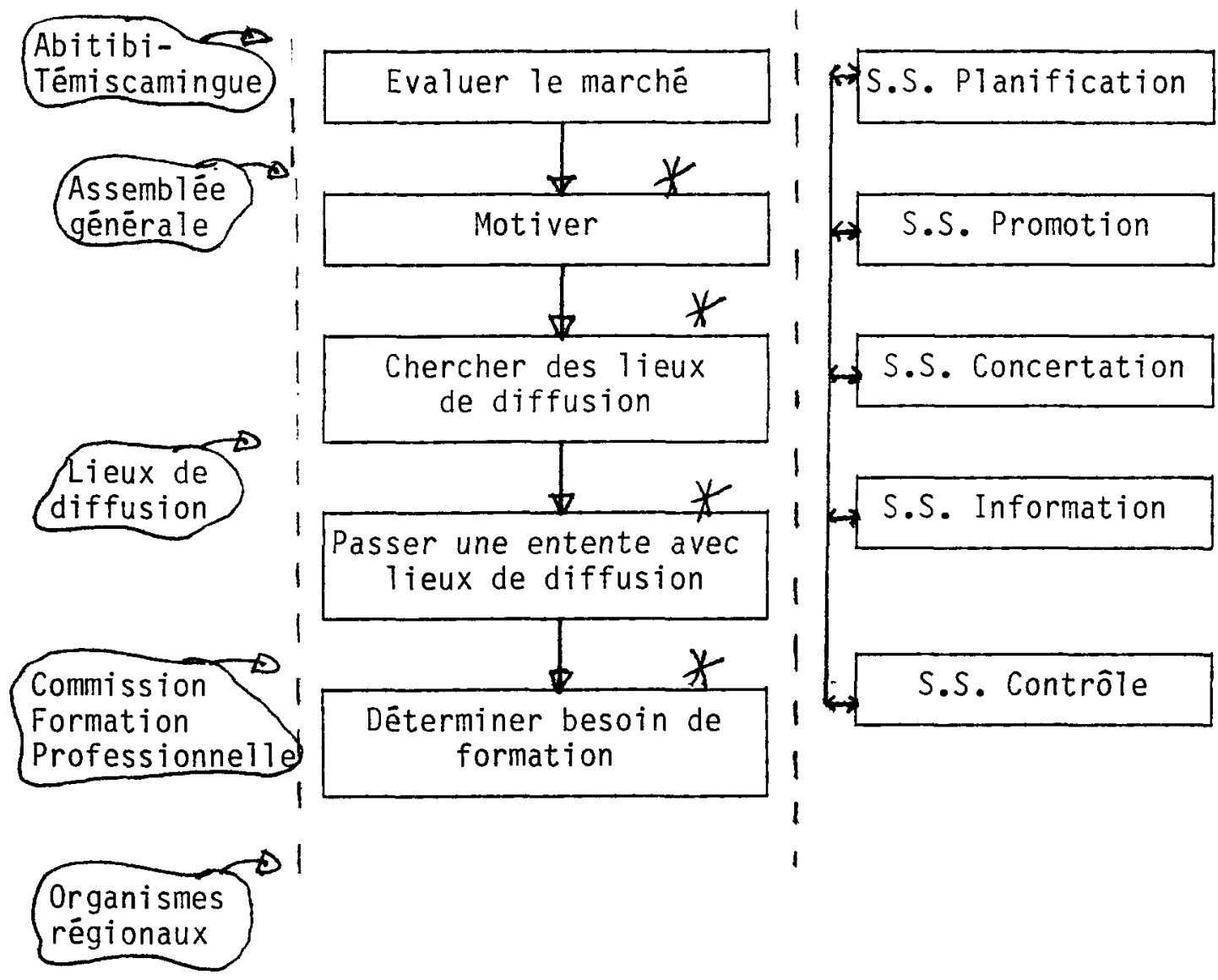

FIGURE 7: Sous-système "dēveloppement"

NOTE: Le sous-système "dēveloppement" est composé de cinq activités. Pour réaliser ces activitēs, il communique avec l'Abitibi-Témiscamingue, l'assemblée générale, les lieux de diffusion, la Commission de formation professionnelle et les organismes régionaux. Il entretient des liens avec cinq autres sous-systèmes interreliēs. 


\section{a) Evaluer le marché}

Evaluer le marché veut dire notamment:

- commander des études (ex.: étude de marketing dans le cadre du programme "Outil de gestion");

- prendre connaissance des différentes études effectuées par des firmes spécialisées;

- rencontrer des artisans et discuter avec eux de leurs ventes;

- rencontrer les responsables des bazars.

Cependant, il semble difficile pour la CMAAT d'évaluer son apport à ce niveau. A vrai dire, seuls les membres peuvent dire si elle leur rapporte quelque chose, et si l'expérience qu'ils vivent dans cet organisme en vaut la peine. Aussi, voyons-nous, d'autre part, certains artisans réussissant bien sans le recours de la CMAAT.

Dans une certaine mesure, les responsables des différents salons s'occupent eux aussi d'évaluer le marché, lors de l'analyse des ventes qu'ils effectuent à la fin des expositions.

b) Motiver

Les critères de sélection et la stimulation du groupe peuvent d'une certaine façon motiver les membres à améliorer leur production. 
Lorsque la boutique était ouverte, ceux-ci sentaient beaucoup plus que la CMAAT assumait ce rôle, car la directrice générale de l'organisme leur suggérait de produire les articles les plus demandés par les consommateurs.

Certains membres ont manifesté, par ailleurs, le désir que la CMAAT puisse les informer lorsqu'elle jugerait qu'un recyclage s'impose. De même, certains aimeraient qu'elle puisse les orienter vers les produits à fabriquer. Mais, pour pouvoir répondre à ce besoin, il faudrait que la responsable de cet organisme soit familière avec toutes les techniques reliées à l'artisanat, ce qui semble quasi impossible. De plus, il peut s'avérer délicat d'assumer cette tâche; l'expérience antérieure démontre, en effet, que les artisans suivent plus ou moins les conseils qu'on leur donne, car ils veulent fabriquer ce qu'ils aiment. Une des caractéristiques du métier d'artisan n'est-elle pas l'importance du plaisir de créer? S'il est important de vendre, il faut tout de même se rappeler que le sondage (annexe 2) effectué en novembre démontre que près de $50 \%$ des membres de 1 a CMAAT ne cherchent pas à vivre de leur métier.

\section{c) Chercher des lieux de diffusion}

Le sondage démontre très clairement que la recherche de lieux de diffusion est importante pour les membres; 26 personnes avouent même être devenues membres pour profiter de l'intermédiaire de la boutique. D'ailleurs, celle-ci fut créée pour répondre à un besoin maintes fois exprimé par les artisans de la région. Pourtant, 
comme l'étude effectuée dans le cadre du programme "Outil de gestion" le démontre, 5 ce lieu de diffusion ne semblait pas le premier choix des artisans.

En 1985, un projet de vente en gros fut élaboré. Donnant suite à l'étude réalisée dans le cadre du programme "Outil de gestion", le Conseil d'administration abandonnait cette idée, puisque l'offre ne correspondait pas à la demande. En outre, les boutiquiers reprochaient aux artisans leur manque de professionnalisme.

La SOMART pourrait devenir une alternative intéressante pour les artisans de la région. Par contre, peu d'entre eux se montrent intéressés par celle-ci.

Nous pouvons nous demander si les ventes d'oeuvres d'art ont diminué par manque de lieux de diffusion ou parce que les pièces offertes ne correspondent pas aux goûts des consommateurs. Si nous retenons la dernière hypothèse, l'activité "formation et perfectionnement" deviendrait plus importante que la recherche de lieux de diffusion.

d) Conclure une entente avec des lieux de diffusion

Les différents bazars annuels de la région sont indépendants de la CMAAT; il n'est pas nécessaire que les exposants soient membres pour pouvoir exposer leurs oeuvres d'art. Au contraire, il est à noter que le Salon des métiers d'art de Montréal exige que les exposants soient membres de MAQAM.

5.COTE, Brigitte, La Corporation des métiers d'art de l'AbitibiTémiscamingue, UQAT, septembre 1983, p. 16. 
En janvier 1986, la CMAAT et les différents responsables des salons se sont rencontrés pour évaluer les salons. Ils espèrent tous établir une meilleure collaboration entre eux. Ils parlent même de rendre obligatoire l'adhésion à la CMAAT. Nous croyons qu'il faudrait ici vérifier l'objectif de cette proposition. Si elle vise seulement l'augmentation du nombre de membres, il faudrait se poser de sérieuses questions sur les raisons qui empêchent présentement les artisans d'adhérer à la CMAAT.

La CMAAT peut aussi négocier avec certaines galeries d'art pour que ses membres puissent y exposer. Aussi les organismes de la région vont-ils souvent passer par la CMAAT pour offrir aux artisans d'exposer lors de certaines manifestations.

\section{e) Déterminer les besoins de formation}

La Commission de formation professionnelle est maintenant responsable de l'organisation du perfectionnement des artisans (aspects physique et financier). Elle peut offrir des services de formation en établissement à plein temps et à temps partiel, de formation spécifique sur mesure et de formation en industrie. En outre, elle perçoit les besoins et publicise les cours offerts. Ce qui veut dire qu'elle doit savoir combien de personnes sont intéressées à suivre un cours, afin de justifier l'offre qu'elle fait à ces personnes auprès de 1 a CFP.

Selon l'Institut des métiers d'art, le développement normal de I'industrie des métiers d'art suppose que les artisans puissent 
connaître les tendances et les conditions du marché, les nouveaux produits et les résultats des dernières découvertes dans le domaine. $L$ 'innovation et le design des produits issus des métiers d'art assurent le maintien de l'intérêt et de la demande. 


\subsection{SOUS-SYSTEME "CONTROLE"}

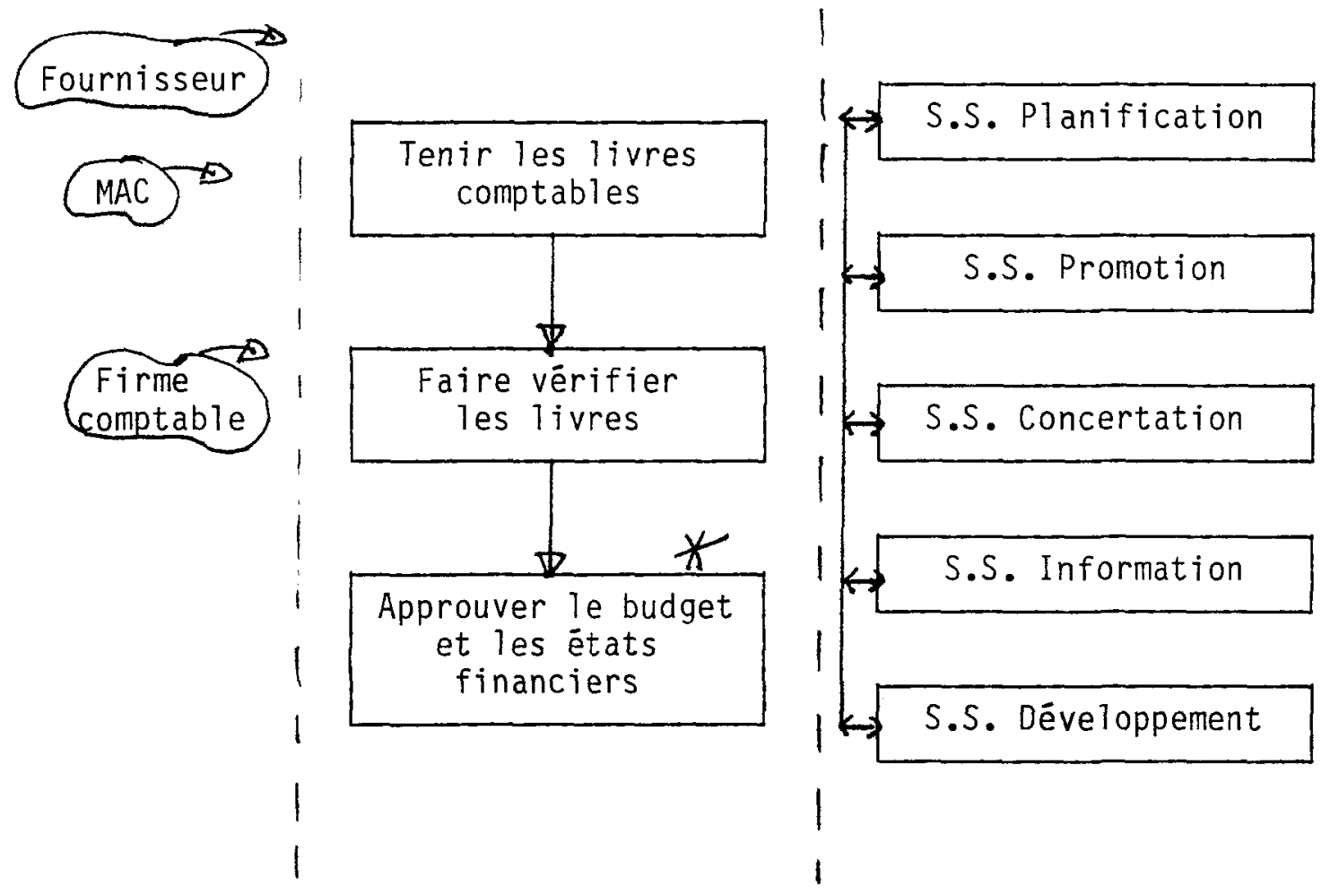

FIGURE 8: Sous-système "contrôte"

NOTE: Le sous-système "contrôle" est composé de trois activités. Pour réaliser ces activités, le sous-sytème reçoit des informations du MAC et de différents fournisseurs. Il doit aussi communiquer avec la firme comptable. Il entretient des liens avec les cinq autres sous-systèmes interreliés. 
a) Tenir les livres comptables

Tenir les livres comptables signifie enregistrer les recettes et les déboursês.

Au cours de l'année 1985-1986, Madelene Rivard Inc. a élaboré, dans un premier temps, un système adéquat de tenue de livres et, dans un deuxième temps, elle a implanté un système de contrôle interne en gestion de documents.

b) Faire vérifier les livres

Selon les règlements généraux, la CMAAT doit faire vérifier les livres par une firme comptable reconnue.

c) Approuver les états financiers et le budget

Pour respecter les formalités, l'approbation des états financiers s'effectue lors de l'assemblée générale annuelle. 
CHAPITRE 5 
CHAPITRE 5

ANALYSE DES RESSOURCES

\subsection{CARACTERISTIQUES DES ARTISANS}

\section{1 .1 Statut}

La principale caractéristique de l'artisan est son absence de statut au niveau fiscal. Comme il n'est pas employé par quiconque, il ne peut bénéficier de l'assurance-chômage, à laquelle il ne souscrit pas. En outre, compte tenu de cela, il n'est pas éligible à la formation professionnelle à temps complet.

Par ailleurs, la boutique artisanale n'étant pas une PME, elle ne peut profiter des avantages consentis aux entreprises détenant ce statut.

Cette situation a finalement comme conséquences qu'il n'y a pas de statistiques disponibles concernant le marché de l'emploi et les besoins de formation de la main-d'oeurre dans ce domaine. Il nous est par conséquent impossible d'estimer les possibilités de création d'emplois dans le secteur des métiers d'art.1

\subsubsection{Philosophie de travail}

Il apparaît très clairement que le premier but de 1'artisan n'est pas de devenir riche par la pratique de son métier. En effet, i1 n'est pas rare d'entendre ceux-ci se plaindre des revenus gagnés.

1.Comité organisateur du Colloque, Colloque régional d'orientations des métiers d'art du Saguenay Lac St-Jean, septembre 1985, 25 pages. 
Mais ils avouent retirer du plaisir à créer leurs oeuvres et se sentent valorisés. Comme le mentionnait le président sortant du SMAQ (Salon des métiers d'art du Québec), M. Armand Brochard, représentant du journal La Presse, le 14 décembre 1985: "C'est plutôt le fait de pouvoir toucher du doigt au plaisir de vivre. Au plaisir de contrôler la totalité des étapes de ce que l'on fait."

\subsubsection{L'artisan et 1 a gestion}

En 1985, plusieurs artisans sont devenus des chefs de PME, faisant face au quotidien d'un petit industriel: marge de crédit congestionnée, difficultés d'approvisionnement, relations de travail parfois malheureuses, incertitudes liées à la mise en marché, formation problématique de la main-d'oeuvre, etc.

Toujours selon le journal La Presse du 14 décembre 1985, i1 semble que la plupart des artisans ne connaissent de la PME que les contraintes administratives auxquelles celle-ci doit faire face et le fonctionnement discipliné qu'elle se doit d'adopter. Et, nombreux seraient ceux qui, après avoir joué au petit industriel pendant quelques années, ont quitté les PME qu'ils dirigeaient.

D'autre part, les artisans éprouvent souvent des difficultés de communication avec le gérant de leur institution financière. Ils n'ont souvent pas les garanties qu'exigent ceux-ci pour de toute PME. Par exemple, leur métier exige des équipements difficiles à revendre.

En 1983, la firme conseillère en gestion Mallette, Major \& Martin affirmait que, si la tendance continuait, seuls les artisans 
qui intégreront harmonieusement les fonctions de créateur-concepteur et d'entrepreneur-producteur, tout en maintenant I'ABC de la gestion et du marketing, pourront survivre. Ainsi faudrait-il s'assurer de la motivation des artisans et de leur capacité d'assumer ces fonctions. Mais, pour survivre, ces derniers ont-ils d'autres choix?

Ceux qui ont affaire aux grands idéaux, tels qu'éducation, créativité ou liberté, devraient mieux accepter le fait que ces idéaux ne peuvent se passer d'arrangements administratifs, terre à terre mais inévitables.?

\subsection{LA PRODUCTION}

La production artisanale du Québec rapporte environ deux millions et demi au trésor public, au chapitre de la taxe de vente.

En 1984, la production des artisans québécois représentait, au Québec, environ 40\% du marché des métiers d'art.3 L'entreprise artisanale qui désire augmenter sa capacité de production se heurte principalement aux difficultés suivantes:

- carence et désuétude de l'outillage;

- lieux de production inadéquats aux plans de l'espace et de la sécurité;

- manque de financement à court et moyen terme;

- accès difficile à des services de recherche appliquée.

2.SELZNICK, Philip, "Au-delà du concept d'organisation" dans Encyclopédie du management, France, France Expansion Kluwer, 1973, vol. 1.

3. Comité national des métiers d'art, Document d'orientations pour 1 a journée nationale des métiers d'art, Montréal 1984, 58 pp. 
La production de la pièce unique a été largement développée dans le passé, entre autres parce qu'elle est valorisante pour le créateur. Cependant, son coût de production étant élevé, l'artisan doit produire des séries pour rentabiliser son entreprise. 4

La production en séries entraîne cependant des exigences particulières, d'une part compte tenu des équipements spécialisés qu'elle requiert, et, d'autre part, parce qu'elle nécessite l'achat de matières premières et le stockage du produit fini. L'artisan doit donc assumer les frais encourus par la production, ce qui n'est pas sans comporter de sërieux risques, surtout si son produit ne trouve pas immédiatement preneur, en raison de son design, des modes changeantes, de son coût, de sa qualité, de sa promotion, etc. 5

Les artisans doivent nécessairement s'attendre à supporter une certaine part de risques, mais leur capacité à cet égard est 1 imitée. Ils cherchent des marchés sûrs et veulent travailler davantage sur commande, ou encore confier la mise en marché de leur production à des intermédiaires. Dans ce dernier cas, ils peuvent consacrer une plus grande part de leurs énergies au design et à la fabrication de leurs produits. 6

4. Ministère des Affaires culturelles. (Services des programmes régionaux), Mémoire sur la mise à jour des orientations en matière de métiers d'art et d'artisanat, mai 1985.

5. Idem.

6. Idem. 
La rentabilisation de 1 'étape production, requérant un design adéquat, des matériaux de qualité et des équipements spécialisés, demande également une excellente connaissance technique permettant à l'artisan de produire rapidement, tout en répondant à des standards de qualité reconnus. ${ }^{7}$

L'artisan qui veut vivre de son métier doit en plus faire face à une forte compétition aux plans national et international, ce qui l'oblige à renouveler régulièrement et rapidement sa production, en fonction des tendances et conditions du marché et de certaines nouveautés technologiques. 8

\subsection{LA MISE EN MARCHE ET LA COMMERCIALISATION}

Lors de la journée de consultation tenue le 19 novembre 1984, les participants admettaient que le développement des métiers d'art ne peut se faire sans la mise en place de mécanismes de commercialisation qui répondent aux besoins des divers marchés visés. Les principaux outils de commercialisation mis sur pied par les regroupements d'artisans ont été les salons d'hiver et d'été et les boutiques de vente au détai1. L'effort de commercialisation des artisans s'est aussi fait au plan individuel par la vente au détail, dans le cadre de l'atelier ou de 1'atelier-boutique. ${ }^{9}$

7. Idem.

8. Idem.

9. Idem. 
La plus grande activité commerciale du secteur, les salons d'artisanat, est en nette régression depuis 1983. Au surplus, les salons constituent souvent une expérience à risques élevés pour l'artisan qui, sans en connaître la demande, est obligé d'accélérer sa production afin de constituer un inventaire adéquat et de réaliser une production variée. Et celle-ci n'est évidemment pas sans engendrer des coûts fort élevés.

Selon le témoignage des artisans, les principaux avantages de la vente lors d'expositions sont les suivants:10 connaitre les commentaires et les exigences des clients et toucher le plein montant des ventes (sans avoir à laisser de commission). Quant aux principaux inconvénients, il s'agit du: caractère temporaire des expositions; et du coût généralement élevé des kiosques.

L'étude effectuée dans le cadre du programme "Outil de gestion"11 conclut que la nomination d'un intermédiaire permettrait aux artisans d'être libérés de certaines tâches administratives; ainsi pourraient-ils consacrer plus de temps à la production et à la création.

\subsection{LA CREATION}

L'artisan est un individu qui conçoit, réalise ou fait réaliser, sous son entière responsabilité, des objets de métiers d'art.

10.COTE, Brigitte, La Corporation des métiers d'art de T'AbitibiTémiscamingue, Rouyn-Nornada, UQAT, septembre 1985, p. 14.

11. Ibidem, p. 19. 
I1 s'agit d'un créateur et d'un producteur, puisqu'en plus de concevoir un produit, il entretient toujours une relation avec la matière: celle qu'exige sa transformation. 12

La création est à la fois l'aspect le plus important du métier d'artisan créateur-producteur et le moins rentable financièrement, à court terme. L'artisan est parfois même dans l'impossibilité de consacrer, faute de ressources financières adéquates, le temps et les énergies nécessaires à la création de nouveaux produits. 13

\subsection{RENTABILITE SOCIALE}

L'impact d'une corporation d'artisans professionnels sur la population environnante ne peut être évalué facilement. Nous constatons, cependant, que la population d'une région semble toujours fière lorsque l'un des siens réussit. Et, compte tenu de la conjoncture économique actuelle, un organisme se doit de justifier sa subvention face à la population en général, en faisant connaîtré les gens qui ont réussi dans tel ou tel domaine, par exemple. Car la société ne juge pas l'entreprise uniquement d'après son produit fini, mais aussi en considérant l'utilité qu'il y a à consacrer des ressources à ce dessein. 14

12. Mémoire sur la mise à jour des orientations en matière de métiers d'art et d'artisanat, op.cit.

13. Idem.

14.THOMPSON, J.-P. et McEWEN, W. J., "Objectifs d'organisation et environnement" dans Psychologie sociale, de A. Lévy, Dunod, 1958, 10 pp. 
Il y a deux ans, le ministère des Affaires culturelles adoptait un plan de développement pour rendre accessible la culture à toute la population. La CMAAT vise-t-elle le même but? Aucune donnée n'est disponible sur le sujet. Par contre, certaines personnes affirment que le maintien d'une boutique d'oeuvres d'art permanente, à Rouyn-Noranda, améliorerait la qualité de vie des citoyens; pour elles, les gens doivent avair la possibilité de se procurer des oeuvres d'art créées par des artisans de la région en tout temps de 1 'année.

\subsection{RESSOURCES FINANCIERES}

De 1977 à 1982, la CMAAT était subventionnée par le MAC, suivant un plan quinquennal selon lequel 1'aide financière accordée aux organismes décroissait à chaque année. Le ministère des Affaires culturelles voulait rendre les corporations autonomes financièrement. Avant la conjoncture de 1982-1983, le Ministère encouragé par les initiatives du milieu, est revenu sur sa position et a accepté de maintenir l'aide financière habituelle en instaurant un plan triennal. Il a hésité avant d'accepter la participation de la CMAAT au plan triennal, parce qu'il lui reprochait de ne pas répondre aux critères d'admissibilité qui concernent la participation financière des membres aux coûts administratifs et opérationnels de l'organisme. Finalement, après des pourparlers intenses entre le MAC et la CMAAT, cette dernière a pu bénéficier du plan triennal. Pour l'année financière 1985-1986, le MAC a versé à la CMAAT le même montant que celui qu'elle lui a octroyé pour la dernière année du plan triennal. 
En août 1985, l'organisme connaissait de sérieuses difficultés financières: les deux tiers de la subvention étaient dêpensés, alors qu'il restait encore six mois d'opération avant la prochaine année financière. La direction régionale du MAC ne voulant pas injecter de nouvelles sommes ou garantir d'éponger les déficits, l'assemblée générale décidait de fermer la boutique.

Pour les fins du calcul de la subvention (annexe 4), on tenait compte des revenus générés par les boutiques communautaires. Des cinq corporations toujours existantes, aucune d'elles ne gère à présent une boutique. Le MAC se voit donc contraint de revoir ses critères d'évaluation.

Au moment de la présente étude, le MAC se pose de sérieuses questions sur le renouvellement de la subvention. Il évalue que la CMAAT n'a pas su répondre à ses attentes. Mais, pour les membres de cet organisme, les attentes du MAC ne sont pas claires. En génëral, dans l'entreprise privée, l'évaluation est basée sur l'augmentation des profits. Toutefois, dans un organisme sans but lucratif, les critères ne peuvent être établis si facilement. Comme l'explique Dewarrat, l'évaluation devient souvent une question d'interprétation: dans les OSBL, par définition, l'évaluation des activités est subordonnée à des jugements subjectifs et des interprétations personnelles. 15

15. DEWARRAT, Gêrard, "La mesure d'efficience des organisations non profit (ONP): aspects et problèmes" dans Direction et gestion des entreprises, no 4, jui 1let-août 1984, p. 14. 
Kimberly s'est aussi penché sur la difficulté qu'éprouvent certaines organisations pour l'évaluation de leur rendement. Il cite l'exemple de l'évaluation de la qualité de l'éducation.

The importance of input measures in most nonautonomous human service organizations is enhanced by the difficulty in developing reliable and valed measures of output, such as quality of education. This difficulty then, means that a surrogate measure must be developed by the parent agency one that are in term, be acceptable to its parent. Indicators of levels of activity in the core technology serve purpose well.16

Toujours selon Kimberly, certaines organisations doivent développer des critères basés sur les intrants pour satisfaire leur organisme parrain.

The discussion, then, suggests that input measures of size are an important operational goal in many organizations and that it is sometimes the criterion in term of which organizational performance is measured by parent organization.17

16. KIMBERLY, John. R., "Organizational Size and The Structuralist Perspective: a review, critique and proposal" dans Administrative Science Quaterly, vol. 21, no 4, December 1976.

17. Idem. 
CHAPITRE 6 
Le Consej] d'administration élu en mai 1985 a dû faire face à plusieurs problèmes depuis le début de son mandat. Le 11 juin, la directrice générale, qui était en fonction depuis la fondation de la CMAAT, annonce sa démission. Quelque temps après, le propriétaire annonce une augmentation du loyer de $200 \$$ par mois. Et pendant tout ce temps, les ventes d'oeuvres d'art continuaient à baisser à la boutique.

Tous ces événements ont créé un climat de pessimisme au sein du Conseil d'Administration. Si la fermeture de la boutique représentait un échec, elle prouvait surtout que la demande pour les métiers d'art ètait à la baisse.

Le Conseil d'Administration se retrouvait avec une corporation à redéfinir, la diffusion étant un des principaux services offerts par la CMAAT. Quel rôle doit jouer la CMAAT maintenant? Une permanence est-elle encore nécessaire? Auparavant, la gestion de la boutique occupait en grande partie le travail de la directrice générale. Un climat de méfiance s'installait face à la nouvelle directrice générale.

Le contexte n'êtait pas des plus facile pour la nouvelle directrice générale. A son arrivée, le 5 août 1985, elle débordait de dynamisme; cependant, l'état dans lequel la Corporation était 
plongée l'amenait à se poser de sérieuses questions sur son mandat. Bien que la situation précaire ne résultait pas de son arrivée, elle devait travailler souvent avec des artisans qui se rappelaient les belles années de l'ex-directrice générale... Il Tui devenait difficile de vivre avec cette comparaison, présente à l'esprit de bien des intervenants. Elle se méfiait des intervenants qui voulaient collaborer; elle s'isolait. De plus, le climat pessimiste freinait son envolée; serait-elle encore directrice générale le mois prochain? Valait-il la peine d'établir un plan d'action si, de toute façon, la CMAAT devait fermer ses portes? Devant cette situation, le Conseil d'Administration décide, le 14 février 1986, de mettre temporairement à pied la directrice générale.

En outre, au cours de cette même période, deux clans se forment au sein de l'assemblèe générale. Nous pouvons discerner ceux qui veulent développer de nouvelles techniques, mieux s'organiser et vivre de leur métier, et ceux qui sont réfractaires aux changements, qui se méfient des nouvelles orientations, et pour qui la pratique du métier ne représentent pas leur principal moyen de subsistance. Ces deux groupes aux idéologies opposées sont en quelque sorte en compétition à l'intérieur du Conseil d'Administration.

Pour Yves Saint-Arnaud ${ }^{1}$, observer certains conflits ou obstacles dans un groupe de travail ne signifie pas que le groupe ne 
croît pas normalement. Il faut cependant que le groupe soit capable de repérer rapidement les obstacles pour les supprimer ou en atténuer les effets. De même, un autre document ${ }^{2}$ précise que, le conflit fait partie de la vie d'un groupe. Il peut même devenir un signe de santé, une preuve que le groupe est en mouvement. Il faut, par contre, rechercher des voies d'entente. Ce qui s'avère important, c'est que le groupe accepte de travailler pour atteindre un objectif commun à tous les membres, et que ces derniers réalisent qu'ils sont différents les uns et les autres:

Un groupe de travail est la réunion d'un certain nombre d'individus qui acceptent de travailler ensemble à la poursuite d'un objectif commun:

- des individus... c'est-à-dire pour chacun des caractéristiques propres, un bagage personnel où se conjuguent des besoins, des intérêts, des motivations, des sentiments, des valeurs, une histoire individuelle et sociale, des expériences, des connaissances, des habilités, etc.;

- qui acceptent de travailler ensemble... $c^{\prime}$ est-à-dire d'entrer en relation avec d'autres pour discuter, décider et organiser des actions;

- à la poursuite d'un objectif... c'est-à-dire ce pourquoi le groupe est formé, sa raison d'être. ${ }^{3}$

L'absence de participation devient par contre plus inquiétante. Peu de membres se présentent d'ailleurs aux différentes réunions organisées pour discuter de la survie de la CMAAT.

2. "La gestion d'organismes bénévoles", document de base, Télé-Université,

3. Idem. 
Pendant ce temps, le bureau régional du MAC remet en question le versement de la subvention. Il veut que la CMAAT puisse démontrer ce qu'elle vise comme action. Il faut se rappeler que la CMAAT émane du MAC, selon une volonté politique qui voulait augmenter la production d'oeurres d'art dans la région. Rappelons-nous, toutefois, qu'au moment où la CMAAT fut créée, le marché des métiers d'art se portait très bien. Mais aujourd'hui, compte tenu de la conjoncture, le bureau régional du MAC se pose de sérieuses questions sur l'existence même de la corporation.

Malgré toutes les difficultés que connait la CMAAT, quelques membres tiennent encore à son existence. Ces personnes ont beaucoup travaillé pour la création de la CMAAT et pour son maintien depuis le début. Il devient difficile pour eux de penser que l'existence de l'organisme est remise en cause. C'est comme si les efforts déployés l'auraient été pour rien. Lorsque, dans les discussions, on évoque la fermeture de la CMAAT, l'émotion gagne ces personnes. La fermeture peut même représenter, pour certains, un échec personnel.

Cependant ces membres créateurs ne savent pas eux-mêmes ce que leur rapporte concrètement la CMAAT. Ils organisent par contre des réunions pour que d'autres se battent avec eux pour la survie de l'organisme. Ils cherchent le responsable de la situation dans laquelle est plongée leur regroupement. La confiance entre les administrateurs, quasi-inexistante, les enlise dans le passé. En fait, 
ils éprouvent beaucoup de difficulté à travailler ensemble pour élaborer un plan d'action.

La citation qui suit explique clairement ce qui se produit dans un groupe à ce moment-là:

Le plus souvent, les conflits résultent de l'absence d'une bonne méthode de travail. Ainsi, si le groupe se cherche, $n^{\prime}$ avance pas et que tous les membres ont l'impression de tourner en rond, toutes les conditions sont réunies pour qu' il y ait affrontements et tensions, chacun cherchant a identifier les responsables de la mauvaise marche. Ces conflits, dans la mesure où ils sont surmontés, permettent souvent au groupe un nouveau départ, une révision des objectifs et une meilleure organisation de ses actions. ${ }^{4}$

Ainsi un groupe, en surmontant les conflits, s'accorde donc un nouveau départ. Mais est-ce que les membres créateurs sont prêts pour un nouveau départ, pour une révision complète des objectifs de la Corporation? Comment se sentiraient-ils face à une nouvelle orientation? Voyons ce que Selznick dit à ce sujet:

Si on arrive à un changement complet, d' où émerge un nouveau caractère, ceux qui ont formé et soutenu l'organisation à ses débuts risquent de découvrir qu'ils ne lui conviennent plus. Il y a aussi la possibilité que le caractère ne soit pas réellement transformé mais seulement atténué et rendu confus. Attênuation signifie que la compétence distinctive recherchée devient vague et abstraite, incapable d'influencer profondément le travail des états majors et les divisions. Le caractère est confus si l'on y trouve un mélange désordonné et discordant de capacités. Le résul-

4. "La gestion d'organismes bénévoles", op.cit. 
tat pratique est que l'organisation ne parvient pas a remplir efficacement aucune tâche, ce qui affaiblit ses capacités de survie face a une forte concurrence. 5

5.SELZNICK, Philip, "Au-delà du concept d'organisation" dans Encyclopédie du management, France, France Expansion Kluwer, 1973, vol. 1. 
CHAPITRE 7 
CHAPITRE 7

CANDIDATS AU POSTE PROBLEME

\subsection{LIENS AVEC SON ENVIRONNEMENT}

L'analyse des liens qu'entretient une organisation avec son environnement se traduit souvent par une mesure d'efficience que l'on utilise lors de son évaluation:

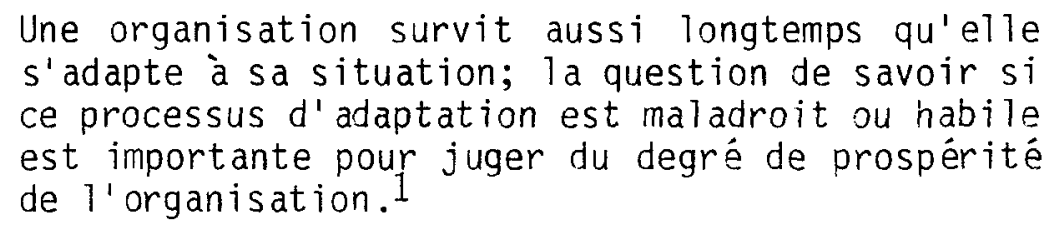

Cette étude de la CMAAT nous indique que celle-ci n'a pas su suivre l'évolution de son environnement et, conséquemment, elle n'a pas su tirer profit de celui-ci. Par exemple, elle aurait pu laisser tomber certains services, qui sont maintenant dispensés par d'autres organismes, pour consacrer ses énergies vers d'autres orientations ou améliorer l'efficacité de ses services." De plus, sa crainte de perdre des acquis l'a amenée à se méfier de tout changement au niveau national. Elle n'a pas évalué si le regroupement de certains services à ce niveau apporterait de meilleurs résultats. La CMAAT devait voir également si, compte tenu des ressources financières disponibles, il ne s'avèrerait pas préférable de laisser d'autres intervenants assumer la responsabilité de certains services et de chercher plutôt à améliorer ceux qu'elle voulait maintenir. D'ailleurs, à ce sujet, notons que:

1.THOMPSON, J.-P. et MCEWEN, W.J., "Objectifs d'organisation et environnement dans Psychologie sociale de A. Lévy, Dunod, 1958, 10 pp. 
Etant donné que la fixation des objectifs est essentiellement un problème de définition des relations désirées entre une organisation et son environnement, une altération de l'une ou de l'autre entraîne donc la reconsidération sinon la modification des objectifs.?

Ces quelques observations nous amènent déjà à percevoir une faiblesse au point de vue de 1 a gestion de la CMAAT; elle n'a pas su, selon nous, s'acquitter d'une tâche essentielle à son développement.

La tâche du dirigeant est de sonder l'environnement pour découvrir les exigences qui risquent de devenir de véritables menaces, de modifier cet environnement en trouvant des alliés et d'autres sources de soutien extérieur et de préparer son organisation à la lutte en créant les moyens et 1 a volonté de résister aux attaques. 3

Il est à remarquer que les valeurs des dirigeants influencent le mode de gestion exercé. Face à un même environnement, la réaction sera différente d'un dirigeant à l'autre. Au sein de la CMAAT, cette réaction est influencée par les valeurs des artisans. A ce chapitre, prenons note que, comme nous l'avons laissé entendre:

Face à un même environnement socio-politique, les entreprises d'une même industrie adoptent des comportements différents attribuables à trois

facteurs:

\section{Idem}

3.SELZNICK, Philip, "Au-delà du concept d'organisation" dans Encyclopédie du management, France, France Expansion Kluwer, 1973, vol. 1. 
- le pouvoir de contrainte que peuvent exercer les membres de l'environnement socio-politique sur 7 'entreprise pour 1'amener à satisfaire leurs attentes;

- Tes ressources dont dispose l'entreprise pour satisfaire ces attentes;

- les valeurs des dirigeants;

...Elles orientent la façon dont les dirigeants perçoivent ce qui est important dans leur environnement socio-politique. Elles influencent leur stratégie d'action face aux pressions. ${ }^{4}$

Ces quelques remarques ne veulent pas dire que les changements dans l'environnement vont modifier l'organisation du tout au tout. En effet, ceux-ci ne devraient en rien altérer l'identité de l'organisation, puisqu'il devrait exister un équilibre dynamique entre le système et son environnement, lui permettant de maintenir son identité propre malgré les variations du milieu externe." 5

D'autres auteurs ont abordé cette capacité de s'adapter à son environnement, en terme de créativité:

La créativité s'exerce à travers une planification à long et court terme, c'est-à-dire par l'analyse de l'environnement en vue de déterminer la meilleure manière d'utiliser les ressources existantes et les possibilités de 1'organisation. 6

4.MILLER, Roger, La direction des entreprises: concepts et applications, Montréal, McGraw-Hi17, 1985, p. 199.

5. Le développement organisationnel, op. cit., p. 15.

6. Au-delà du concept d'organisation., op. cit., p. 4. 
Ces auteurs signalent en outre que:

En se fiant à la seule adaptation, on laisse la société à la merci des courants les plus violents. L'innovation et la créativité sur laquelle elle s'appuie, peuvent permettre à une société de forger son avenir, plutôt que de dépendre simplement de circonstances favorables.?

Tous ces auteurs nous confirment que nous ne saurions insister trop sur l'importance qu'accorde une organisation aux changements qui se produisent dans son environnement immédiat.

\subsection{ACTIVITES DE PLANIFICATION}

La lecture des buts poursuivis par la CMAAT ne nous permet pas de cerner ce qu'elle apporte concrètement à ses membres (clients). Très vagues, ces buts laissent place à interprétation, parce qu'ils ne définissent pas clairement les champs d'activités de cette organisation. Peu importe le service qu'elle décide de dispenser, celui-ci n'entrera pas en conflit avec ses buts. Nous ne pouvons vraiment identifier ce qu'elle offre de plus aux artisans que ce qu'ils peuvent obtenir des autres composantes de l'environnement. Pourtant, un système ouvert devrait toujours être intentionnel et se définir par rapport à un projet sur l'environnement. 8

Aussi, à l'intérieur même de l'organisation, les membres ne connaissent pas leur rôle. Pourtant:

7.KENNETH, Andrew, "Le concept de stratégie d'entreprise", dans Encyclopédie du management, vol. 1, p. 24.

8. GAGNON, Dominique, Le développement organisationnel dans une perspective d'excellence, Ottawa, Agence d'Arc Inc., 1986, p. 18. 
Pour que les buts fixés aient un sens pour l'institution, ils doivent être énoncés en termes de caractère ou d'identité, c'est-à-dire, montrer à chacun ce qu'il doit faire afin de devenir ce qu'il veut être. 9

En plus de manquer de clarté, ces buts n'ont pas été modifiés depuis la naissance de la corporation. Et ce, même si certains organismes ont pris la responsabilité de services autrefois rendus par la corporation. Par exemple, la CFP s'occupe maintenant de la formation. Face à ces changements dans l'environnement, nous nous attendons à des modifications dans les buts, car:

L'organisation est un lieu de confrontation et d'absorption des contradictions: individuel vs collectif, formel vs informel, intégration vs différenciation, etc. Elle requiert donc un effort continuel de restructuration et de redéfinition. 10

Nous devons aussi souligner 1'absence d'objectifs explicites au sein de cet organisme. L'élaboration de buts ne suffit pas; les objectifs viennent les compléter, en précisant ce que l'organisation va faire concrètement: les buts ont un sens beaucoup plus qualitatif tandis que les objectifs sont plus quantifiables. 11

9. Au-delà du concept d'organisation, op. cit., p. 5. 10. Ibidem, p. 18 .

11. CRENER, M. et MONTEIL, B., Principes de management, Sillery, Les Presses de 1'Université du Québec, 1981, p. 267. 
Les objectifs se traduisent par la mise au point de programmes d'action. C'est pourquoi ils doivent être précis, chiffrés et réalistes. 12

Les objectifs vont s'exprimer en chiffres et en éléments concrets; les finalités expriment la philosophie des dirigeants de 1 'entreprise.13

Pour terminer, mentionnons aussi l'absence d'une mission claire confiée à la CMAAT. Comment assurer la pérennité d'un organisme si sa mission est mal définie?

Lorsqu'on tient à préserver la continuité et $l^{\prime}$ identité de T'institution, il est nécessaire de définir la mission de l'entreprise en prenant en considération son caractère distinctif, notamment ses capacités présentes ou prospectives, ainsi que le rôle qu'elle devra jouer dans un contexte industriel et commercial donné. 14

Ne disperse-t-elle pas trop ses efforts sur plusieurs champs? Quel est son domaine primordial d'activité? Quelle est sa vocation, l'orientation de son activité?

...intéressant de chercher à savoir où se situe la véritable compétence de l'entreprise, si ses produits correspondent bien, ou non, à cette compétence. La question est de savoir si les choix récents restent compatibles avec la vocation initiale. 15

12. JUBIN, PAUL, Le pilotage économique de l'entreprise, Paris, Entreprise moderne d'édition, 1972, p. 59.

13. Idem.

14. Au-delà du concept d'organisation, op. cit., p. 5.

15. DEVE, J.-C. et Le MOAL, J.Y., Le guide du décideur, Paris, Les éditions d'organisation, 1985, 228 pp. 


\subsection{ACTIVITES DE PROMDTION}

Les outils de promotion utilisés par la CMAAT ne peuvent être évalués aisément, car ils sont tributaires de la mission qu'elle se donne. Nous pouvons d'ailleurs observer deux orientations au point de vue de la promotion: 1) si la CMAAT se veut une association d'artisans mettant en commun des services, la promotion devrait être orientée vers les artisans de la région, afin de recruter le maximum de membres; 2) si la CMAAT se veut une association de mise en marché, $i 1$ faudrait alors 1 a promouvoir auprès des consommateurs d'oeuvres d'art.

\subsection{ACTIVITES DE CONCERTATION}

Af in de dégager les lacunes de ce sous-système, $i 1$ apparait nécessaire de définir d'abord le concept de concertation:

La concertation implique une action. Elle est le fruit d'une entente entre deux personnes, deux groupes, deux entreprises dans le but d'agir en accord l'un avec l'autre, d'agir de concert. Lorsque deux entreprises se concertent, elles décident d'agir dans une direction commune, mais chacune de leur côté. 16

Suivant cette définition, nous pouvons affirmer que les membres de la CMAAT ne se concertent pas. Les assemblées générales annuelles et spéciales semblent les seules occasions où les membres se rencontrent. Mais, à la suite de ces rencontres, quelle action est entreprise par les membres?

16. Principes de management, op. cit., p. 235 . 
D'autre part, nous remarquons une tentative de concertation entre les différents regroupements régionaux. En effet, lors des réunions du regroupement national, les divers représentants régionaux s'entendent sur une orientation à suivre. Mais, la problématique des divers regroupements régionaux diffère de l'un à l'autre; c'est pourquoi la concertation à laquelle ceux-ci aboutissent ne correspond pas vraiment aux attentes de la CMAAT.

Toutefois, s'il n'y a pas la concertation entre les membres de 1a CMAAT, que dire de la participation? Précisons premièrement ce que nous entendons par participation:

La participation sera un moyen de mettre en commun des richesses individuelles et, par un effet synergique de l'action collective, une source de richesses nouvelles qui rejailliront tant sur les individus que sur la collectivité.17

La participation semble très difficile à obtenir. Comme la clientèle est très diversifiée, nous nous demandons si l'effet de synergie peut émaner d'un tel regroupement. Pour Georgiou, cette condition est essentielle pour juger de la pertinence d'un groupe:

Instead of goals being the key to organizational behavior, Barnard regarded the motives of the individuals participa-ting in organizations as the critical determinants. 
...its capacity to survive through being able to elicit sufficient contributions from its participants by providing them with sufficient rewards. 18

\subsection{ACTIVITES D'INFORMATION}

Au niveau du sous-système "information", i1 y a dédoublement d'information entre la CMAAT, le MAC et le Conseil régional de la culture. De plus, compte tenu que la clientèle est diversifiée, la sélection de l'information à divulguer présente des problèmes. Qui faut-il informer? Quelles informations devrait-on transmettre? Quels sont les buts à atteindre? L'outil utilisé est-il approprié?

\subsection{ACTIVITES DE DEVELOPPEMENT}

Les activités de développement sont reliées principalement à la vente de produits d'oeuvres d'art. Bien que cet objectif s'avère très important pour les membres de la CMAAT, celle-ci éprouve quelques difficultés à y répondre. La principale activité fut sans contredit la mise sur pied d'une boutique communautaire; mais, rappelons que celle-ci a dû fermer ses portes, à la suite de difficultés financières.

Nous remarquons aussi qu'aucune action $n^{\prime}$ est entreprise en vertu des études commandées par la CMAAT. Par exemple, l'étude effectuée dans le cadre du programme "Outil de gestion" a démontré qu'il existait un certain potentiel de vente en Ontario. Aucune dé-

18. GEORGIOU, P., "The Goal Paradigm and Notes Towards a Counter Paradigm" in Administrative Science Quaterly, vol. 18, 1973. 
marche ne fut toutefois effectuée par les artisans de la CMAAT pour pénétrer ce marché.

Déterminer les besoins de formation, même si la dispensation de celle-ci poserait des problèmes, (comment expliquer à un artisan qu'il a besoin de formation?) pourrait devenir une activité très importante pour l'organisme.

\subsection{ACTIVITES DE CONTROLE}

Compte tenu qu'il s'agit là de l'un des problèmes majeurs de la Corporation, nous ne pouvons passer sous silence l'absence de contrôle dans cette organisation. C'est pourtant là une activité importante du système de gestion, consistant à déterminer si les activités engendrent des résultats conformes aux intentions et aux objectifs arrêtés:19

Demestère et Viens traitent aussi de cette notion d'atteinte d'objectifs dans leur définition de la fonction-contrôle.

Le contrôle de gestion est le processus par lequel les responsables s'assurent que les ressources sont obtenues et utilisées efficacement et avec efficience pour la réalisation des objectifs de l'organisation.

Ajoutons que le rôle du contrôle de gestion n'est pas seulement d'inciter à obtenir le maximum d'output avec un minimum d'input mais aussi et surtout d'obtenir des outputs adaptés aux objectifs donnés. 20

19. DEWARRAT, Gérard, "La mesure d'efficience des organisations non profit (ONP): aspects et problèmes" dans Direction et gestion des entreprises, no 4, juillet-août 1984, p. 8 .

20. DEMESTERE, R. et VIENS, G., "Le contrôle de gestion des organisations sans but lucratif" dans Revue française de gestion, no 6 , sept.-oct. 1976, p. 22. 
Nous avons vu que la CMAAT ne définit pas ses objectifs. Alors comment peut-elle évaluer s'ils sont atteints? Sans système de contrôle, elle ne peut réagir et revoir son plan d'action. C'est pourtant cette fonction qui donne au système de contrôle toute son importance:

Un bon système de contrôle permet d'entreprendre des actions correctives à temps et favorise le changement. Il nécessite toutefois une analyse pertinente et approfondie des causes des carences constatées. Ces démarches sont de nature à éviter de graves erreurs de gestion et doivent permettre d'assurer la continuité et la stabilité du pilotage de l'organisation. Le contrôle d'efficience est un élément du système de gestion.21

Comme toutes les organisations sans but lucratif (OSBL), la CMAAT se caractérise par l'absence d'objectifs financiers et d'outputs tangibles. De plus, elle n'est pas capable de se définir des critères d'évaluation. Il nous est donc difficile de mesurer les résultats obtenus, de contrôler son efficience. Comme chaque OSBL vise une mission particulière, nous ne pouvons les comparer. Si les entreprises à but lucratif peuvent être confrontées au point de vue de leur rentabilité, il n'en va pas ainsi lorsqu'il s'agit de mettre en relation des organismes et des finalités qui n'ont pas de points communs, comme, par exemple, une école, un syndicat et une fondation de bienfaisance. Mais, malgré cet obstacle, le contrôle, dans une OSBL, n'en demeure pas moins important. Dewarrat insiste du reste sur 1 'importance de cette fonction dans les OSBL:

21. "La mesure d'efficience des organisations non profit (ONP)", Op. cit., p. 15. 
L'efficience traduit le degré d'atteinte des objectifs. Sa mesure et son contrôle dans les ONP représentent une phase importante du cycle de gestion méritant autant d'attention que dans les enteprises à but lucratif. 22

L'activité à but non lucratif est une des formes des efforts humains axés sur des buts spécifiques, elle mérite donc une gestion aussi précise que celle de la plupart des activités commerciales, privées ou publiques. 23

Note: ONP: Organisation non profit.

\subsection{CLIMAT ORGANISATIONNEL}

Le climat organisationnel de la CMAAT s'est beaucoup détérioré depuis la fermeture de la boutique. Cette décision, découlant de la situation financière de l'organisme, représente pour. plusieurs de ses membres un échec.

Comme le sondage nous l'indique, chez les artisans, la vente de leur production devient leur principale préoccupation. Ils ont amendé la charte de la CMAAT, en 1980, pour permettre l'ouverture d'une boutique communautaire. Pour plusieurs, ce lieu de diffusion représentait la raison pour laquelle ils en étaient membres. Nous avons pu observer en outre que la gestion de la boutique occupait une large part du travail de la directrice générale de 1a CMAAT.

22. "La mesure d'efficience des organisations non profit (ONP)", op. cit., p. 14.

23. Idem. 
La fermeture de la boutique a suscité une remise en question de la CMAAT. Les membres devaient se réorganiser et revoir la raison d'être du regroupement. Rappelons que nous avons été mandatée par le Conseil d'administration pour assumer cette tâche, à l'époque.

Une telle réorganisation ne se fait habituellement pas sans difficulté. Nous avons $v u$, au chapitre 6 , que la participation des membres au processus de remise en question était très mauvaise. Cette réalité nous a poussée à nous demander s'il existait chez les membres, un sentiment d'appartenance à ce regroupement. Car, comment expliquer que les membres de cet organisme ne participent pas aux réunions convoquées pour discuter de sa survie?

Si l'existence du groupe est menacée et que personne ne s'en soucie, le sentiment d'appartenance n'est alors que peu développé. 24

Comment assurer, d'autre part, le développement d'une organisation, alors que les membres eux-mêmes ne contribuent pas à réaliser cet objectif?

In turn, organizations depend upon the contributed talent and effort of people who work in them. Every organization must obtain these contributions and other resources and convert them into some outputs that yield sufficient rewards

24. "La gestion d'organismes bénévoles", document de base, Télé-Université. 


$$
\begin{aligned}
& \text { to keep } 25 \text { the organization alive and func- } \\
& \text { tioning. }
\end{aligned}
$$

Nous pouvons difficilement comprendre que peu d'artisans se montrent intéressés à s'impliquer au niveau du Conseil d'administration. Comment expliquer qu'ils ne veuillent pas travailler pour un organisme qui devrait, en principe, répondre à leurs besoins? Ils évoquent souvent le manque de temps pour justifier cela; pourtant, la CMAAT ne devrait-elle pas chercher à mettre des services en commun qui permettraient aux artisans de se libérer de certaines tâches et, du même coup, d'épargner du temps? Est-ce que le désintéressement des membres signifie que les activités de la CMAAT ne sont pas tellement utiles, et qu'il est préférable pour eux de consacrer leurs énergies à répondre à leurs propres besoins? Les membres sont-ils intêressés par les services offerts par 1a CMAAT?

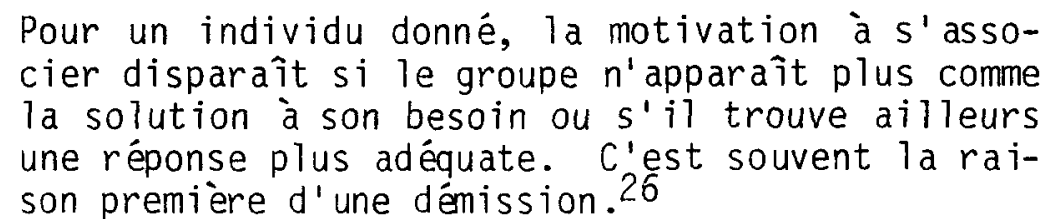

Nous avons vu aussi, au chapitre 6 , que le petit groupe qui, durant cette période de remise en question, déploie des efforts pour maintenir la CMAAT, éprouve beaucoup de difficultés à travail-

25. HAMPTON, David, R., Management Third Edition, USA, McGraw-Hil1 Book Company, 1986, p. 85.

26. "La gestion d'organismes bénévoles", document de base, TêléUniversité. 
ler ensemble. Le fait que nous retrouvons à peu près toujours les mênes membres sur le Conseil d'administration peut expliquer les conflits personnels auxquels nous assistons. Dans les organisa-tions, une rotation des membres ne permet-elle pas de réduire certains conflits personnels?

Nous croyons que ces différents faits observés durant la période de remise en question reflètent une réalité qui était jusqu'à ce moment camouflée. Le sondage (annexe 2) a démontré que les artisans sont différents les uns des autres. Ils cherchent à combler des besoins différents. Sont-ils trop différents pour travailler ensemble à l'atteinte d'un même objectif?

Le mauvais climat organisationnel découle selon nous de cette réalité dont nous avons parlé. Compte tenu des différences individuelles, nous doutons qu'un effet de synergie puisse émaner d'un tel regroupement. Les membres éprouvent en effet beaucoup de difficultés à réorienter leur organisation. Cette situation provoque des conflits, des attitudes négatives, un manque de confiance, etc. Et le climat organisationnel se détériore. 
CHAPITRE 8 
CHAPITRE 8

\section{GOULDT D 'ETRANGLEMENT}

Au chapitre 7 , nous avons identifié les zones problématiques qui viennent affecter l'efficacité de la CMAAT. Dans le présent chapitre, nous devons traiter du problème ayant la plus grande incidence sur le fonctionnement de l'organisme.

\subsection{CHOIX DE LA PROBLEMATIQUE A TRAITER}

La CMAAT ne réussit pas à planifier son action et rien ne nous indique ce qu'elle envisage faire dans 1'avenir. Quelle est sa mission? Quels sont ses buts? Quels objectifs vise-t-elle? Toutes ces questions demeurent sans réponse. Tout est relié à l'obtention d'une subvention. Il s'avère primordial de trouver des solutions pour rendre la CMAAT capable de se donner une vision future. Il faut qu'elle soit capable de déterminer des buts et des objectifs fondamentaux, à long terme, et d'adopter des modes d'action et d'allocation des ressources nécessaires pour atteindre ces buts. En fait, i1 faut que la CMAAT élabore une stratégie organisationnelle efficace qui démontre ce qu'elle veut faire: ${ }^{1}$

La stratégie d'entreprise est l'ensemble des missions et objectifs principaux, ou des buts, des politiques et plans essentiels à l'accomplissement de ces buts, présenté de manière à définir le genre d'activités auxquelles l'entreprise se consacre ou va se consacrer et le type d'entreprise qu'elle constitue ou qu'elle va constituer.2

1. KENNETH, Andrews, "Le concept de stratégie d'entreprise" dans Encyclopédie du management, vol. 1, p. 24.

2. Idem. 
Cette stratégie doit en outre:

(...) en priorité discerner et définir les buts et les objectifs à long terme de l'entreprise et les moyens ( $p l a n s)$ à mettre en oeuvre en vue de les atteindre, ainsi que les allocations de ressources nécessaires. 3

Voilà donc ce qui en est de la stratégie, si essentielle, au cheminement de l'entreprise.

\title{
8.2 JUSTIFICATION DU CHOIX
}

Mais la stratégie pose aussi le problème de la survie de l'organisation:

\begin{abstract}
L'élaboration d'une stratégie peut devenir une question de survie pour l'organisation. La décision stratégique porte sur le développement à long terme de l'organisation, car elle se projette obligatoirement et continuellement dans 1 'avenir. Elle permet de ne pas se fier à la seule adaptation pour ainsi éviter que 1'organisation soit laissée à la merci des courants les plus violents. 4
\end{abstract}

Comme 1'auteur précité l'affirme, l'élaboration de la stratégie assure souvent la survie d'une organisation. Dans le cas de la CMAAT, la planification est quasi-inexistante et cette carence de mission, de buts et d'objectifs, dans cette organisation, se trouve

3.CRENER, M. et MONTEIL, B., Principes de management, Sillery, Les Presses de 1'Université du Québec, 1981, p. 265.

4. "Le concept de stratégie d'entreprise", op. cit., p. 25. 
à l'origine de la situation précaire dans laquelle elle est plongée. L'existence d'une stratégie organisationnelle au sein de la CMAAT nous permettrait de connaitre son orientation. Quels sont ses objectifs pour les années à venir, pourquoi pense-elle que ces objectifs sont réalistes et comment envisage-t-elle de les atteindre? 5

Toute organisation doit répondre à ces questions si elle désire assurer sa pérennité. Il faut bien comprendre que nous parlons d'absence de stratégie organisationnelle au sein de la CMAAT. Cette remarque ne signifie pas que las membres de cet organisme ne suivent pas une certaine stratégie. Chercher à obtenir une subvention peut s'avérer stratégique pour un regroupement. Le groupe planifie un ensemble de moyens pour parvenir à un résultat bien précis. Par contre, une organisation doit être capable d'assurer son développement à long terme. Et nous croyons que le problème fondamental de 1a CMAAT tient à cette absence d'informations sur son avenir.

5. DES JARDINS, Marcel, "Le planning stratégique et structurel dans les P.M.E." dans Recueil de cas et d'articles, no 1401, Tome II, Montréal, HEC, $20 \mathrm{pp}$. 
CHAPITRE 9 
CHAPITRE 9

ANCRAGE

\subsection{CHOIX DU SYSTEME PERTINENT}

Nous avons expliqué au chapitre 8 que le problème fondamental de la CMAAT réside dans l'absence de stratégie organisationnelle: ce qu'elle est, ce qu'elle veut devenir et comment elle va parvenir à ses fins, compte tenu de ses ressources. Nous avons aussi souligné dans ce même chapitre, Ta distinction entre une stratégie de regroupement et une stratégie organisationnelle. Mais, pour élaborer une stratégie organisationelle, il faut d'abord définir ce qu'est une organisation. Selon Crener et Monteil, une organisation est une entité sociale, humaine, composée d'un ensemble d'éléments interdépendants agencés pour atteindre un ou des objectifs et être capable de s'adapter à un environnement changeant.1

Porter, Lawler et Hackman² proposent aussi. cette notion d'entité sociale à laquelle un groupe de personnes décident d'adhérer pour atteindre un but. Ils insistent sur le fait que le regroupement doit être formé pour faire quelque chose. Il faut aussi que l'organisation planifie les moyens pour atteindre les objectifs qu'elle vise. Ainsi deux processus doivent-ils être mis en branle: la différenciation des fonctions et des positions et l'élaboration d'un plan

1.CRENER, M. et MONTEIL, B., Principes de management, Sillery, Les Presses de 1'Université du Québec, 1981, p. 300.

2. PORTER, L., LAWLER, E. and HACKMAN, R., Behavior in Organizations, New-York, McGraw-Hi11, 1975, p. 69. 
bien défini pour coordonner et diriger les activités. Finalement, ces mêmes auteurs traitent de la notion de continuité dans l'organisation et des interrelations qui doivent exister.

Il est à signaler également que ces auteurs accordent une importance capitale aux objectifs qui motivent un groupe de personnes à former une organisation. En effet, une organisation est crée seIon eux, pour atteindre un objectif qui requiert l'énergie de plus d'une personne. Elle doit ensuite organiser ses actions pour parvenir à ses fins, en tenant compte des ressources à sa disposition:

Organization emerges whenever there is a shared set of beliefs about a state of affairs to be achieved and that state of affairs requires the effort of more than a few people. That is, the relationships among the people involved become patterned. The behavior patterns or structure derive from a division of labor among the ${ }_{3}$ people and a need to coordinate the divided work. ${ }^{3}$

Gérard Dewarrat, de son côté, aborde aussi l'organisation comme système ouvert et finalisé. Ouvert, parce qu'il est en relation constante avec son environnement. Finalisé, parce que ses activités et ses structures s'orientent vers 1'atteinte d'objectifs: 4

3. GALBRAITH. Jay R., Organization Design, USA, Addison Wesley Publishing Company, 1977, p. 3.

4. DEWARRAT, Gérard, "La mesure d'efficience des organisations non profit (ONP): aspects et problènes" dans Direction et gestion des entreprises, no. 4, juillet-août 1984, p. 10 . 
"L'organisation en tant que système se définira en fonction de:

1. L'accomplissement d'un but;

2. L'intégration des hommes et des unités organisationnelles;

3. L'adaptation à l'environnement externe et interne;

4. La recherche et l'aliocation de ressources nécessaires (personnel, matérie1, compétence)."5

Bref, si l'on se fie à ces différents auteurs, la CMAAT $n^{\prime}$ est pas une organisation. Et $n$ 'étant pas une organisation, elle ne peut élaborer une stratégie organisationnelle. Et, sans stratégie, elle va continuer de tourner en rond et d'être inefficiente au point de vue des services qu'elle offre aux artisans.

Aussi, on ne doit pas oublier que trois phénomènes sont intimement reliés au développement à long terme des entreprises, soit:

- la volonté fréquente d'appuyer les stratégies de développement sur les compétences spécifiques de 1 'entreprise, ses atouts particuliers et ses know-hows propres qui la différencient de ses concurrents;

- I'ancrage de ces compétences au niveau de facteurs structurels internes tels que son organisation, ses procédures de gestion, la personnalité de ses dirigeants, les mentalités du personnel et le climat organisationnel;

- l'image de l'entreprise au plan interne et externe, c'est-à-dire la perception qu'ont les gens de ces compétences." 6

5.CRENER, M. et MONTEIL, B., Principes de management, Sillery, Les Presses de l'Université du Québec, 1981, p. 300.

6. LARCON, J.-P. et REITTER, R., "L'identité de T'entreprise, un facteur-clé de sa survie" dans Direction et gestion des entreprises, no 3, mai-juin 1979, p. 12. 
Nous proposons un système de détermination d'une organisation comme système pertinent. Après quoi, la CMAAT devrait pouvoir élaborer une stratégie organisationnelle.

\subsection{DEFINITION DU SYSTENE PERTINENT}

Un système de détermination d'une organisation, pour la CMAAT, est un ensemble d'activités humaines qui permettent à l'assemblée générale de reprendre le processus de création de l'organisme. En tenant compte des caractéristiques des artisans, des particularités géographiques, du marché des métiers d'art et des disponibilités financières, ce système permettra à la CMAAT d'être plus efficiente au point de vue des services qu'elle offre en assurant la promotion des métiers d'art.

\subsection{VALIDATION DE LA DEFINITION}

Nous voutons nous assurer que la définition du système de détermination d'une cible commune est cohérente avec la notion de système d'activités humaines. Elle doit nous permettre de bien identifier le propriétaire du système, c'est-à-dire le décideur, de cerner les contraintes environnementales qui ne contrôlent pas directement le système mais qui l'influencent, d'identifier les clients, c'est-à-dire ceux qui bénéficieront du système, d'identifier les acteurs, c'est-à-dire ceux qui effectueront les activités et, finalement, de décrire le point de vue qui sert de cadre de référence, en délimitant de façon précise la perspective retenue. 
Propriétaire du système: l'assemblée générale de la CMAAT.

Environnement: caractéristiques des artisans et particularités géographiques de l'Abitibi-Témiscamingue; marché des métiers d'art de 1'Abitibi-Témiscamingue; disponibilités financières.

Clients: les membres de la Corporation des métiers d'art de l'Abitibi-Témiscamingue.

Activités de transformation: reprendre le processus de création d'une organisation.

Acteurs: assemblée générale de la CMAAT.

Point de vue: 1) la promotion de 1'artisanat en AbitibiTémiscamingue; 2) l'efficience des services offerts. 
CHAPITRE 10 
CHAPITRE 10

CONCEPTUALISATION

\subsection{Préambule}

Les sections précédentes s'inscrivaient dans un processus inductif de recherche; nous cherchions à connaître et comprendre la situation. Nous avons, premièrement, exposé l'état de la situation (environnement, structure, processus, climat, etc.) et les candidats au poste "problème". Ensuite, lors de l'étape de la définition de l'ancrage, nous avons choisi la perspective selon laquelle la problématique sera étudiée.

La conceptualisation, elle, est un exercice déductif qui consiste à construire un modèle à partir de l'ancrage sélectionné. Le modèle proposé n'est pas une conception d'une ou de plusieurs soTutions à implanter, mais sert plutôt de cadre de référence pour questionner de façon systématique une situation jugée problématique. Les résultats de ce questionnement organisé permettront d'identifier les lieux où des actions correctives devront être entreprises. 


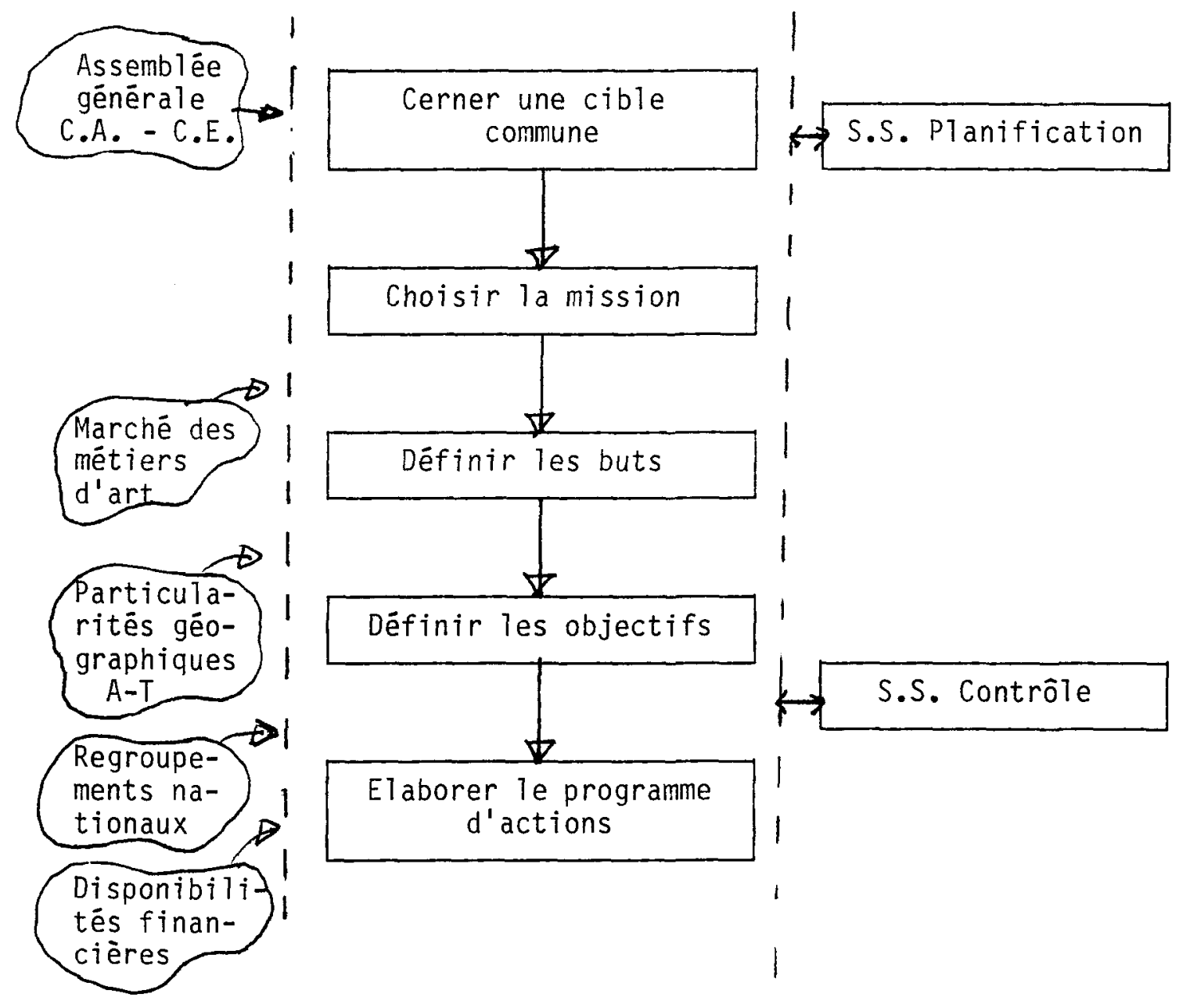

FIGURE 9: Modèle conceptuel 


\subsection{DESCRIPTION DU MODELE}

A) Cerner une cible commune

Rappelons-nous ici qu'une organisation est différente de la somme des individus qui la composent; elle est une totalité non réductible à la somme de ses parties. C'est en fait un groupe d'éléments interdépendants interagissant formant un ensemble unifié en vue d'atteindre un même objectif.1

Il est important que les membres de la CMAAT soient capables d'identifier un objectif commun et qu'ils croient que seul le groupe va leur permettre d'atteindre cet objectif. Comme l'explique Yves Saint-Arnaud, 2 il faut que 1 e groupe devienne indispensable, soit parce que plusieurs personnes doivent être solidaires dans une activité commune, soit parce que l'interaction entre plusieurs types de ressources est nécessaire pour atteindre la cible poursuivie. (...) une cible commune est possible dans la mesure où. la somme d'énergie mobilisée pour l'atteindre est justifiée.

Toujours selon le même auteur, la perception d'une cible commune et les relations entre les personnes sont considérées comme des mécanismes qui transforment l'énergie individuelle en énergie

1.CRENER M. et MONTEIL, B., Principes de management, Sillery, Les Presses de T'Université du Quêbec, 1981, p. 300.

2.SAINT-ARNAUD, Yves, Les petits groupes Participation et Communication, Montréal, Les Presses de l'Université de Montréal, 1978. 
groupale; c'est alors l'énergie qui permet au système-groupe de se déve lopper."3 Aussi:

...lorsque dans un rassemblement de personnes une cible commune capte l'intérêt de plusieurs membres, leur énergie est spontanément convertie dans le système-groupe en énergie de production. 4

\section{B) Choisir la mission}

La première étape a permis au groupe de personnes de se reconnaitre une cible commune. Mais d'autres conditions doivent être respectées si le groupe veut devenir une organisation.

Il est à souligner qu'une organisation repose initialement sur un certain type de mission. Comme l'exprime Hampton, la mission représente la raison d'être de l'organisation:

To state an organization's mission is to state its main, transcending reason for existing. It is to identify the function the firm performs for society, and more, its basic character and philosophy. 5

C'est la mission qui exprime la philosophie des dirigeants. Elaborer une mission, c'est donc apporter une signification, à long terme, à l'activité quotidienne, c'est donner un objectif à

\section{Idem.}

4. Idem.

5. HAMPTON, David, R., Management Third Edition, USA, McGraw-Hill Book Company, 1986, p. 138. 
celle-ci. Pour Sallenave, la mission permet à une organisation de délimiter son champ d'activité:

La mission de l'entreprise n'est qu'une délimitation du champ d'action que les dirigeants fixent a priori à l'entreprise. Ne comporte pas de jugement de valeur: - af in de polariser les ressources de l'entreprise sur un domaine général ou un objectif permanent; - premier acte du processus de décision stratégique; - la mission devient le cadre disciplinaire à l'intérieur duquel le dirigeant travail1e. 6

En fait, choisir une mission, c'est répondre aux questions suivantes:

- Qui sommes-nous?

- Que voulons-nous devenir?

- Quelle est la raison d'être de notre organisation?

- Quelle est notre mission économique?

D'autres auteurs définissent la mission comme 1 a personnalité de l'organisation. Par exemple, pour le professeur Selznick, une organisation en tant qu'entité vivante se reconnaît une mission à accomplir et un rôle à jouer dans la société. Elle se choisit des valeurs et les traduit dans sa structure interne et ses modes de fonctionnement. Toujours selon le même auteur, elle se signale pour ses compétences spécifiques, et, comme les individus qui la composent, elle a une personnalité. La tâche du dirigeant est d'incarner

6.SALLENAVE, Jean-PauT, Direction générale et stratégie d'entreprise, Paris, Les éditions d'organisation, 1984, p.237. 
et de défendre la spécificité de ces éléments, afin que l'organisation acquiert de la sorte une identité propre et qu'elle devienne une institution."7

En plus de se révéler très importante à la création de l'organisation, la définition d'une mission lui assure son développement. Citons trois auteurs qui abordent cette notion. D'abord, David R. Hampton qui soutient que la mission permet d'atteindre et de maintenir l'intégrité d'une organisation.

The principal virtue of a clear thinking about an organization's mission is that knowing and being able to articulate core purposes and values contribute to achieving and maintaining the integrity or unification of the organization.8

Et pour J.P. Larcon et R. Reitter, l'existence d'une véritable identité d'entreprise qui de la même manière que la personnalité d'un individu, marque d'une manière profonde son potentiel de développement. Toujours selon ces auteurs, la personnalité de l'organisation est un ensemble de caractéristiques interdépendantes qui lui donnent au fil de l'histoire sa spécificité, sa stabilité et sa cohérence. ${ }^{9}$

7.SELZNICK, Philip, "Au-delà du concept d'organisation" dans Encyclopédie du management, France, France Expansion Kluwer, 1973, vol. 1.

8. HAMPTON, David, R., Management Third Edition, USA, MCGraw-Hill Book Company, 1986, p. 139.

9. LARCON, J.P. et REITTER, R., "L'identifé de l'entreprise, un facteur-clé de sa survie" dans Direction et gestion des entreprises, 15, no 3, mai-juin 1979, p. 12. 
Nous voyons que la définition d'une mission s'avère une étape très importante. Elle oriente l'organisation et lui permet un meilleur développement.

\section{C) Définir les buts}

Les buts au sens précis du terme sont les résultats que l'organisation vise, ce à quoi elle tente de parvenir:

An organization is a relatively enduring grouping of people in a structured, evolving system whose coordinated efforts are meant to reach goals in a dynamic environment. 10

Comme le précise Selznick, pour s'assurer que les buts aient un sens pour 1'institution, ils doivent être énoncés en termes de caractère ou d'identité. Aussi faut-il qu'ils indiquent à chacun ce qu'il doit "faire" afin de devenir ce qu'il veut "être".11

Lors de l'étape précédente, nous avons démontré l'importance de bien choisir la mission de l'organisation. Ici, nous expliquons comment définir les buts. Cette étape ne s'avère pas moins importante que l'autre; elle suit le choix de la mission. Ces étapes nous permettent d'établir la stratégie de l'organisation qui, selon plusieurs auteurs, assure en partie la survie de celle-ci:

10. Management Third Edition, 0p. cit., p. 89.

11.SELZNICK, Philip, "Au-delà du concept d'organisation" dans Encyclopédie du management, France, France Expansion Kluwer, 1973, vol. 
From the mission statement more specific goals could be developed and from this point a strategy for goal attainment could be derived. The strategy would indicate the mix of property, technology, structure and members needed to create and/or distribute specific outputs. We suggested that organizations that limit their social contribution and develop clear-up means-ends chains have better chance for survival.12

D) Définir les objectifs

Nous avons vu ce que nous entendions par mission et par but. Comparons maintenant la notion d'objectif avec celles de mission et de but.

D'abord, précisons que les objectifs sont quantifiables, alors que les buts ont un sens beaucoup plus qualitatif. De même, les objectifs sont plus tangibles que la mission:

Les objectifs sont plus concrets que la mission et ont pour fonction $d^{\prime}$ assurer la concordance entre les programmes d'action (utilisation des moyens) et la mission. Ils représentent des critères de performance contrôlables. 13

Il faut bien comprendre que l'identification de la mission et l'élaboration des buts généraux représentent des étapes qu'il ne faut pas négliger pour autant. Ils servent à définir des objectifs cohérents:

12. HUNT, J.E., OSBORN, N.R., JAUCH, L.R., Organization Theory, Integrated Approach, Toronto, John Wiley and Sons, 1980.

13."La mesure d'efficience", Op. cit., p. 10. 
Objectives ought to specify ends or results sought that are derived from and congruent with the mission the organization has set for itself. Attempts to set objective should always be guided by reference to the mission they are meant to fulfil1.14

Il faut éviter que l'organisation se retrouve avec des objectifs irréalistes engageant trop de ressources, ou encore avec des objectifs trop pauvres traduisant une sous-utilisation des ressources vis-à-vis les opportunités.

\section{E) Elaborer le programme d'action}

Les étapes que nous venons de décrire vont permettre d'élaborer un programme d'actions. Pour mieux les comprendre, définissons ce concept. Selon Crener et Monteil:

Un programme est un plan de réalisation concrète de l'utilisation future des ressources de l'entreprise. Il établit une séquence d'opérations compte tenu du temps disponible pour atteindre un objectif bien précis. 15

Ainsi l'élaboration d'un programme d'actions permet d'établir à l'avance les contributions des personnes qui participeront à la réalisation de l'objectif choisi, les informations qui seront utilisées et les décisions devant être prises. Sans programme détaillé, l'exécution est soumise aux aléas et aux caprices des événements. Le programme confère au processus d'administration une stabilité telle

14. Management Third Edition, 0p. cit., p. 140.

15. Principes de management, 0p. cit., p. 251. 
que les personnes y cheminent et prennent des décisions dans des cadres établis. 16

Afin d'établir son programme d'action, l'assemblée générale de la CMAAT devra:

1. subdiviser le programme en phases successives et établir pour celles-ci des micro-objectifs opérationnels;

2. identifier les opérations élémentaires constitatives de chacune de ces phases (introduire les moyens requis at le temps);

3. tenir compte de la précision qu'exige le programme, eu égard aux limites de temps, d'argent et de personnel.17

\subsection{CONDITIONS}

Dans toute planification, les valeurs que les dirigeants véhiculent doivent être prises en considération. C'est pourquoi, l'assemblée générale procède elle-même, habituellement, à l'èlaboration du processus que nous venons de décrire. Par contre, elle doit toujours garder à l'esprit les limites que lui imposent son environnement et ses ressources disponibles.

Même si les objectifs poursuivis se trouvent conformes aux valeurs des dirigeants, il faut qu'ils tiennent compte des impératifs

16.MILLER, Roger, La direction des entreprises: concepts et applications, Montréal, McGraw-Hi11, 1985, p. 62.

17. Principes de management, 0p. cit., p. 253. 
économiques de l'entreprise, que dicte l'analyse de l'environnement et des ressources. D'un côté, nous avons les valeurs at les aspirations des dirigeants qui représentent ce que 1'organisation veut faire. De l'autre, on retrouve les ressources et les compétences de l'organisation (capacité de faire), et certaines obligations reconnues vis-à-vis du public (ce qu'elle doit faire).18

Le processus de détermination d'une organisation n'est pas linéaire; il suit une boucle. Ainsi, l'analyse de l'environnement et des ressources peut amener l'organisation à reprendre certaines étapes. Par exemple, celle-ci pourrait viser certains objectifs et s'apercevoir que les ressources humaines dont elle dispose ne lui permettent pas de les atteindre.

18. DESJARDINS, Marcel, "Le planning stratégique et structurel dans les P.M.E." dans Recueil de cas et d'articles, no 1401, Tome I I, Montréal, HEC, $20 \mathrm{pp}$. 
CHAPITRE 11 
CHAPITRE 11

COMPARAISON

\subsection{PREAMBULE}

Dans ce chapitre, nous allons comparer le modèle conceptuel avec la réalité vécue à la CMAAT. Cette comparaison nous permettra d'identifier de façon précise les lieux et les changements potentiels qu'il faudrait effectuer dans la situation problématique décrite.

\subsection{DESCRIPTION}

A) CERNER UNE CIBLE COMMUNE

Les membres de 1a CMAAT ne se sont jamais demandé s'ils visaient une cible commune. Or, on sait que, dans une organisation, les membres doivent poursuivre un même objectif, qui sera atteint dans la mesure où tout le groupe mobilisera ses énergies à cette fin.

A la suite d'une discussion avec les artisans de la CMAAT, nous avons constaté qu'ils poursuivaient un même objectif, soit la vente de leurs oeurres d'art. Cependant, comme le sondage le démontre (annexe 2), et bien qu'il s'agit là d'un objectif commun à tous, atteindre cet objectif revêt différentes significations selon les individus. De plus, est-ce que le regroupement peut les aider en cela? Selon eux, dans une certaine mesure, la boutique communautaire y contribuait. 
Nous ne saurions trop insister sur l'importance de cette première étape. Il appert que, même à la fondation de la CMAAT, cette êtape aurait été escamotée. De plus, malgré tous les changements survenus par la suite, les membres de la CMAAT ne sont jamais véritablement posé la question lors des différentes réunions spéciales qui ont eu lieu.

\section{B) CHOISIR LA MISSION}

Aucune mission n'est définie dans cette organisation, semble-t-il. Nous ne pouvons cerner ce qu'elle est, ce qu'elle veut devenir et sa raison d'être. Cette absence de mission peut amener ceux qui agissent au sein de l'entreprise à oeuvrer inefficacement, à viser des cibles dispersées et parfois incompatibles. 1

Comme le souligne David R. Hampton, de son côté:

The lack of a clear sence of basic values and character, the mission of an organization makes it easy for its managers to slip into opportunistic drift: the pursuit result of tempting deals and schemes that can call for competencies unlike those organization possesses and that can lead to dissipating resources, and to other consequences detrimental to the organization's interests.?

Ainsi qu'en témoignent les citations précédentes, cette absence de mission fait en sorte que le champ d'activités de la

1. BENEDETTI, C., GUILLAUME, J., LAMONTAGNE, R. et TURGEON, Bernard, La dynamique de l'entreprise, Chomedey-Laval, Mondia, 1981, p. 208.

2. HAMPTON, David R., Management Third Edition, USA, MCGraw-Hil1 Book Company, 1986, p. 140. 
CMAAT n'est pas délimité. Elle disperse ses ressources et devient inefficace. Nous avons vu, dans le chapitre sur le climat organisationnel, que le Conseil d'administration ne sait plus quelle action entreprendre pour susciter l'intérêt des membres.

Au dépôt du diagnostic lors de l'assemblée générale de mai 1986, les participants ont tenté de répondre à quelques questions concernant la mission de l'organisation (annexe 5). Mais ils ont été incapables de délimiter un champ d'activités. Trois personnes ont d'ailleurs proposé d'assumer trois mandats différents. Nous présumons que ces trois membres ont accepté la responsabilité de certains dossiers qui les intéressaient personnellement. S'agissait-il alors de la mission d'une organisation? Nous croyons que non.

\section{C) DEFINIR LES BUTS}

Bien que cette étape se retrouve dans le sous-système "planification" de la CMAAT, elle $n^{\prime}$ en demeure pas moins imparfaite. Comme nous l'avons souligné, cette organisation n'a pas révisé ses buts depuis sa naissance malgré un environnement changeant. Les buts représentent-ils encore ce que l'organisation vise réellement?

En outre, comme ils sont vagues, i1s ne donnent pas beaucoup d'informations sur ce que vise réellement la CMAAT.

Mais le fait que les buts officiels soient vagues et imprécis n'est pas un problème en soit. Nous retrouvons cette situation, selon des auteurs, dans d'autres organisations et c'est souvent intentionnel pour demeurer flexible. Par contre, à la CMAAT, nous nous 
demandons si des buts même informels sont poursuivis étant donné le manque de motivation que manifestent des membres.

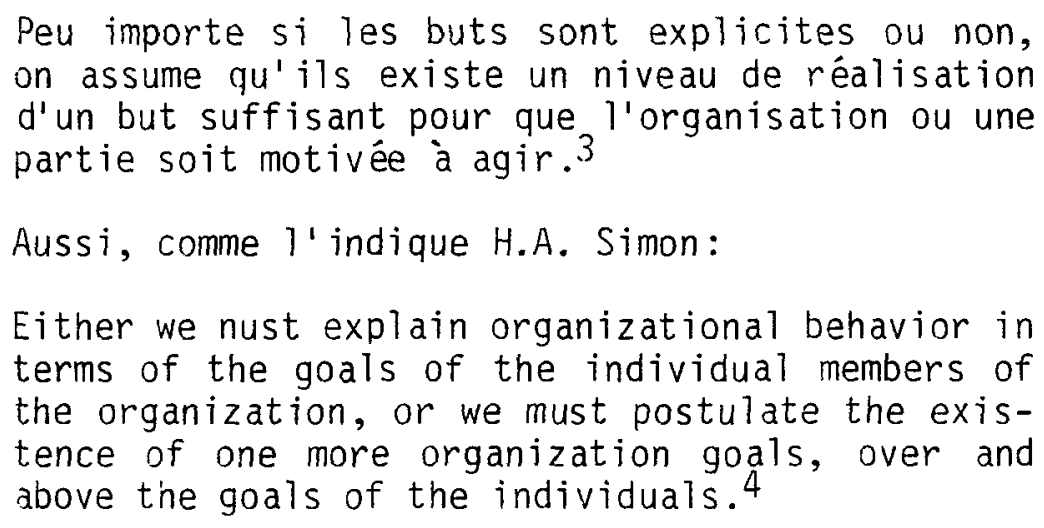

Either we nust explain organizational behavior in terms of the goals of the individual members of the organization, or we must postulate the existence of one more organization goals, over and above the goals of the individuals. 4

Ces quelques remarques nous démontrent à quel point cette étape doit être reprise par l'assemblée générale.

D) DEFINIR LES OBJECTIFS

La définition des objectifs représente une étape inexistante au sein de la CMAAT, même à ses débuts. Nous n'avons retrouvé, dans aucun document, des objectifs précis et quantifiés. Même au cours des assemblées générales spéciales, les membres ne parvenaient pas à préciser dans le temps quels "outputs" ils voulaient obtenir.

3.Organization Design, Op. cit., p. 6.

4.SIMON, H.A., "On the concept of organizational goal" in Administrative Science Quater ly, 9, p. 2. 
E) ELABORER UN PROGRAMME D'ACTION

A toutes les années, en collaboration avec la directrice générale, le conseil d'administration procédait à l'élaboration d'un programme d'actions. Par contre, compte tenu que les étapes précédentes étaient escamotées, nous doutons de la validité de ce programme d'action. Enfin, nous avons pu remarquer que celui-ci comportait des activités très variées, qui dénotaient une absence d'orientation précise au sein de cet organisme. 
CHAPITRE 12 
CHAPITRE 12

RECOMMANDATIONS

Dans un regroupement, l'effet de synergie doit pouvoir ámaner de façon telle que, les membres puissent sentir que seul le groupe leur permettra d'atteindre l'objectif visé.

A la CMAAT, I'hétérogénéité des membres annule l'effet de synergie. Dans le modèle conceptuel proposé, la première étape consistait à cerner une cible commune. Dès cette étape, les membres de la CMAAT se sont heurtés à un obstacle. Deux conditions devaient être respectées, soit viser un objectif commun et croire en la nécessité de l'énergie groupale pour atteindre cet objectif. Bien que la très grande majorité des artisans veulent écouler leur production d'oeuvre d'art, le regroupement $n^{\prime}$ apparait pas comme la solution pour atteindre cet objectif. Les artisans se différencient nettement les uns des autres, soit par leur famille de métiers, leur motivation à produire ou à vendre, leur besoin de formation, etc. En fait, les artisans sont des individualistes éprouvant des problèmes personnels qu'eux seuls peuvent régler individuellement.

Les membres pourraient encore tenter à nouveau de se découvrir une cible commune. Par contre, à deux reprises en 1987, année où le chercheur effectuait son intervention, les membres du Conseil d'administration ont invité les artisans à se prononcer. La participation fut faible et les quelques artisans présents n'ont même pas réussi à identifier la cible commune visée par ce regroupement. De 
cette première étape, fort importante, découlent toutes les autres. Les membres ne réussissant pas à identifier une cible commune, comment peut-on présenter la CMAAT comme une organisation?

Nous recommandons la dissolution de la CMAAT. Nous croyons en effet que l'enveloppe budgétaire destinée aux métiers d'art apportera de meilleurs résultats si elle sert à des projets individuels spécifiques.

La préoccupation première des artisans tient dans la vente de leur production. C'est d'ailleurs pour cette raison qu'en 1980 , la charte fut amendée pour permettre l'ouverture d'une boutique communautaire. Pour des raisons financières, la boutique a dû fermer ses portes en octobre 1985. Le sondage (annexe 2) effectué par le chercheur en novembre 1985, a démontré une fois de plus que les artisans veulent vendre. Par contre, il a aussi permis de constater que la motivation à cet égard $n$ 'est pas la même pour tous. Il rapporte en effet que $25,7 \%$ des répondants pratiquent leur discipline à titre de premier revenu personne1, 25,7\% à titre de second revenu personne1, $25,7 \%$ a titre de passe-temps et $22,9 \%$ pour autre fin. Ceux qui cherchent à vivre de leur métier sont, en général, prêts à déployer beaucoup plus d'efforts pour vendre leur production, pour suivre l'évolution du marché, pour se former, etc.

Dans cette situation, les artisans doivent comprendre qu'il revient à chacun, individuellement, de trouver des solutions pour 
écouler sa production selon son objectif de vente. Cette constatation n'empêche pas les artisans de se regrouper pour profiter d'un lieu de diffusion bien précis.

Les salons des métiers et les expositions peuvent devenir des lieux de diffusion avantageux pour eux. Ils permettent de rencontrer les consommateurs et de vérifier leurs goûts. Rappelons-nous que la recherche effectuée dans le cadre du programme "Outil de gestion" rapportait que les expositions demeuraient le lieu préféré des artisans. Par contre, ces derniers leur reprochaient leur caractère temporaire, et le fait qu'elles pouvaient s'avérer dispendieuses dans certains cas. Quelques artisans ayant des affinités pourraient aussi décider de se regrouper pour partager les frais d'un kiosque.

D'autres solutions peuvent également être envisagées. Un groupe d'artisans de la même famille de métier pourrait chercher un lieu adéquat pour exposer en permanence. Citons 1 'exemple du groupe d'art visuel témiscamien, l'Artouche, qui expose en permanence ses oeurres dans l'édifice de la MRC, à Ville-Marie. A 1'année longue, les personnes travaillant dans l'édifice et les visiteurs peuvent apprécier la production de ces artistes. Cette visibilité fait penser qu'une oeurre d'art peut constituer un excellent cadeau, pour soi ou quelqu'un en particulier. De plus, les initiateurs de cette activité constatent qu'elle représente un excellent moyen pour cultiver les goûts du public. 
Ce moyen pourrait s'appliquer à certaines familles de métiers d'art. Pourquoi les poupées de chiffon ne seraient-elles pas exposées dans des endroits pour les enfants? Par exemple, les garderies et l'étage de la pédiatrie à l'hôpital seraient à cet égard des lieux privilégiés. Chaque artisan pourrait ainsi réfléchir sur ce mode de diffusion. L'important à retenir est que l'endroit doit être fréquenté régulièrement par la clientèle cible. Car il faut comprendre que la visibilité d'une oeurre d'art tente les consommateurs, ce qui s'impose dans la mesure où toute oeuvre demeure un luxe que l'on s'offre à l'occasion seutement.

Les boutiques privées constituent un autre lieu de diffusion devant être considéré. Il faut, par contre, bien choisir la boutique afin de s'assurer qu'elle s'adresse à la même clientèle. Il serait intéressant que les produits des artisans soient complémentaires à ceux vendus par la boutique. Par exemple, les foulards, dans les boutiques de vêtements pour dames, les bijoux de qualité, dans des boutiques de vêtements de haut de gamme et/ou exclusifs, des bonbonnières en poterie, dans des confiseries, etc. Encore une fois, il revient à chaque artisan ou groupe d'artisans de trouver la boutique qui réponde aux critères établis dans son domaine.

Dans la recherche effectuée dans le cadre du programme "Outil de gestion", les boutiquiers reprochaient aux artisans leur manque de professionnalisme. Chaque artisan ou groupe d'artisans devra 
rétablir ce climat de confiance en respectant les conditions émises par les boutiquiers. A court terme, il peut sembler difficile pour les artisans d'effectuer cette tâche. A long terme, cependant, nous croyons qu'elle apportera des résultats.

Cette courte réflexion sur les moyens de diffusion possibles pour les artisans nous a permis de mettre à jour quelques idées. Ainsi sommes-nous convaincus que chaque artisan peut trouver les lieux de diffusion qui lui conviennent. Il devra toutefois être honnête avec lui-même pour savoir si c'est son moyen de diffusion qui est inadéquat ou si sa production ne répond pas aux goûts des consommateurs, le cas échéant. Si cette dernière hypothèse est retenue, l'artisan devra évaluer sa production (la qualité, le style, etc.). Car les artisans n'échappent pas à la loi de l'offre et de la demande. Aussi doivent-ils parfois revoir leurs techniques de production, envisager un perfectionnement, etc.

Nous insistons sur le fait que cette recherche ne conclut pas que les artisans n'ont pas besoin de 1'aide financière du ministère des Affaires culturelles. Mais elle démontre tout de même que le regroupement des artisans en corporation n'est pas la meilleure $f$ açon de leur venir en aide. Nous proposons donc que le MAC octroie l'aide financière habituelle à des projets particuliers tels le développement d'une nouvelle technique, la formation, des études de marché, etc. L'enveloppe budgétaire ainsi partagée permettrait un meilleur développement des métiers d'art en Abitibi-Témiscamingue. 
CHAPITRE 13 
CHAPITRE 13

REFLEXION SUR LA METHODOLOGIE

\subsection{GENERALITES}

Dans ce mémoire, nous avons eu recours à la méthodologie des systèmes souples de Peter B. Checkland, professeur à Lancaster. Cette méthode a été conçue pour s'attaquer à des situations complexes et peu structurées, particulières aux PMO (PME, Coop, organisme communautaire, petite et moyenne organisation publique et para-publique). La Corporation des métiers d'art de l'Abitibi-Témiscamingue était un organisme communautaire sans but lucratif qui vivait un problène complexe.

Dans un premier temps, Checkland suggère de prendre contact avec le milieu problématique en décrivant ce dernier en terme de processus et de structure. Cette première partie nous a permis d'obtenir une représentation riche de la situation. Dans un deuxième temps, le chercheur choisit un point d'ancrage particulier, à partir duquel un modèle conceptuel est élaboré à l'aide d'une approche systémique. Enfin, dans un troisième temps, il utilise le modèle conceptuel comme cadre théorique, comme cadre de réflexion, et il le compare à l'image riche. Ainsi, le chercheur peut-il identifier les lieux de changement et tenter d'effectuer les modifications nécessaires. 


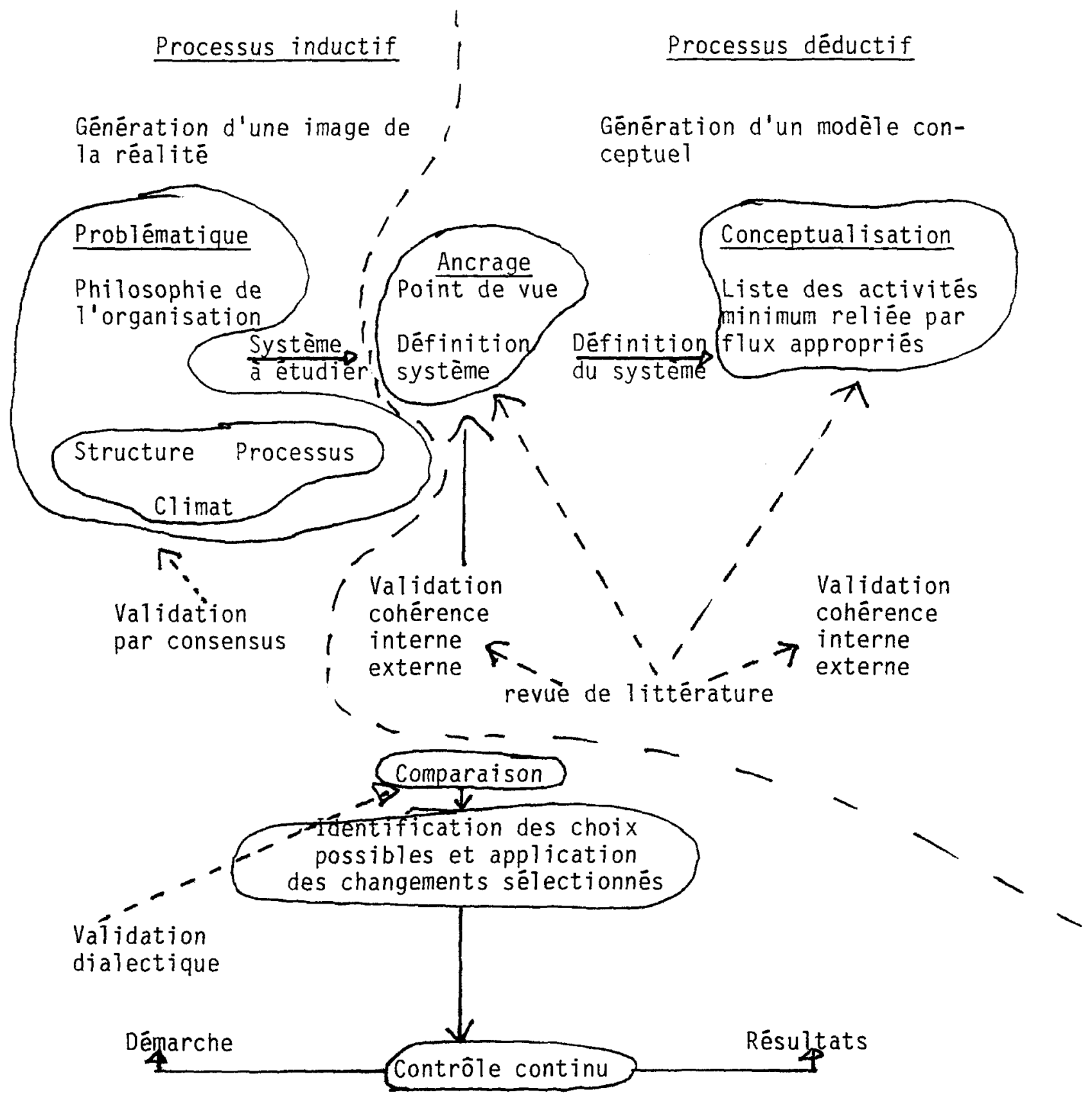

FIGURE 10: Méthodologie systémique de diagnostic organisationnel 


\subsection{LE MANDAT}

Pour qu'un chercheur se voit confier un mandat par une organisation, il faut préalablement que celle-ci se sente confrontée à une situation problématique. Or, c'est au cours de la première rencontre portant sur le mandat que le chercheur connaitra cette problématique.

Les problèmes sont des constructions abstraites et des modèles simplifiés de 1 a réalité. Ces constructions et ces simplifications reflètent nécessairement, et à un degré plus ou moins grand la personnalité, la culture, les objectifs et les ambitions de celui qui définit le problème. 1

Ainsi, les buts et les objectifs du système à étudier peuvent être différents selon les intervenants. Il est donc important pour le chercheur de bien identifier ces intervenants, qui ne forment pas nécessairement un tout homogène.

Il faut faire la distinction entre le décideur du système à diagnostiquer et le client de ce même système.

Décideur: il dispose de ressources qui seront en partie mises à la disposition du spécialiste.

Client: $\quad$ il est celui pour qui le système est diagnost iqué, il en est le bénéficiaire.

1.MALOUIN, J.-L. et LANDRY, M., Des symptômes aux problèmes par 1a démarche systémique, document de travai1, novembre 1979. 
Acteurs: ce sont les personnes ou les agents qui exécutent ou font exécuter les activités du système à diagnostiquer.

Au moment de la négociation du mandat, il était ardu d'identifier les intervenants. D'une part, l'assemblée générale pouvait être perçue comme le décideur, car, formellement, elle détient le pouvoir au sein de la CMAAT. D'autre part, le bureau régionai du ministère des Affaires culturelles avait proposé l'étude et acceptait de la financer. Cette dernière hypothèse fut donc retenue at le MAC fut contacté afin de négocier le mandat. Mais selon lui, le décideur devenait bel et bien l'assemblée générale, le bureau ne s'avérant que le support financier. Et finalement, le mandat fut négocié avec le Conseil d'administration de la CMAAT (annexe 1).

Par contre, en cours de mandat, certains faits ont démontré que le décideur était à vraj dire le MAC comme nous le pensions au début. En effet, la survie de la CMAAT dépendait dans une large mesure des subventions octroyées par le MAC.

\section{3 L'IMAGE RICHE}

Cette première étape vise à présenter le milieu problématique avec le plus de précision possible. Il faut décrire la situation dans laquelle un malaise est perçu, sans toutefois l'analyser. Le chercheur doit adopté une attitude de neutralité. Ainsi, évitera-til de modifier la réalité en l'insérant dans un cadre pré-structuré trop rigide, ou en privilégiant un point de vue particulier. 
Cette première condition fut respectée sans aucune difficulté par le chercheur. Celui-ci ne travaillait pas dans l'organisation et $n^{\prime}$ entretenait aucun lien avec les différents intervenants impliqués.

La première tâche du chercheur fut d'identifier les principaux intervenants et de les rencontrer pour connaitre leurs perspectives. Nous avons donc rencontré:

- l'ancienne et la nouvelle directrice générale;

- le personnel du bureau régional du MAC;

- Ia directrice régionale du Conseil de la culture;

- les membres du Conseil d'administration de la CMAAT;

- les artisans membres de cet organisme;

- les responsables des salons des métiers d'art;

- la consultante externe de l'organisation (comptabilité).

Les membres-artisans furent rencontrés à quelques reprises aux assemblées générales spéciales et annuelles. Etant donné le manque de participation lors de ces réunions, le chercheur a procédé à un sondage par courrier. Dans l'annexe 2, vous trouverez le questionnaire et les résultats de ce sondage.

Par la suite, il a vérifié certaines de ces informations et en a recueilli d'autres par le biais de la documentation existante à 1a CMAAT. Cette tâche s'est avérée très fastidieuse étant donné la quantité de documents à consulter. Cette recherche a débouché sur 
d'autres questionnements. Le chercheur a donc rencontré certains des intervenants à plusieurs reprises et a même cru essentiel de participer à une rencontre du Conseil des métiers d'art à Québec.

Tout au long de l'étude, le chercheur était invité à assister en tant qu'observateur aux réunions du Conseil d'administration et aux assemblées générales. Cette présence lui permettait de cerner le processus de décision. Par contre, il lui fallait éviter d'influencer les décisions afin de demeurer impartial tout au long de l'intervention.

En mars 1986, le chercheur avait terminé l'élaboration de l'image riche. Il a donc convoqué une réunion spéciale du Conseil d'administration afin de procéder à la validation de cette première étape. Il appréhendait quelque peu cette première validation, car le portrait de la CMAAT était plutôt négatif. Sans aucune insistance de la part du chercheur, les membres du Conseil d'administration ont validé cette image riche: "C'est un portrait triste mais réel!", disaient-ils.

Ces derniers se sont montrés très satisfaits de cette présentation. Lors de cette même réunion, le chercheur leur a expliqué de nouveau la méthodologie suivie. Il a insisté sur la démarche d'une recherche-action, qui nécessite la participation des divers intervenants : 
Les chercheurs et les acteurs, conjointement, investiguent systématiquement une donnée et posent des actions, en vue de solutionner un problème immédiat vécu par les acteurs et d'enrichir le savoir cognitif, le savoir-faire et le savoirêtre, dans un cadre d'éthique mutuellement accepté.2

Soulignons que ce même exercice fut répété lors de l'assemblèe générale annuelle, tenue le ler juin 1986.

\subsection{ANCRAGE ET CONCEPTUALISATION}

Contrairement à beaucoup d'autres méthodes, qui n'énoncent pas de règle opérationnelle de simplification du réel perçu, celle de Checkland le fait en faisant ressortir la nécessité de choisir un point d'ancrage, une perspective, un angle particulier et privilégié pour l'examen d'une situation. Cette perspective privilégiée doit être sélectionnée par les intervenants eux-mêmes.

Au cours de la réunion de mars 1986, les membres du Conseil d'administration et le chercheur ont retenu le problème de planification comme zone problématique à étudier.

A cette étape, les acteurs et le chercheur n'ont pas discuté du système pertinent, en terme de détermination d'une organisa-

2. PREVOST, PauT, Le diagnostic-intervention: une approche systémique du diagnostic organisationnel et a la recherche-action, Chicoutimi, UQAC, 1983, p. 34 . 
tion. Ils ont, par contre, abordé certains éléments de ce processus (choix d'une mission, buts, objectifs, etc.).

Lors de l'assemblée générale annelle du ler juin 1986, quelques questions furent proposées aux participants (annexe 5). Ce modèle représentait une première esquisse. Afin de l'améliorer, le chercheur a procédé à une revue de littérature. Le modèle conceptuel du chapitre 10 est ainsi basé sur un cadre théorique très rigide.

\subsection{COMPARAISON ET RECOMMANDATIONS}

Après l'élaboration du modèle conceptuel, la méthodologie de Checkland prévoit de le comparer avec la réalité. Cet exercice fut effectué au cours de l'assemblée générale spéciale tenue en octobre 1986. Comme beaucoup d'émotions étaient ressenties lors de cette dernière réunion, le chercheur a repris l'étape avec le nouveau Conseil d'administration.

Les acteurs ont avoué qu'effectivement, ils n'avaient jamais cerné une cible commune. Et même après une longue discussion, les membres présents n'ont pas réussi à s'entendre sur une cible commune. A la suite de ces rencontres et en se basant sur plusieurs faits soulignés dans l'étude, le chercheur n'a pas cru valable d'essayer de nouveau de cerner une cible commune. Il a recommandé la fermeture de ce regroupement d'artisans.

\subsection{VALIDATION D'UNE RECHERCHE-ACTION}

Le chercheur veut s'assurer à cette étape que le mémoire présenté corresponde à une recherche-action. Pour procéder à cette 
validation, nous allons comparer l'intervention réalisée à la CMAAT avec cinq postulats du Groupe d'étude sur la recherche-action.

\section{Premier postulat}

La recherche-action doit être un processus d'investigation d'un donné et de pose d'action. En d'autres mots, $i 1$ doit y avoir recherche( $s$ ) et $\operatorname{action}(s){ }^{3}$

Le diagnostic présenté ici respecte ces deux premières conditions. D'une part, une recherche fut effectivement effectuée. ETle incluait un processus inductif (élaboration d'une problématique) et un processus déductif (conceptualisation). D'autre part, on peut parler d'action dans cette intervention. En effet, comme on I'a expliqué tout au cours de l'étude, le chercheur entretenait des relations étroites avec les différents intervenants. Ceux-cj étaient toujours impliqués à chaque étape. Incidemment, au fur et à mesure qu'une donnée nouvelle ressortait, les acteurs pouvaient ajuster certains éléments. Ainsi, de plus en plus, le Conseil d'administration s'efforçait d'éviter d'élargir ses champs d'intérêt. De même, dans sa demande de subvention, il a tenté d'inclure des objectifs.

3. Groupe d'étude sur la recherche-action, Vers une définition de la recherche-action, LEER, novembre 1981. 


\section{Deuxième postulat}

La recherche-action doit reconnaître deux entités distinctes et actives dans l'acquisition du savoir: un ou des acteurs, un ou des chercheurs. 4

Sans aucun doute, on peut affirmer que ce postulat fut respecté. Tout au cours de l'intervention, le chercheur et les acteurs travaillaient souvent ensemble. D'un côté, le chercheur a recueilli beaucoup d'informations auprès des acteurs, afin de connaître les liens que 1 a CMAAT entretenait avec son environnement, ses structures, ses processus, etc. De l'autre, les acteurs ont pu profité de l'expertise du chercheur et de la revue de littérature réalisée.

\section{Troisième postulat}

La recherche-action doit solutionner un problème immédiat vécu par les acteurs. 5

Pour que la CMAAT ressente la nécessité de profiter d'une expertise externe, il fallait au préalable qu'elle soit confrontée à une situation problématique. Effectivement, au moment du mandat, e 1le venait de décider de fermer la boutique communautaire. Le Conseil d'administration était quelque peu désorienté et voulait une expertise pour l'aider à restructurer la CMAAT.

4. Idem.

5. Idem. 
Comme le mandat l'indiquait, le consultant devait émettre des recommandations dans le but de rendre efficiente la CMAAT, au point de vue des services qu'elle offrait aux artisans. Mais le diagnostic a démontré que ce regroupement ne pouvait identifier une cible commune. Conséquemment, il ne répondait pas aux critères $d^{\prime}$ une organisation. Le chercheur a donc dû recommander la fermeture de celui-ci.

La recherche-action ne demeure pas moins valable. Le processus démontre bien que, dans les circonstances, la fermeture de la CMAAT S'avérait la meilleure solution. Le chercheur peut affirmer qu'il a solutionné un problème immédiat vécu par les acteurs.

\section{Quatrième postulat}

La recherche-action doit se définir un cadre éthique, méthodologique et théorique, mutuellement accepté par le ou les acteur(s) et le ou les chercheur(s). 6

Le chercheur s'est inspiré de 1 a méthodologie de Checkland pour procéder à ce diagnostic. Déjà, lors de la première rencontre avec le mandant, le chercheur a décrit les bases de cette méthodologie. Il a aussi montré quels étaient les avantages de cette méthode et exprimé pourquoi il la privilégiait. Par la suite, il a êlaboré un plan de travail, dans lequel on retrouvait toutes les étapes du processus.

6. Idem. 
Pour s'assurer que le mandant comprenait bien les fondements de la méthodologie suivie, le mandataire en a souvent repris l'exposé. Après chaque étape, il expliquait ce qu'il venait de faire et décrivait comment 11 allait procéder par la suite.

\section{Cinquième postuTat}

La recherche-action doit enrichir le savoir cognitif, le savoir-faire et le savoir-être. ${ }^{7}$

Sans nui doute, cette recherche a enrichi le savoir cognitif du chercheur et des acteurs. La revue de littérature a en effet permis au chercheur de revoir et $d^{\prime}$ approfondir les bases de la théorie organisationnelle. Les acteurs ont aussi profité de cette couverture théorique par l'intermédiaire du chercheur.

Cette recherche a aussi enrichi le savoir-faire des acteurs et du chercheur. Du côtê des acteurs, le processus dé détermination d'une organisation leur a permis de faire le point sur leur propre organisation. Dès la première étape, soit la recherche d'une cible commune, ils se sont heurtés à une difficulté: ils devaient saisir cette notion. Parce que tous les artisans cherchaient à écouler leur production, ils croyaient que la CMAAT devait exister pour répondre à cet objectif commun. Mais la recherche-action leur a démontré que, même $s^{\prime} i l s$ visaient un même objectif, celui-ci ne répondait pas à

7. Idem. 
toutes les conditions d'une cible commune. Il fallait aussi que le regroupement soit nécessaire pour atteindre cet objectif. Or, plusieurs faits nous ont démontré que l'effet de synergie ne pouvait émaner de ce regroupement. Face à cette réalité, le chercheur a suggéré quelques pistes de solutions aux artisans, afin qu'ils organisent individuellement la vente de leurs produits. Du côté du chercheur, cette réflexion sur les bases d'une organisation lui a permis de remettre en question 1 a structure organisationnelle de sa propre organisation. Les outils développés dans cette recherche lui ont apporté des arguments pour motiver sa position devant ses confrères de travail.

Enfin, quoique plus difficile à visualiser, cette recherche a aussi enrichi le savoir-être des acteurs et du chercheur. Les acteurs sont maintenant sensibilisés aux critères de base d'une organisation. Ils adoptent une attitude beaucoup plus prudente dans leur recherche de mise en commun de services. Chez le chercheur, cette recherche a provoqué un changement d'attitudes face à toute organisation. Il se pose beaucoup plus de questions qu'auparavant sur l'effet de synergie pouvant émaner de différents regroupements. 
CHAPITRE 14 
CHAPITRE 14

GENERALISATION

La prêsente étude visait à diagnostiquer la Corporation des métiers d'art de 1'Abitibi-Témiscamingue et à élaborer les recommandations nécessaires pour la rendre efficiente au niveau des services qu'elle offrait aux artisans. Nous avons $v u q u^{\prime} i l$ apparaissait difficile qu'un effet de synergie puisse émaner d'un tel regroupement. L'étude concluait que les subventions destinées aux métiers d'art, en Abitibi-Témiscamingue, devraient être affectées à des projets individuels.

Cette réflexion sur la CMAAT nous amène à nous questionner sur la pertinence des corporations des mëtiers d'art dans tout le Québec. Rappelons-nous ici qu'au moment où cette recherche fut commandée, i1 ne restait que cinq des 12 corporations instituées par le ministère des Affaires culturelles. Par la suite, nous avons su que la Corporation de l'Estrie éprouvait elle aussi de sérieuses difficultés. Par contre, il semblait que les deux plus grandes corporations, Métiers d'art du Québec à Montréal (MAQAM) et la Corporation des métiers d'art du centre du Québec (CAQ), demeuraient dans une bonne position.

Ces quelques remarques nous laissent présumer que l'effet de synergie ne serait possible que dans ce type de corporation. Etant donné qu'elles comptent plusieurs artisans du même métier, il est plus probable que celles-ci puissent se définir une cible commune. 
BIBLIOGRAPHIE 
BENEDETTI, C., GUILLAUME, J., LAMONTAGNe, R., TURGEON, B., La dynamique de l'entreprise, Chomedey Laval, Mondia, 1981, $393 \mathrm{pp}$.

COTE, Abravanel, BELANGER, Jacques, Individu, groupe et organisation, Chicoutimi, Gaétan Morin Editeur, 1986, 440 pp.

CRENER, M. et MONTEIL, B., Principes de management, Sillery, Les Presses de l'Université du Québec, 1981, 531 pp.

CROZIER, M. et FRIEDBERG, E., L'acteur et le système, Viennes, Edition du Seuil, 1977, $436 \mathrm{pp}$.

DEVE, J.-C. et LE MOAL, J.-Y., Le guide du décideur, Paris, Les éditions d'organisation, $1985,228 \mathrm{pp}$.

ETZIONI, A., Modern Organizations, New Jersey, Prentice Ha11, 1963.

GAGNON, Dominique, Le développement organisationnel dans une perspective d'excellence, Montréal, Les éditions Agence d'Arc Inc., 1986, $119 \mathrm{pp}$.

GALBRAITH, Jay R., Organization Design, USA, Addison Wesley Publishing Company, 1977, $426 \mathrm{pp}$.

GRAVEL, Chantal, Base P lein-Air St-Gédéon, Chicoutimi, UQAC, décembre $1981,123 \mathrm{pp}$.

HAMPTON, David R., Management Third Edition, USA, MCGraw-Hill Book Company, $1986,765 \mathrm{pp}$.

HUNT, J.G., JAUCH, L.R. and OSBORN, N.R., Organization Theory - an Integrated Approach, Toronto, John Wi ley and Sons, 1980, 611 pp.

MILLER, Roger, La direction des entreprises: concepts et applications, Montréa7, McGraw-Hi11, 1985, $744 \mathrm{pp}$.

MINTBERG, Henry, Structure et dynamique des organisations, Montréal, Les éditions Agence d'Arc Inc., 1984, $434 \mathrm{pp}$.

PORTER, L., LAWLER, E., HACKMAN, R., Behavior in Organizations, NewYork, McGraw-Hi11, 1975, pp. 69-71.

SAINT-ARNAUD, Les petits groupes Participation et Communication, Montréa1, Les Presses de T'Université de Montréa1, 1978, $176 \mathrm{pp}$.

SALLENAVE, Jean-Paul, Direction générale et stratégie d'entreprise, Paris, Les éditions d'organisation, 1984, $277 \mathrm{pp}$. 
Revues

DEMEESTERE, R., et VIENS, G., "Le contrôle de gestion des organisations sans but lucratif" dans Revue française de gestion, no 6 , sept.-oct. 1976, pp. 14-24.

DESJARDINS, Marcel, "Le planning stratégique et structurel dans les PME" dans Recueil de cas et d'articles, no 1401, Tome II, Montréal, HEC, $20 \mathrm{pp}$.

DEWARRAT, Gérard, "La mesure d'efficience des organisations non profit (ONP): aspects et problèmes" dans Direction et gestion des entreprises, no 4, juillet-août 1984, p. 8-21.

GEORGIOU, P., "The Goal Paradigm and Notes Towards a Counter Paradigm" dans Administrative Science Quaterly, vol. 18, 1973, p. 291-310.

KENNETH, Andrews, "Le concept de stratégie d'entreprise" dans Encyclopédie du management, France, France Expansion Kluwer, 1973, vol. 1, $23 \mathrm{pp}$.

KIMBERLY, John, R., "Organizational Size and the Structuralist Perspective: A review, critique and proposal" dans Administrative Science Quaterly, vol. 21, no 4, décembre 1976.

LARCON, J.-P. et REITTER, R., "L'identité de l'entreprise, un facteur-clé de sa survie" dans Direction et gestion des entreprises, 15, no. 3, mai-juin 1979, pp. 11-16.

MALOUIN, J.-L. et LANDRY, M., Des symptômes aux problèmes par la démarche systémique, document de travail, novembre 1979.

PERROW, Charles, "Organizational Goals" dans Encyclopédia of Social Sciences, 11, N.Y., MacMil1an, p. 305-316.

PERROW, Charles, "The Analysis of Goals in Complex Organizations" dans American Sociological Review, vol. 26, 1961 , p. 854-866.

PREVOST, Paul, Le diagnostic-intervention: une approche systémique au diagnostic organisationnel et à la recherche-action, Chicoutimi, UQAC, 1983, $92 \mathrm{pp}$.

SELZNICK, Philip, "Au-delà du concept d'organisation" dans Encyclopédie du management, France, France Expansion Kluwer, 1973, vol. 1.

THOMPSON, J.-P. et MCEWEN, W. J., "Objectifs d'organisation et environnement" dans Psychologie sociale de A. Lévy, Paris, Dunod, $1958,10 \mathrm{pp}$.

XAVIER, Greffe, "La gestion du non marchand" dans Revue française de gestion, sept.-oct. 1979. 
COTE, BRIGITTE, La Corporation des métiers d'art de l'Abitibi-TémisCamingue, Rouyn-Noranda, UQAT, septembre 1985, 57 pp.

Comité national des métiers d'art, Document d'orientations pour 1a journée nationale des métiers d'art, Montréal, 1984, 58 pp.

, "La gestion d'organismes bénévoles", document de base, Montréal, Télé-Université, 1983.

Comité organisateur du Colloque, Colloque régional d'orientations des métiers d'art du Saguenay Lac St-Jean, sept' 85.

Groupe d'étude sur la recherche-action, Vers une définition de la recherche-action, LEER, novembre 1981.

, Document synthèse, Journée de réflexion et d'échan-

ge sur la situation des métiers d'art en Abitibi-Témiscamingue, mars 1984.

Comité Interministériel MIC-MAC, Pour une stratégie d'intervention dans le secteur des métiers d'art, octobre 1976.

MAC - Service des programmes régionaux, Mémoire sur la mise à jour des orientations en matière de métiers d'art et d'artisanat, ma 1985 .

Conférence des conseils régionaux de la culture du Québec, L'avenir des métiers d'art au Québec, mars 1984.

Procès-verbaux, rapports d'activités, correspondance, notes, etc. (Documents non paginés à consulter aux archives du MAC) 
ANNEXE 1

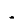


CONTRAT

entre

FRANCINE BESSETTE

et

LA CORPORATION DES METIERS D'ART DE L'ABITIBI-TEMISCAMINGUE

relativement à un diagnostique

de la Corporation des Métiers d'art de I'Abitibi-Témiscamingue 
CONTRAT exécuté en quatre (4) exemplaires à Rouyn, ce 25 ième jour du mois d'octobre 1985.

ENTRE Francine Bessette, étudiante au Programme de Mấtrise en gestion des petites et moyennes organisations de I'Université du Québec en Abitibi-Témiscamingue,

Partie de première part,

La Corporation des Métiers d'art de I'Abitibi-Témiscaminque renrésentée par son conseil d'administration,

Paxtie de seconde part.

1. Attentes du client

Emettre des suggestions dans le but de rendre la Cornoration des Métiers d'art de l'Abitibi-Témiscaminque efficiente au niveau

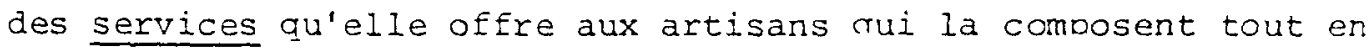
tenant compte de ses ressources financières et humaines, de ses grandes orientations gestionnaires et de son environnement socioéconomique. Le client veut s'assurer qu'il répond aux besoins de ses membres. Un système est efficient quand il fait "les bonnes choses". 
2. Principales étapes de l'étude

Dans la mesure du possible, le contractant s'inspirera de la méthodologie de diagnostic de Peter Checkland.

L'étude comportera deux principales étapes soit l'élaboration de la problématique et la recherche de solutions.

\subsection{L'élaboration de la problématique}

Dans cette première partie, le contractant prendra contact avec le milieu problématiaue.

\subsubsection{Description de l'organisme}

- Bref historique

- Mission

- Principales activités

- Structure et règlements internes

- Ses ressources humaines et financières

2.1.2 Description des artisans membres de la Corporation des Métiers d'art de l'abitibi-Témiscamingue

- Répartition géographique

- Répartition par secteur d'activité

- Principales source de revenu ou hobby

- Leurs attentes face à la Corporation des Métiers d'art de I'Abitibi-Témiscamingue 
2.1 .3 Description de l'environnement

- Environnement économique (le marché, la concurrence)

- Environnement physique (caractéristiques de la région)

- Environnement politique (politiques du Ministère des Affaires Culturelies)

\subsection{Recherche de solutions}

A partir de l'image riche (première partie) le contractant sera en mesure d'émettre des suggestions sur les grandes orientations que devrait prendre la Corporation des Métiers d'art de I'Abitibi-Témiscamingue.

3. Méthodologie utilisée

- Lecture des procès-verbaux des réunions du conseil d'administration de la Corporation des Métiers d'art d'AbitibiTémiscamingue.

- Assistance aux réunions du conseil d'administration de la Corporation pour la durće de l'étude.

- Rencontre avec les princinaux intervenants (le conseil d'administration - la Direction régionale du Ministère des Affaires Culturelles - les artisans).

- Documentation existante.

- Etc. 
4. Echéancier

Mai 1986 - Dépôt de I'image riche

Octobre 1986 - Dépôt du rapport final

5. Aspect financier

Honoraires professionnels (incluant les dépenses) Zan

Modalités de paiement

Décembre $1985-1 / 3$

Mai $1986-1 / 3$

Octobre $1986-1 / 3$

6. Entente

Le conseil d'administration de la Corporation des Métiers d'art de l'Abitibi-Témiscamingue s'engage à respecter ledit contrat.

Le conseil d'administration de la Corporation des Métiers d'art s'engage à fournir toutes les informations que le contractant jugera utiles.

Le contractant s'engage à respecter ledit contrat.

7. Signatures

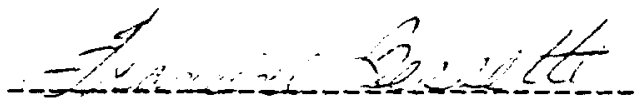

Francine Bessette

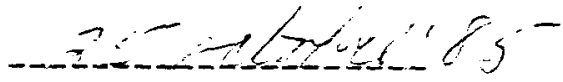

Date

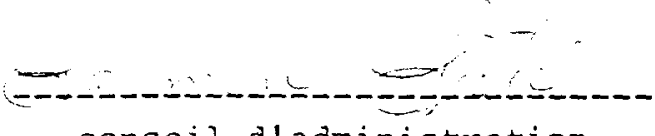

conseil d'administration

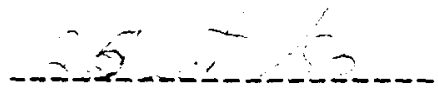

Date 
ANNEXE 2 
RECHERCHE SUR

LA CORPORATION DES METIERS D'ART

DE L 'ABITIB I -TEMISCAMINGUE

QUESTIONNAIRE DE L'ETUDE

A) Identification de l'artisan

1. Secteur géographique

1. Val-d'Or

2. Amos

3. La Sarre

4. Ville-Marie

5. Rouyn-Noranda

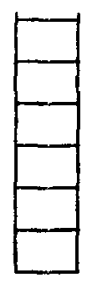

2. Votre groupe de métiers. Précisez votre discipline.

1. Textile, cuir et peaux

2. Silicates et métaux

3. Bois, pierre et produits nouveaux

4. Graphisme et techniques bidimentionnelles

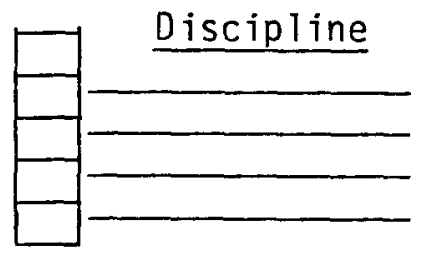

3. Que représente pour vous la pratique d'une discipline des métiers $d^{\prime}$ art?

1. Principal revenu personnel

2. Second revenu personnel

3. Hobby

4. Autre

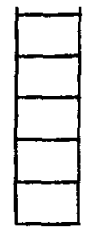


4. A combien évaluez-vous vos ventes de produits d'oeuvres d'art?
$0-1000$
$1000-5000$
$5000-10000$

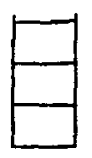
$10000-20000$
$20000-30000$
30000 et plus

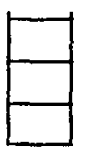

5. Parmi les éléments énumérés ci-dessous, quel serait celui qui vous aiderait le mieux à augmenter vos ventes de produits d'oeurres d'art?

1. Temps pour produire davantage

2. Etre plus familier avec les techniques de ventes

3. Mieux connaitre les conditions du marché et/ou les goûts des consommateurs

4. Plus de temps à consacrer à la recherche de nouveaux produits et/ou de nouvelles techniques

5. Autre(s) (spécifiez)

B) La Corporation des métiers d'art de l'Abitibi-Témiscamingue

1. Depuis combien d'années êtes-vous membre de la Corporation des métiers d'art de l'Abitibi-Témiscamingue?

$a n(s)$ 
2. Pourquoi êtes-vous devenu membre de la Corporation des métiers d'art de l'Abitibi-Témiscamingue? Si vous choisissez plus d'une réponse, inscrivez-les par ordre d'importance (un (1) étant 1a raison la plus importante et six (6) la moins importante).

1. Pour faire partie d'un groupe d'artisans reconnus

2. Pour vendre mes produits par l'intermédiaire de la boutique

3. Pour profiter d'un centre d'information et de documentation sur les métiers d'art

4. Pour participer à des activités de formation (stages, bourse de perfectionnement)

5. Pour profiter du service d'approvisionnement en matières premières

6. Autre(s) (spécifiez)

3. Avez-vous recommandé à d'autres artisans de devenir membre de la Corporation des métiers d'art de l'Abitibi-Témiscamingue?

1. OUI $\square$

2. NON

$\square$

Pourquo i? 
4. Au cours des années avez-vous cessé d'être membre de la Corporation des métiers d'art de l'Abitibi-Témiscamingue?
1. OUI
$\square$
2. NON
$\square$

Pourquo i?

5. Avez-vous recommandé à d'autres artisans de cesser d'être membre de la corporation des métiers d'art de l'Abitibi-Témiscamingue?
1. OUI
$\square$
2. NON

Pourquo i?

6. Les raisons pour lesquelles vous êtes devenu membre ont-elles changées au cours des années?
1. OUI
$\square$
2. NON

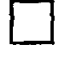


7. Quelle est maintenant la raison pour laquelle vous êtes membre de la Corporation des métiers d'art de l'Abitibi-Témiscamingue? Si vous choisissez plus d'une question, inscrivez-les par ordre d'importance (un (1) étant la raison la plus importante et six (6) la moins importante).

1. Pour faire partie d'un groupe d'artisans reconnus

2. Pour profiter d'un intermédiaire pour vendre mes produits (dans l'éventualité qu'un autre moyen de distribution soit mis sur pied)

3. Pour profiter d'un centre d'information et de documentation sur les métiers d'art

4. Pour participer à des activités de formation

5. Pour profiter d'un service d'approvisionnement en matières premières

6. Autre(s) (spécifiez)

8. Avez-vous participé à certaines activités organisées par la Corporation des métiers d'art de 1'Abitibi-Témiscamingue? Lesquelles?

1. Ventes de produits à la boutique

2. Programme d'aide à la création

3. Stages de perfectionnement

4. Colloque sur la vie d'artisan

5. Emprunt de Tivres

6. Approvisionnement en matières premières

7. Autre(s) (spécifiez)

8. Aucune 
9. Etes-vous satisfait des services rendus par la Corporation des métiers d'art de l'Abitibi-Témiscamingue?

1. OUI

2. NON

Pourquo i?

0 . Assistez-vous aux assemblées annuelles de la Corporation des métiers d'art de l'Abitibi-Témiscamingue?

1. OUI

$\square$

2. NON

Pourquo i?

1. Etes-vous intéressé à poser votre candidature à un poste au Conseil d'administration de 1 a Corporation des métiers d'art de l'Abitibi-Témiscamingue?

1. OUI

2. NON 
C) Autres organismes

1. Connaissez-vous d'autres organismes qui s'occupent du développement des métiers d'art?

1. OUI

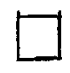

2. NON

Si oui, lesquels?

2. Etes-vous membre de d'autres organismes qui touchent les métiers $d^{\prime}$ art?

1. OUI $\square$

2. NON $\square$

Si oui, lesquelles?

Si non, pourquoi?

D) Commentaires et suggestions 


\section{REPONSES DES QUESTIONNAIRES}

A) Identification de l'artisan

1. Secteur géographique:

$\begin{array}{llr}\text { Val-d'Or } & : & 16,13 \% \\ \text { Amos } & : & 6,45 \% \\ \text { La Sarre } & : & 35,48 \% \\ \text { Ville-Marie } & : & 6,45 \% \\ \text { Rouyn-Nor anda: } & 35,48 \%\end{array}$

NOTE: Sur 41 questionnaires envoyés, nous en avons reçus 31.

2. Le groupe de métiers:

Textile, cuir et peaux

Silicates et métaux

Bois, pierres et produits nouveaux

Graphismes et techniques bidimensionnelles:

Autres
$: \quad 35,0 \%$

: $\quad 25,0 \%$

: $\quad 15,0 \%$

$\quad 22,5 \%$

: $\quad 2,5 \%$

3. Représentation de la discipline:

Principal revenu personnel: $\quad 25,7 \%$

Second revenu personne $1: 25,7 \%$

Hobby

: $\quad 25,7 \%$

Autres

: $\quad 22,9 \%$ 
4. Ventes de vos produits:

$\begin{array}{rr}0-1000: & 43,33 \% \\ 1000-5000: & 30,00 \% \\ 5000-10000: & 13,33 \% \\ 10000-20000: & 10,00 \% \\ 20000-30000: & 0,00 \% \\ 30000 \text { et plus : } & 3,33 \%\end{array}$

5. Quel facteur vous aiderait à augmenter vos ventes?

Temps pour produire davantage $\quad: \quad 26,8 \%$

Se familiariser avec les techniques de ventes : $12,5 \%$

Meilleures connaissances du marché et/ou des

goûts des consommateurs $\quad 17,9 \%$

Avoir plus de temps à la recherche de nouveaux

produits et/ou de nouvelles techniques : $\quad 5,3 \%$

Autres : $16,0 \%$

NOTE: Plusieurs personnes ont répondu plus d'un facteur.

B) La Corporation des métiers d'art

1. Depuis combien de temps êtes-vous membre?

1 an $: 2$

2 ans: 5

3 ans: 3

4 ans: 5

5 ans: 2

6 ans: 3

7 ans: 10 
2. Pourquoi êtes-vous devenu membre?

\begin{tabular}{|c|c|}
\hline Faire partie d'un groupe reconnu & $\begin{array}{l}: \quad 22 \text { réponses } \\
13 \# 1,6 \# 2\end{array}$ \\
\hline Vendre mes produits par boutique & $\begin{array}{l}26 \text { réponses } \\
14 \# 1,6 \# 2\end{array}$ \\
\hline Profiter d'un centre d'information & $\begin{array}{l}20 \text { réponses } \\
14 \# 1,6 \# 2\end{array}$ \\
\hline Participer aux activités de formation & $\begin{array}{l}18 \text { réponses } \\
1 \# 1,5 \# 2\end{array}$ \\
\hline Profiter du service d'approvisionnement & $\begin{array}{l}9 \text { réponses } \\
0 \# 1,2 \# 2\end{array}$ \\
\hline Autres & $\begin{array}{l}: \quad 2 \text { réponses } \\
0 \# 1,1 \# 2\end{array}$ \\
\hline
\end{tabular}

3. Avez-vous recommandê à d'autres artisans de devenir membre?

OUI: 24 , soit $77 \%$

Pourquoi? Les réponses sont variées, mais surtout pour la position de force qu'ils auront ensemble.

NON: 7 , soit $23 \%$

Pourquoi? Que cela ne profitait qu'à une minorité.

4. Avez-vous cessé de devenir membre?

OUI: 2, soit $6 \%$

Pourquo i? Mais ils sont revenus et la cause de leur cessation est qu'ils ont habité à l'extérieur de la région.

NON: 29 , soit $94 \%$

Pourquoi? 
5. Avez-vous recommandé à d'autres artisans de cesser d'être membre?

OUI: 3 , soit $10 \%$

Pourquo i? Voir la question précédente.

NON: 28 , soit $90 \%$

Pourquoi? Voir la question précédente.

6. Les raisons pour lesquelles vous êtes devenu membre ont-elles changées?

OUI: 5 , soit $16 \%$

NON: 26 , soit $84 \%$

Si non, passer à la question 8.

7. Quelle est maintenant la raison pour laquelle vous êtes membre de la Corporation? Inscrivez par ordre d'importance.

Faire partie d'un groupe reconnu : 3 réponses 1 \# 1,2 \# 3

Vendre mes produits par 1a boutique : 4 réponses

2 \# 1,1 \# 2

Profiter d'un centre d'information : 5 réponses 2 \# 1,2 \# 2

Participer aux activités de formation : 3 réponses 1 \# 2,1 \# 3

Profiter du service d'approvisionnement : aucune réponse

Autres

: 1 réponse

1 \# 4 
8. Avez-vous participé à certaines activités organisées?

Ventes de produits à la boutique : 28 réponses, soit $32,9 \%$ Programme d'aide à la création : 3 réponses, soit 3,6\% Stages de perfectionnement : 15 réponses, soit $17,7 \%$ Colloque sur la vie d'artisan : 11 réponses, soit 13,0\% Emprunt de livres : 12 réponses, soit $14,1 \%$ Approvisionnement : 11 réponses, soit 13,0\% Autres : 4 réponses, soit $4,7 \%$ Aucune : 1 réponse, soit $1,2 \%$ TOTAL : 85 réponses

NOTE: Plusieurs personnes ont fait plus d'une activité.

9. Etes-vous satisfait des services rendus?
OUI : 19 , soit $67.9 \%$
MOYEN : 4 , soit $14.3 \%$
NON : 6 , soit $21,4 \%$

10. Assistez-vous aux assemblées de la Corporation?

OUI : 20 , soit $66,7 \%$

MOYEN : 10 , soit $33,3 \%$

Pourquoi? Pour les nouveautés

11. Etes-vous intéressé à poser votre candidature?

OUI: $\quad 7$, soit $22,6 \%$

NON: 24 , soit $77,3 \%$

Pourquo i? 
C) Autres organismes

1. Connaissez-vous d'autres organismes qui s'occupent du développement des métiers d'art?

OUI: 16 , soit $53,3 \%$

NON: 14 , soit $46,7 \%$

2. Etes-vous membre de d'autres organismes qui touchent les métiers d'art?

OUI: 13 , soit $43,3 \%$

NON: 17 , soit $56,7 \%$

D) CORRELATION ENTRE DIFFERENTES QUESTIONS

1. Satisfaction versus origine:

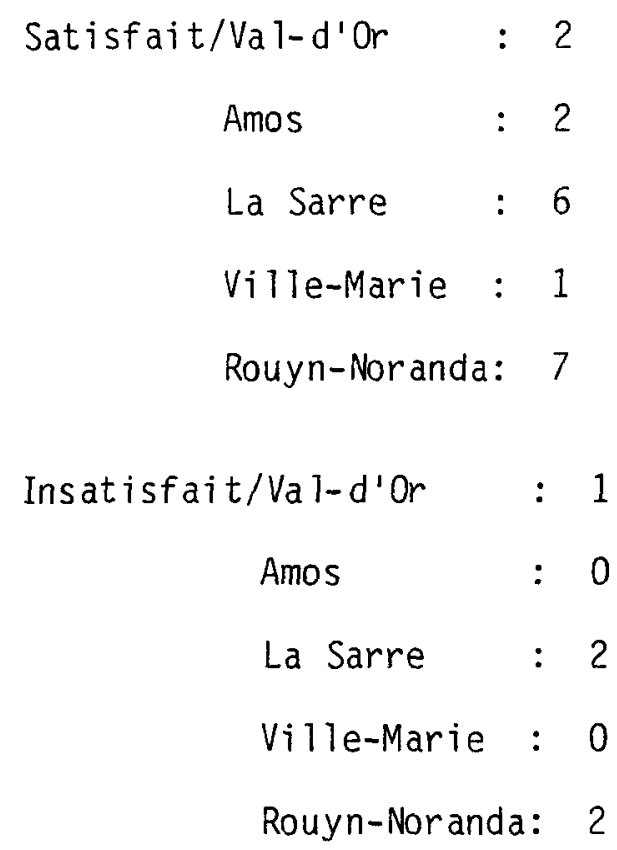


$1 / 2$ satisfait/Val-d'or $: 1$

Amos : : 0

La Sarre : 1

ville-Marie : 1

Rouyn-Noranda: 1

TOTAL: 27 réponses et 4 ont dû être rejetées.

2. Satisfaction versus revenu:

Satisfait/Principal revenu: 2

Second revenu : 4

Hobby $\quad: 6$

Autres : 4

Insatisfait/Principal revenu: 6

Second revenu : 1

Hobby : 0

Autres $\quad: 1$

1/2 satisfait/Principal revenu: 2

Second revenu : 0

Hobby $\quad: 0$

Autres $\quad: 0$

NOTE: 6 rêpondants ont été rejetés dû à la confusion de leur réponse et une personne $n^{\prime}$ a pas répondu. 
3. Satisfaction versus métiers

$$
\begin{aligned}
\text { Satisfait/Textile } & =7 \\
\text { Silicates } & : 3 \\
\text { Bois }: & 2 \\
\text { Graphisme }: & 0
\end{aligned}
$$

NOTE: En plus, il y a trois personnes qui sont satisfaites et qui ont plus d'un métier.

$$
\begin{array}{r}
\text { Insatisfait/Textile }: 1 \\
\text { Silicates }: 1 \\
\text { Bois }: 3 \\
\text { Graphisme }:
\end{array}
$$

NOTE: I I y a une personne insatisfaite et qui a deux métiers.

$$
\begin{aligned}
& 1 / 2 \text { satisfait/Textile }: 1 \\
& \text { Silicates : } 1 \\
& \text { Bois : } 1 \\
& \text { Graphisme : } 1
\end{aligned}
$$

NOTE: Il y a eu trois réponses qui ont été rejetées. 
TABLEAU I

SECTEUR GEEOGRAPHIQUE

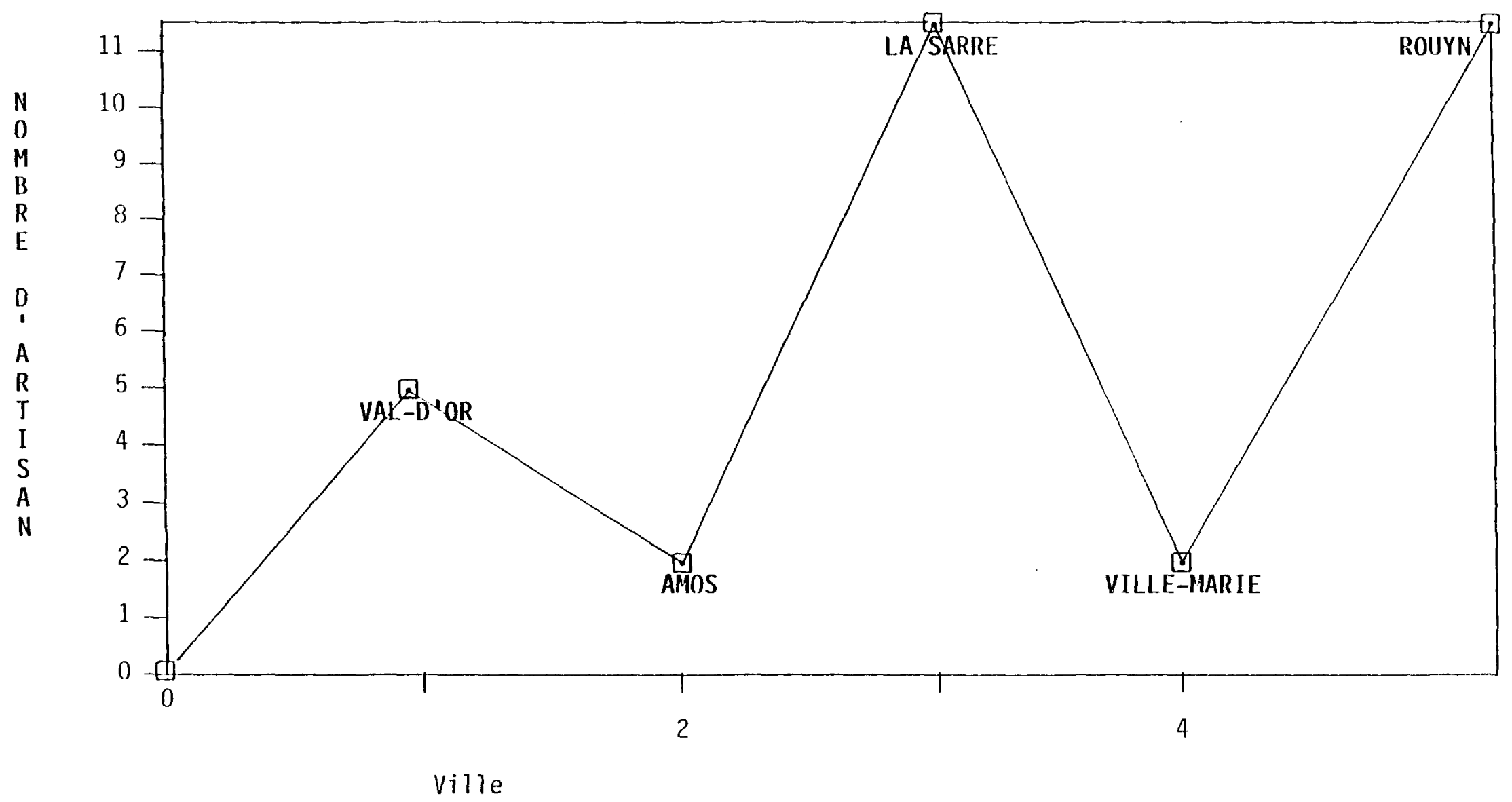


TABLEAU 2

DISCIPLINE

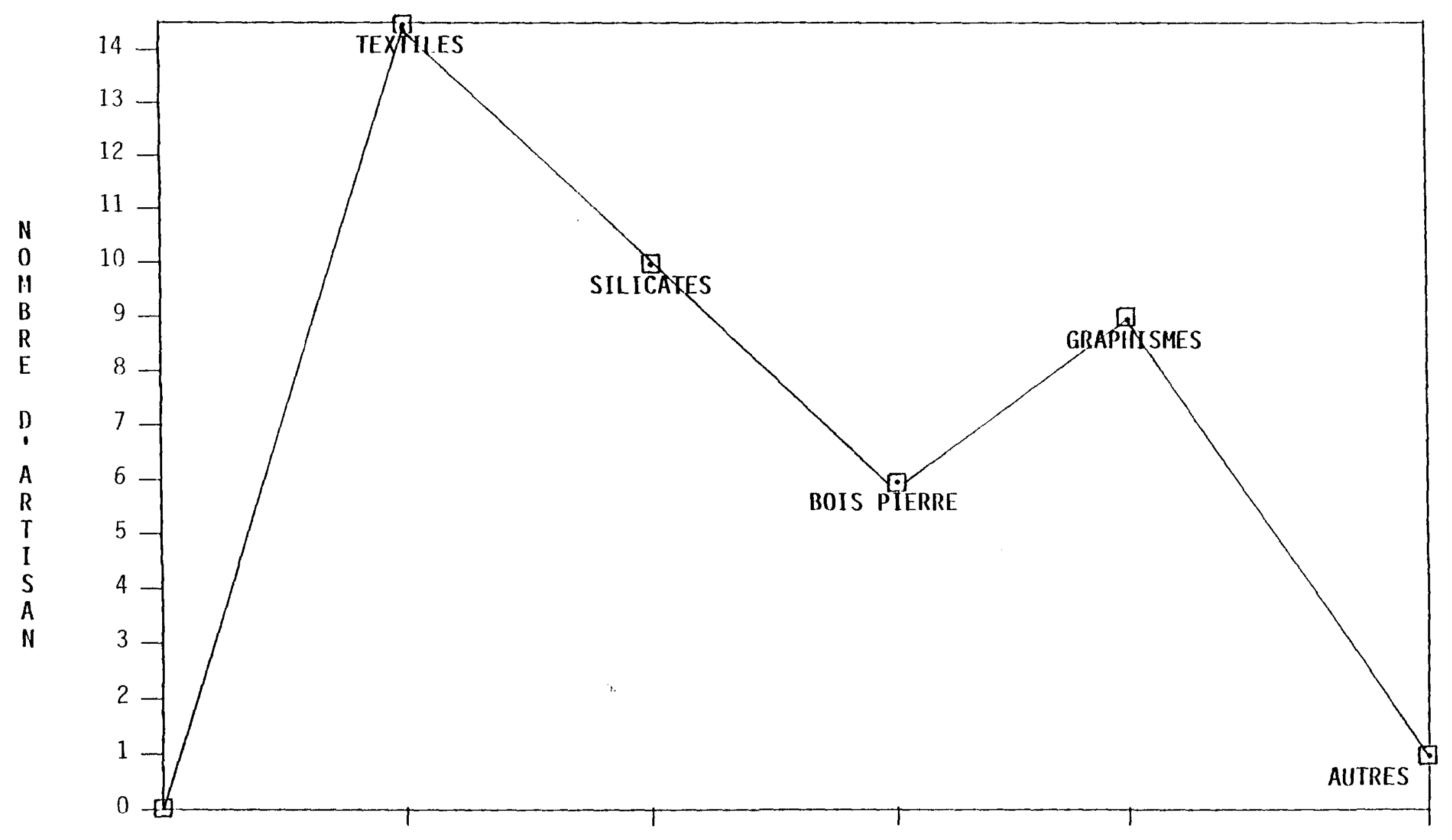




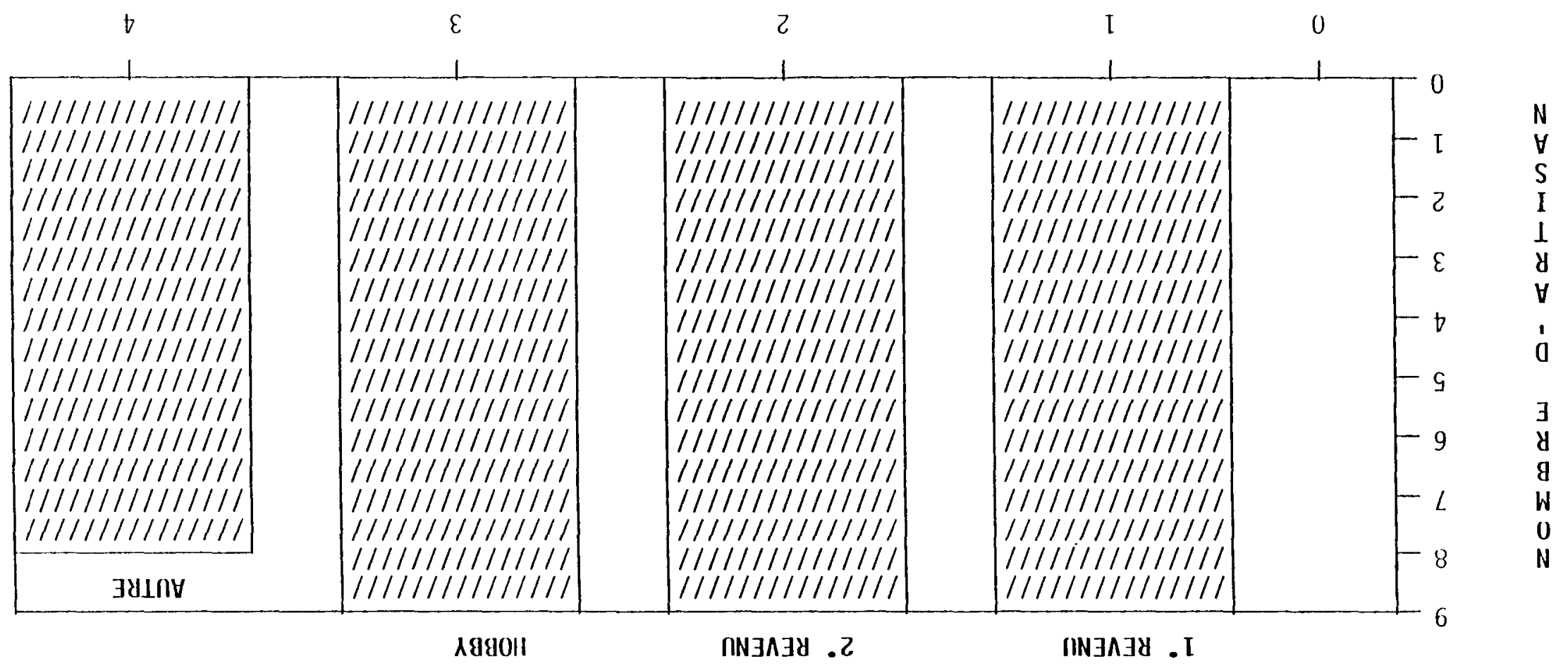

ヨyI

$\varepsilon \cap \forall \exists า g \forall \perp$ 
TABLEAU 4

VENTE DANS PRODUITS

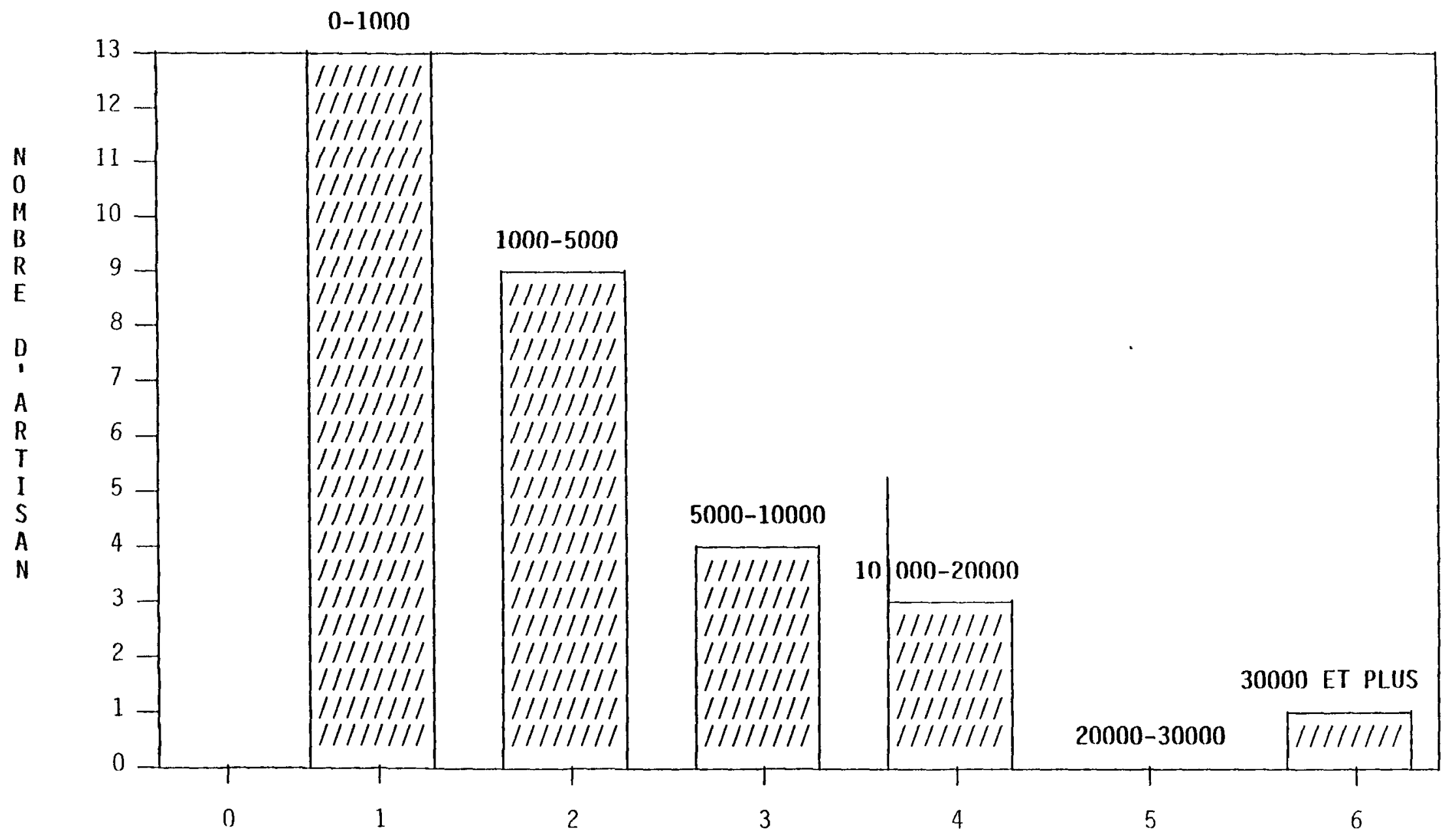


TABLEAU 5

OBJECTIF PRIMAIRE

VERSUS VENTES

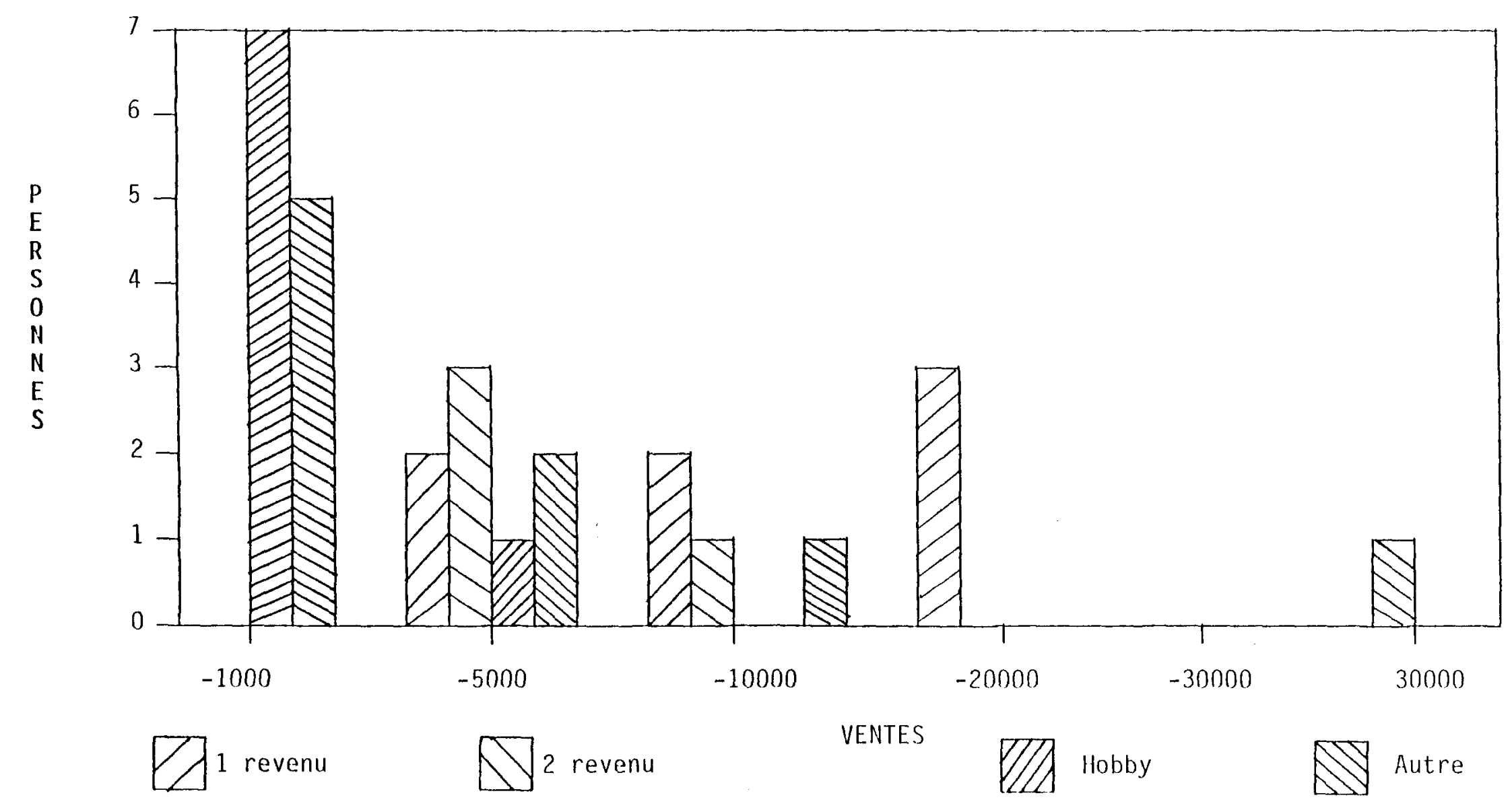


TABLEAU 6

RAISON DE DEVENIR MEMBRE

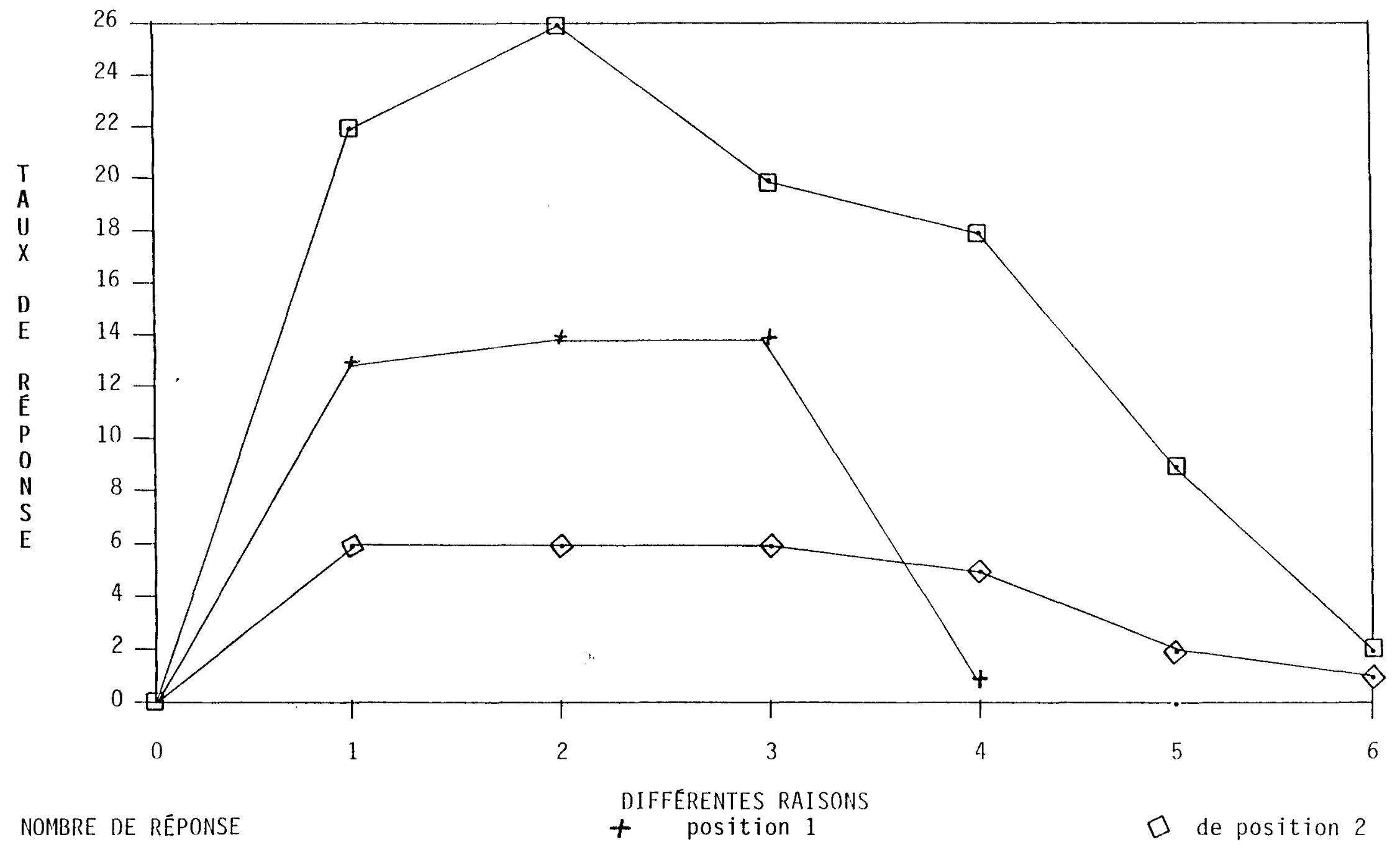


TABLEAU 7

PARTICIPATION AUX ACTIVITEES

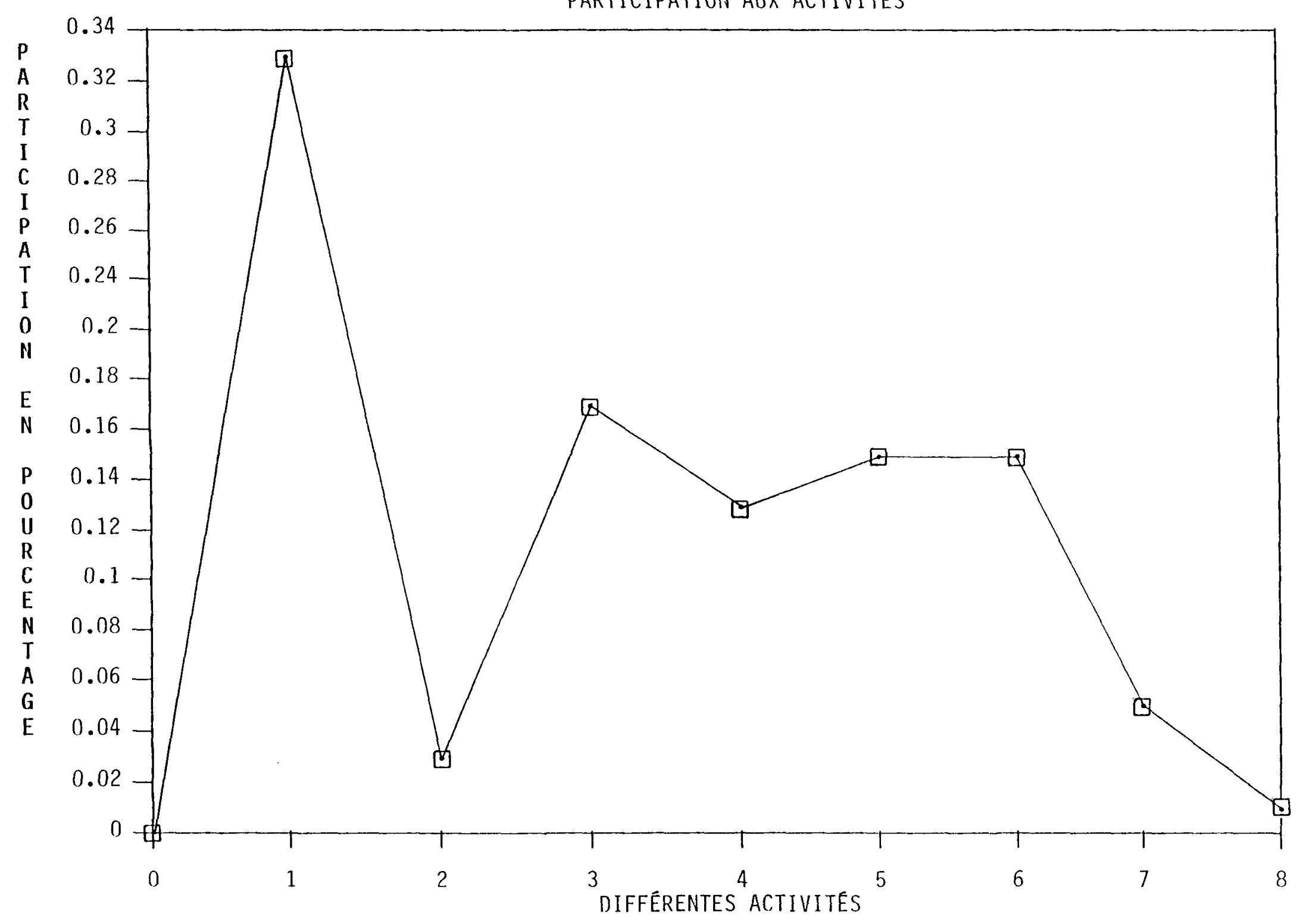


ANNEXE 3 
ANNEXE 3

LE PARTAGE

RENCONTRE DE REFLEXION DU 23 ET 24 JUILLET 1986

Comte tenu du peu d'artisans professionnels (de 30 à 40 personnes réparties sur plusieurs corps de métiers différents), la CMAAT ne peut pas réaliser les différentes tâches décrites dans la colonne "régionale".

Pour les éléments $(1.1,1.3,1.4,11.1)$, une collaboration avec le national est indispensable.

Pour les éléments 1.2 (identification de besoins en formation et perfectionnement), 11.2 (évēnements de diffusion) et 111.1 et 111.2 (relais régionaux et bulletin de liaison), il est possible de le faire en région en utilisant au maximum les ressources disponibles, dont Bill'Art et les services des centres d'exposition.

On s'aperçoit clairement que plusieurs services professionnels essentiels aux artisans (consolidation des corps de métier, formation, évaluation et étiquette de certification, services individualisés d'information, assurance-salaire, promotion) ne peuvent pas être offerts sur une base strictement régionale. 


\begin{tabular}{|c|c|c|c|}
\hline & $\begin{array}{c}\text { REGIONAL } \\
\text { (LES } 5 \text { CORPORAIIONS) }\end{array}$ & $\begin{array}{l}\text { POLES (EST - OUEST) } \\
\text { (QUEBEC - MONTREAL) }\end{array}$ & $\begin{array}{l}\text { COUSEIL } \\
\text { DES METIEISS D'ART }\end{array}$ \\
\hline$\underline{1.1}$ & $\begin{array}{l}\text { - planiffer et animer des réunions de familles } \\
\text { et de corps de métiers }\end{array}$ & $\begin{array}{l}\text { - consolidation des familles et des corps de } \\
\text { coetiers est/ouest }\end{array}$ & \\
\hline $\begin{array}{l}1.2 \\
\text { FORMATION \& } \\
\text { PERFECTIONMEMENT }\end{array}$ & $\begin{array}{l}\text { - renselgnements sur les cours } \\
\text { - lien avec les CFP en région } \\
\text { - perception besoins régionaux } \\
\text { - pré-inscription } \\
\text { - représentation au Comité national de } \\
\text { perceptions des besoins }\end{array}$ & $\begin{array}{l}\text { - coordonne les besoins est/ouest } \\
\text { - Stège au C.A. de CFCMA et IMA } \\
\text { - particlpe à l'élaboration des monographies } \\
\text { de cours a temps plein et à temps partiel } \\
\text { - négocle les contenus et les modalités } \\
\text { d'application des prograngines d'aide directe } \\
\text { à l'entreprise } \\
\text { - particfpe aux comités d'accréditation des } \\
\text { écoles-ateliers et atellers-écoles }\end{array}$ & - Comité National \\
\hline $\begin{array}{l}\text { EYALUATIOH \& } \\
\text { CONTROLE DE } \\
\text { QUALITE }\end{array}$ & $\begin{array}{l}\text { - évaluation réglonale } \\
\text { - rendre accessible à l'êvaluation nationale } \\
\text { - suivi national - contrôle de qualité } \\
\text { - respect du code d'éthique } \\
\text { - formation des évaluateurs }\end{array}$ & - source de références pour les régions & $\begin{array}{l}\text { - pilote le dossier } \\
\text { - étiquette de certification }\end{array}$ \\
\hline $\begin{array}{l}\text { SERYICES } \\
\text { INOIVIDUALISES }\end{array}$ & $\begin{array}{l}\text { - service de premlère ligne dans l'application } \\
\text { des programes gouvernementaux } \\
\text { - élabore les dossters et refére aux services } \\
\text { spéclalisés au besoln } \\
\text { - assurance-salaire } \\
\text { - renselgnements divers }\end{array}$ & $\begin{array}{l}\text { - sources références pour les réglons } \\
\text { - répond aux demandes des non-membres } \\
\text { est/ouest }\end{array}$ & $\begin{array}{l}\text { - revise et reconmande les modlfica- } \\
\text { tions a des programaes existants } \\
\text { (contenu et nodalites d'applica- } \\
\text { tion) } \\
\text { - recolnande les contenus et moda- } \\
\text { lites des nouveaux progranmes }\end{array}$ \\
\hline
\end{tabular}


il - agent econohique et culturel.

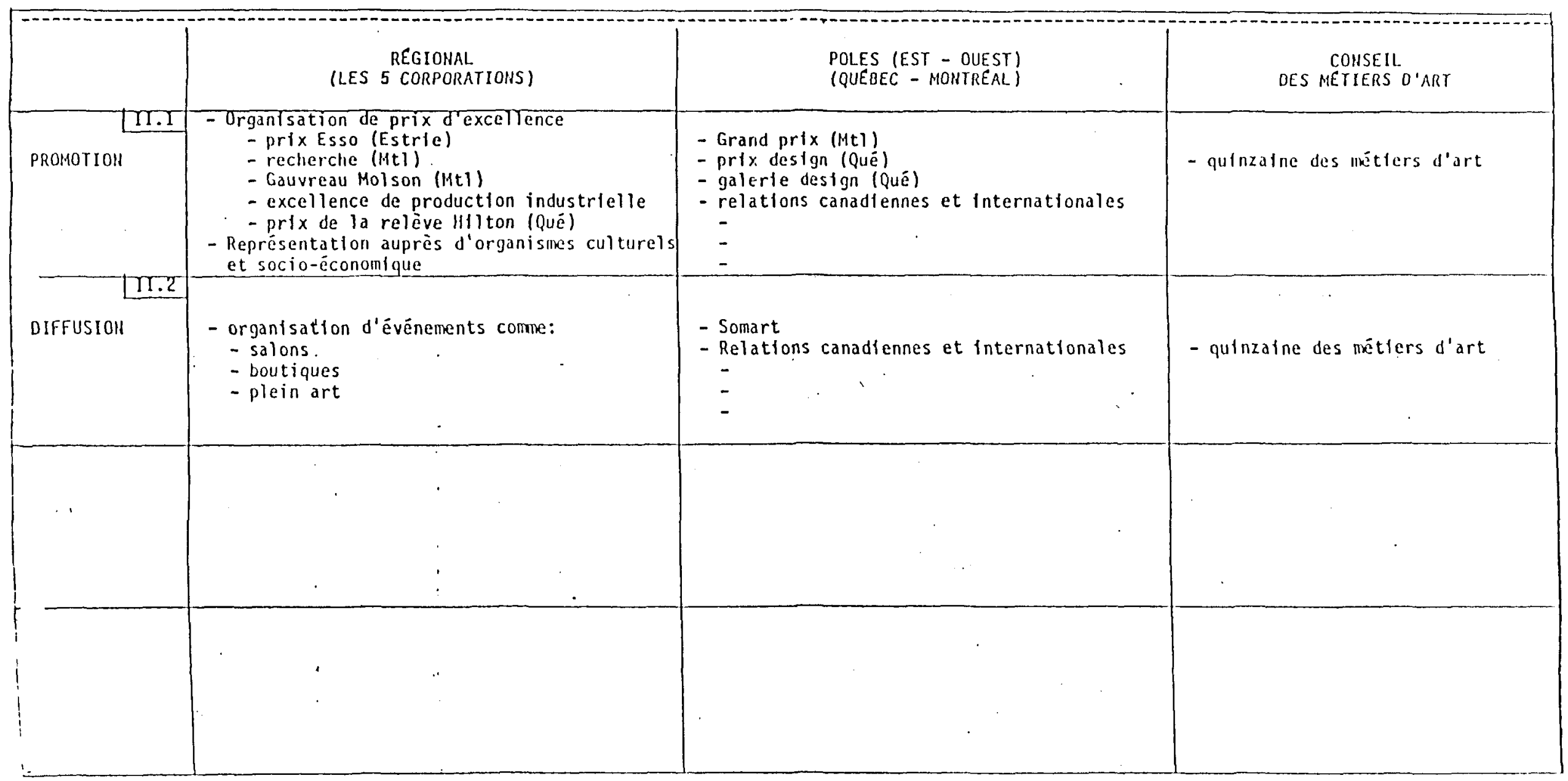




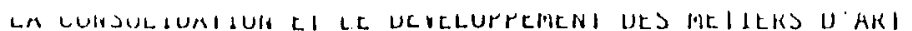

111 - AGEHT DE COHHUHICATIOH D'IMFORMATIOH

PARTAGE DES RESPOHSABILITES REGIOHILES - EST/OUEST-HATIOHALES

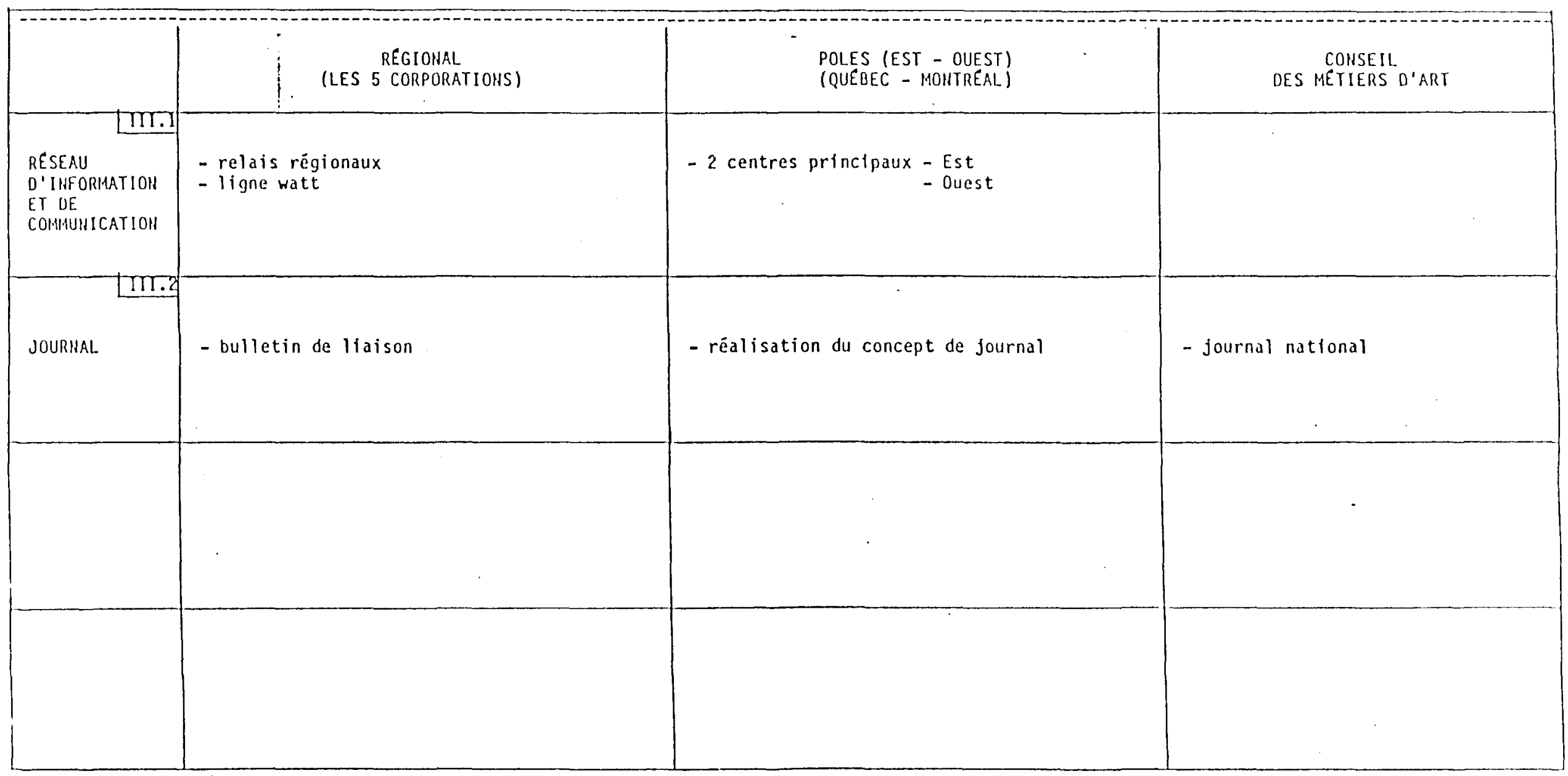


ANNEXE 4 
ANNEXE 4

CRITERES D'ADMISSIBILITE A L'AIDE FINANCIERE DU MAC

Pour pouvoir bénēficier de 1'enveloppe financière offerte par le MAC aux corporations, la CMAAT doit répondre à certains critères d'admissibilité. Ces critères influencent la structure que se donne la CMAAT. Voici ces six (6) critères:

1. L'existence légale de l'organisme, c'est-à-dire un statut de corporation sans but lucratif, d'association ou de coopérative;

2. la représentation de tous les milieux d'artisanat autant en assemblée générale qu'au Conseil d'administration;

3. le "membership" en termes nominal, de professionnalisme et de représentativité de 1 'artisanat régional;

4. Ia participation des membres aux coûts administratifs et opérationnels de l'organisme;

5. la qualité de son administration basée sur le rendement budgétaire, sur ses objectifs et sa stabilité;

6. la qualité et la diversité des programmes réalisés ou en voie de réalisation. 
ANNEXE 5 


\section{ANNEXE 5}

REFLEXION SUR LES GRANDES ORIENTATIONS DE LA CMAAT

ASSEMBLEE GENERALE ANNUELLE

31 MAI 1986

1. CHOIX DE LA MISSION

Que voulons-nous être?

Exemples:

- Une association de mise en marché?

- Une association d'artisans professionnels voulant se faire reconnaître dans le milieu?

- Un regroupement d'artisans qui veulent mettre en commun des services?

- etc.

2. CHOIX DU PORTEFEUILLE D'ACTIVITES

Que devrait faire la CMAAT de manière précise?

Exemples:

- Informer les membres (si oui, quelles informations devraientelles fournir?)

- Rechercher des lieux de diffusion?

- Tenir des réunions de concertation?

- Etc. 


\section{ANALYSE DES RESSOURCES}

- L'assemblée gēnérale

Quelle devrait être 1a participation de chaque membre?

- Le Conseil d'administration

Quel mandat donne-t-on au Conseil d'administration?

- Employés de la CMAAT

Comte tenu des ressources financières disponibles, la CMAAT peut-elle s'offrir les services d'une directrice générale? Si oui, quel rôle devrait-elle jouer? 